\title{
Grundoperation Unendliche Aktualisation
}

Dieses Großkapitel beschäftigt sich mit Versuchen, die Leser dazu anzuhalten, die jeweiligen Schriftzeichen resp. Texte unendlich oft erneut zu lesen. Solche Versuche können einerseits positiv darauf fokussieren, die Leser direkt zum Wieder- oder Weiterlesen zu zwingen, in diesem Fall werden sie im Folgenden unter der Unteroperation Unendliche Lektüre gefasst. Sie können andererseits aber auch negativ die semiologische Flüchtigkeit eines jeden Schriftzeichens und Textes, die zugleich die Möglichkeitsbedingung von potenziell unendlich vielen neuen und weiteren Lektüren ist, derart einsetzen, dass die Leser gerade dadurch dazu gedrängt werden, diese Flüchtigkeit durch ein Wiederlesen oder gar durch ein ergänzendes Weiterdenken, Weiterschreiben und letztlich wiederum Weiterlesen aufzuhalten. Ein Aufhalten, das semiotisch nicht möglich ist und gerade deshalb zu immer weiteren Versuchen Anlass geben kann. Diese Versuche fasst die Unteroperation Unendliches Verstummen. Die beiden Unteroperationen Unendliche Lektüre und Unendliches Verstummen sind also gewissermaßen zwei Seiten derselben Medaille, zwei komplementäre Seiten der Grundoperation Unendliche Aktualisation. Es ist deshalb nicht verwunderlich, wenn es bei den Unteroperationen zu Überschneidungen kommt, bedingen sie einander doch letztlich gegenseitig. Dennoch ist eine Unterteilung in Unendliche Lektüre und Unendliches Verstummen heuristisch wertvoll, mag sie doch in vielen Fällen aufzeigen, welche der beiden Unteroperationen jeweils dominant ist. Sie führt so zu einem geschärften Blick, der sich nicht nur in der Auseinandersetzung mit den einzelnen Textbeispielen, sondern besonders auch in literatur- und geistesgeschichtlicher Hinsicht als äußerst gewinnbringend erweist.

Das Kapitel umfasst die Auseinandersetzungen mit den Textbeispielen Lebens-Ansichten des Katers Murr, Miss Sara Sampson, Der Spinnerin Nachtlied und Ermunterung. Besondere Aufmerksamkeit liegt dabei auf den Anfängen und Enden der jeweiligen Textbeispiele, da davon auszugehen ist, dass die betreffende Grundoperation dort ihre größte Wirkmächtigkeit entfaltet und somit klarer und umfassender zu beobachten ist als an anderen Stellen. Auf die Auseinandersetzung mit den einzelnen Textbeispielen folgt abschließend das Kapitel, das die Grundoperation Unendliche Aktualisation in den geistesund literaturgeschichtlichen Kontext der Zeit zwischen 1755 und 1821 einzubetten sucht. 


\section{Unteroperation Unendliche Lektüre}

Entgegen der chronologischen Folge der Erscheinungsdaten eröffnet E. T. A. Hoffmanns Lebens-Ansichten des Katers Murr und nicht Lessings Miss Sara Sampson das Kapitel zur Unendlichen Lektüre. Dies liegt weniger daran, dass die vorliegende Arbeit ihr literaturhistorisch letztes Textbeispiel an den Anfang stellen möchte, um ihrerseits die Leser nach der Lektüre des Schlussteils wieder an den Anfang der Arbeit zu zwingen, sondern hat vielmehr folgende zwei Gründe: Erstens ist das Kapitel zu den Lebens-Ansichten des Katers Murr - den Umfängen der beiden Textgrundlagen entsprechend - das wesentlich größere und kann dadurch bereits zu Beginn des Hauptteils verschiedene Aspekte und Variationen der Operation Unendliche Lektüre sowie später noch relevantere Überschneidungen zu den anderen Grundoperationen aufzeigen. Dadurch ist es absichtlich etwas breiter angelegt als die nachfolgenden Kapitel und befasst sich vertieft mit Verfahren, die auch bei anderen Textbeispielen immer wieder zu beobachten sein werden: etwa mit dem metonymischen Titel, intertextuellen Verweisen, dem gezielten Einsatz von Absatz, Abschnitt und Gedankenstrich samt deren entortender Eigendynamik oder auch mit der Undarstellbarkeit des Todes durch die Sterbenden selbst. Zweitens hat das Kapitel zur Miss Sara Sampson so die Möglichkeit, sich ergänzend und unnötige Redundanzen vermeidend ganz auf Lessings Ästhetik des Endens zu konzentrieren und damit eine wichtige Grundlage für den nächsten Schritt, nämlich die literatur- und geistesgeschichtliche Einbettung der betreffenden Operation, zu legen. Diese Einbettung wird sich dann u. a. ausführlich mit dem Einfluss von Lessings Ästhetik des Endens auf die Auflösung der aristotelischen Einheit eines aus Anfang, Mitte und Ende bestehenden Werkes befassen, die wiederum auch für die Lebens-Ansichten des Katers Murr von wesentlicher Bedeutung ist.

\subsection{Lebens-Ansichten des Katers Murr}

Das vorliegende Kapitel ${ }^{1}$ folgt mittels eines ausgeprägten Close Readings dem Zweig der Hoffmann-Forschung, der mit Blick auf die Autor- und Herausgeberfiktion sowie auf die Verhandlung der Materialität von Texten und deren drucktechnischer Herstellung bereits darauf hingewiesen hat, dass Hoffmanns

1 In dieses Kapitel ist die unveröffentlichte Masterarbeit des Verfassers eingegangen: Gut, Markus: Figur(ation) der Unverortbarkeit, unverortbare Figur(ation). Eine Untersuchung zur Konstitution von Text als Gegenstand des Verstehens anhand von E. T. A. Hoffmanns LebensAnsichten des Katers Murr, Masterarbeit zur Erlangung des akademischen Grades Master of Arts der Philosophischen Fakultät der Universität Zürich, Abgabedatum: 30.10.2013. 
Roman Lebens-Ansichten des Katers Murr (1819/1821) die auctoritas des Autors ${ }^{2}$ resp. des Herausgebers über seinen Text infrage stellt. Ein Hinweis, der bereits das Unterlaufen der vermeintlichen Einheit und Ganzheit des Romans impliziert. Ein solches Unterlaufen aber verlangt wiederum geradezu - und hier decken sich die Beobachtungen des Verfassers mit denen Uwe Wirths -, dass der Leser mittels interpretativer Aufpfropfungen rahmend tätig zu werden hat. ${ }^{3}$ Dies ist jedoch eine Tätigkeit, die selbst nie an ein Ende gelangen kann, was die folgenden Kapitel anhand der Makro- als auch der Mikroebene von Hoffmanns Doppelroman zeigen werden.

Was die erwähnte Forschung betrifft, so sind dabei von besonderer Wichtigkeit: die Monographie von Sarah Kofman, die als Erste konsequent eine solche, dekonstruktivistisch geprägte Lektüre des Kater Murr vornahm, sowie aus der jüngeren Forschung insbesondere die Arbeiten von Claudia Liebrand, Remigius Bunia und Uwe Wirth. ${ }^{4}$ Während Uwe Wirth mit Bezug auf Derrida und Foucault vor allem mit den Begriffen der Aufpfropfung und der Funktion Autor resp. Funktion Herausgeber arbeitet, ${ }^{5}$ wird hier die textlinguistische Begrifflichkeit von Hausendorf/Kesselheim hinzugezogen. Angesichts der von Wirths Fokus auf Herausgeberfiktion, Rahmung und Aufpfropfung abweichenden Konzentration auf die Frage nach Anfang und Ende eines Textes und dessen potenziell endloser Lektüre soll diese linguistische Begrifflichkeit vor allem im zweiten Teil dieses Kapitels zur terminologischen Schärfung des Close Readings beitragen.

Hausendorf/Kesselheim teilen die Hinweise, die uns ein Text (samt Textträger) liefert, ihn als solchen $\mathrm{zu}^{\mathrm{k}} \mathrm{lesen},{ }^{6}$ in folgende Gruppen ein:

2 Gerade auch des genialen Autors; vgl. Kapitel IV.3.3.

3 Siehe unten, insbesondere Kapitel II.1.1.2; resp. Wirth 2008, u. a. S. 376 f. und 385 f.

4 Die in das Jahr 1927 zurückreichende Arbeit von Gustav Egli: E. T. A. Hoffmann, Ewigkeit und Endlichkeit in seinem Werk, die auch auf die Lebens-Ansichten des Katers Murr eingeht (vgl. Egli 1927, S. 104-121), kann aus heutiger Perspektive trotz vielversprechendem Titel nichts mehr zur hier vorliegenden Fragestellung beitragen.

5 Vgl. vor allem Wirth 2008.

6 „Sie [Textualitätshinweise, MG] signalisieren Textualität und sorgen auf ebenso unscheinbare wie effektive Weise dafür, dass wir etwas Geschriebenes beim Lesen als eine Art natürliche Lektüreeinheit und in diesem Sinn als Text wahrnehmen. Was uns in unserem kommunikativen Alltag als eine natürliche Lektüreeinheit, als ein lesbares Etwas erscheinen mag - ein Buch, ein Zeitungsartikel [...] -, steht also nicht von vorneherein fest, sondern ist gerade in seiner vermeintlichen Natürlichkeit durch und durch gemacht. Die Orientierung [des von den Autoren vorgeschlagenen Modells, MG] an Textualitätshinweisen soll dabei helfen, diese Herstellung von Textualität durch Textualitätshinweise sichtbar zu machen. Was ein Text ,ist', ergibt sich deshalb erst beim Lesen: Lesen ist nichts anderes als das Aufnehmen und Verarbeiten, das Auswerten und Verstehen von Textualitätshinweisen " (Hausendorf/Kesselheim 2008, S. 21). Wie Hausendorf/Kesselheim geht auch der Verfasser der 
Abgrenzungs- und Gliederungshinweise, Verknüpfungshinweise, Themahinweise, Funktionshinweise, Textsortenhinweise, Intertextualitätshinweise. ${ }^{7}$ Die beiden im Folgenden verwendeten Begriffe - Abgrenzungshinweis und dessen Unterbegriff Ganzheitshinweis ${ }^{8}$ - sind aus ebenjener Gruppe der Abgrenzungs- und Gliederungshinweise ${ }^{9}$ entlehnt:

\begin{abstract}
Alles, was dazu beiträgt, auf das Ganze eines Textes im Sinne einer textuellen Obereinheit hinzuweisen, betrachten wir in diesem Kapitel als Abgrenzungshinweis [...]. Abgrenzungshinweise leisten die Abgrenzung einer textuellen Obereinheit nach außen [...]. Alles, was dazu beiträgt, auf die Teile eines Textes im Sinne textueller Untereinheiten hinzuweisen, betrachten wir in diesem Kapitel als Gliederungshinweise. [...] Gliederungshinweise leisten die Gliederung einer textuellen Einheit in weitere Untereinheiten [...]. Zwischen Abgrenzungsund Gliederungshinweisen ist von Fall zu Fall mit fließenden Übergängen zu rechnen..$^{10}$
\end{abstract}

Auf die weitere Unterteilung in Gliederungshinweise wird in diesem Kapitel verzichtet: einerseits, um den ausgeprägten Abstraktionsgrad der unten stehenden Ausführungen nicht zusätzlich zu erhöhen; andererseits, weil der in Titelblatt und Vorwort aufgebauten Herausgeberfiktion des Romans folgend sowohl Murr-Autobiographie als auch Kreisler-Biographie als je eigene "textuelle Obereinheit" betrachtet werden, die, wenngleich zweifellos thematisch miteinander verknüpft und in der vermeintlich zufälligen Abfolge ihrer Teile aufeinander abgestimmt, dennoch so konzipiert sind, dass sie den Anschein erwecken sollen, zwei verschiedene eigenständige Texte zu sein: eine Autobiographie und eine Biographie.

Schließlich seien zur besseren Leserorientierung vorab die für das Folgende relevanten Aspekte von Komposition und Inhalt des Romans knapp umrissen: Der volle Titel des Romans lautet Lebens-Ansichten des Katers Murr nebst

vorliegenden Arbeit davon aus, dass ein Text erst durch sein Gelesenwerden zu einem Text (geworden sein) wird.

7 Hausendorf/Kesselheim 2008, S. 37.

8 „Amäußeren RandvonTextenstehenHinweise, dieeinenTextinseinermaterialen Ganzheit als Einheit identifizieren“ (ebd., S. 42). Diese Ganzheitshinweise unterteilen Hausendorf/ Kesselheim wiederum in Textträgerhinweise, Textsammlungshinweise, Titel, bibliographische und Impressumshinweise (vgl. ebd.).

$9 \quad$ Für die folgenden Unterkapitel ist dies zweifellos die wichtigste Kategorie, wenngleich in dem hier untersuchten Roman andere Hinweise wie Verknüpfungshinweise oder Textsortenhinweise sich ebenfalls für eine Untersuchung anbieten würden; oder z. B. Intertextualitätshinweise, die - wenngleich dort nicht so benannt - in der Forschung zu den Lebens-Ansichten des Katers Murr bislang auf breites Interesse gestoßen sind (siehe dazu repräsentativ: Genz 2009; Schäfer 20o1; Swales 1992-1993; Kofman 1985). 
fragmentarischer Biographie des Kapellmeisters Kreisler überliefert in zufälligen Makulaturblättern. Wie der Titel schon verrät, handelt es sich um einen Doppelroman, ein Umstand, der gemäß dem Vorwort durch „literarischen Vandalismus" des Katers Murr sowie durch das Versehen des Herausgebers zustande gekommen sei. ${ }^{11}$ Dieser Doppelroman ist wiederum in zwei Bänden erschienen, der erste Band 1819 (vordatiert auf 1820), der zweite 1821 (ebenfalls vordatiert auf 1822). ${ }^{12}$ Der in der "Nachschrift des Herausgebers" zu Ende des zweiten Bandes angekündigte dritte Band blieb aus. ${ }^{13}$ Im Folgenden wird jeweils aus der Ausgabe der "Bibliothek deutscher Klassiker" zitiert, ${ }^{14}$ die den Erstausgaben sehr nahe folgt. Aufgrund der ausgesprochen textnahen Lektüre, die in hohem Maße auch Typographie und Interpunktion berücksichtigt, wurden die betreffenden Stellen jedoch mit der Erstausgabe abgeglichen und Abweichungen vermerkt. ${ }^{15}$

Jener für die inhaltliche Doppelung verantwortliche „literarische[] Vandalismus" hat folgende Ursache: Murr hat nämlich während der Arbeit an seiner Autobiographie die Biographie des Kapellmeisters Kreisler zerrissen und deren Seiten als Löschpapier oder Unterlage verwendet, die dann aus Versehen ebenfalls mitabgedruckt wurden. Nun sind aber die Fragmente der KreislerBiographie $^{16}$ - die sich freilich nicht zu einem lückenlos kohärenten Text zusammensetzen lassen und damit jeweils auch als Einzeltexte fragmentarisch

11 Die entsprechende Stelle wird unten zu Beginn von Kapitel. II.1.1.2 zitiert.

12 Vgl. Hoffmann, Werke, Bd. 5, S. 899.

13 Es ist nicht gänzlich zu klären, ob dies dem Tode Hoffmanns (15. Juni 1822) geschuldet ist oder ob ein dritter Band grundsätzlich gar nicht vorgesehen war. Die durch die versetzte Anordnung der Murr- und Kreisler-Teile zustande kommende Kreisstruktur, die Band 1 und 2 miteinander verschränkt, spräche für Letzteres; Hoffmanns Arbeitsweise sowie sein Verhalten resp. seine Ankündigungen gegenüber seinem Verleger für Ersteres, also die Annahme, die auch vom Forschungsstand zur Zeit des Erscheinens der hier verwendeten Textgrundlage der „Bibliothek deutscher Klassiker“ klar präferiert wurde (vgl. zusammenfassend Steinecke 1992, S. 911 f.). Neuere Forschungen, denen sich auch das vorliegende Kapitel mit seinen Ergebnissen näher verbunden fühlt, präferieren wieder das Argument der Kreisstruktur (vgl. zusammenfassend Wirth 2008, S. 392), stellvertretend dafür sei hier vor allem auf Claudia Liebrand verwiesen (dies. 1996, S. 197-200).

14 Hoffmann, E. T. A.: Lebens-Ansichten des Katers Murr, in: Werke, Bd. 5, 1820-1821, herausgegeben von Hartmut Steinecke unter Mitarbeit von Gerhard Allroggen, Frankfurt am Main 1992.

15 Dies ist jeweils mit der Sigle ,Kater Murr $1820^{\prime}$ resp. ,Kater Murr 1822 ' kenntlich gemacht. Für ihre große Unterstützung bei der Beschaffung von Scans der betreffenden Stellen der Erstausgaben bedanke ich mich herzlich bei Bernhard Schemmel von der E. T. A. Hoffmann-Gesellschaft und Gerald Raab von der Staatsbibliothek Bamberg.

16 Im Folgenden der Einfachheit und Kürze halber ,Kreisler-Teil(e)‘ genannt; Gleiches gilt für die ,Murr-Teile‘, die durch die Einschübe der Kreisler-Biographie entstandenen Teile von Murrs Autobiographie. 
sind - zufällig so überliefert, dass der erste Kreisler-Teil des ersten Bandes, in der Chronologie der Biographieerzählung betrachtet, eigentlich der letzte sein müsste; ${ }^{17}$ während der letzte Kreisler-Teil des zweiten Bandes in dieser Hinsicht eigentlich der zweitletzte ist. Zudem beginnt der erste Band mit einer Reihe von Vorworten, während der zweite Band mit einer Nachschrift endet. Schematisch dargestellt sieht dies wie folgt aus:

- Titelblatt;

- Vorwort des Herausgebers [darin ist ironisch integriert eine Liste der in der Erstausgabe des ersten Bandes tatsächlich unterlaufenen Druckfehler];

- Vorrede des Autors;

- Vorwort. Unterdrücktes des Autors [als ein fiktiver, im Zuge des Drucks unterlaufener Fehler];

- N.[ach] S.[chrift] [...] d.[es] H.[erausgebers, der sich für das Versehen, dass das unterdrückte Vorwort Murrs ebenfalls abgedruckt wurde, entschuldigt];

- 1. Murr-Teil;

- letzter Kreisler-Teil;

- 2. Murr-Teil;

- 1. Kreisler-Teil;

- 3. Murr-Teil;

- 2. Kreisler-Teil;

$-[\ldots]$

- letzter Murr-Teil;

- zweitletzter Kreisler-Teil;

- Nachschrift des Herausgebers

Bei all dem wird ersichtlich, und die oben erwähnte Forschung hat bereits darauf hingewiesen, dass Hoffmanns Roman plakativ ausgedrückt nicht nur anhand der Figur Murr die Genieästhetik im Allgemeinen und Goethes Dichtung und Wahrheit im Speziellen parodiert und ihnen in der fragmentarischen Biographie Kreislers die prekäre Seite des Genies gegenübergestellt, ${ }^{18}$ sondern auch die Konstituenten der vermeintlichen Einheit Buch hinterfragt ${ }^{19}$ - Letzteres auch und gerade unter Berücksichtigung der drucktechnischen Herstellung und Materialität eines Buches. Dass die prekäre originale Einheit des göttlichen Genies und die prekäre Einheit seiner göttlichewigen Werke eng miteinander verknüpft sind, ist noch zu zeigen. So viel sei jedoch schon vorweggenommen: Die im hier untersuchten Roman stattfindende Verhandlung beider Einheiten ist zumindest kein Zufall; ebenso

17 Vgl. u. a. Hoch 1999, S. 63 f.

18 Dass sich diese Gegenüberstellung derart plakativ nicht halten lässt und die Nähe des Genies zum Wahnsinn nicht erst in der Romantik, wenngleich dort besonders akzentuiert, mitgedacht wurde, zeigt u. a. Kapitel IV.3.3.

Vgl. dazu auch Engelmann 1985, S. 141. 
wenig die damit verknüpfte Gegenüberstellung des „göttliche[n] Murr[s]“20 einerseits, der sich selbstbewusst seiner "unsterblichen Werke“ versichert, ${ }^{21}$ und des Kreiselns Kreislers um das geniale Werk andererseits - eines Kreiselns Kreislers, der ein solches geniales Werk nie zu erreichen glaubt und der seine Kompositionen, ${ }^{22}$ seine mittels schriftlich fixierter Zeichen verewigten Stücke in Anflügen von Wahnsinn immer wieder verbrennt.

\subsubsection{Makroebene: unendlicher Anfang und unendliches Ende}

Für die Auseinandersetzung mit Verfahren, die eine potenziell unendliche Lektüre zu provozieren suchen, bietet sich selbstredend der nähere Blick auf Textenden an. Bevor jedoch ebendieser Blick eingenommen wird, gilt es aufzuzeigen, dass für die vorliegende Fragestellung die genaue Analyse von Textanfängen ebenso zu berücksichtigen ist.

Um einen Textanfang genauer zu betrachten, muss man ihn zunächst finden - eine vermeintlich banale Aufgabe, die einen jedoch insbesondere beim hier untersuchten Roman zunächst nicht zu Antworten, sondern vielmehr zu einer ganzen Reihe von Fragen führt: Beginnt er mit dem Titel, dem Vorwort des Herausgebers oder der Vorrede des Autors? Oder beginnt der Roman erst mit dem ersten Satz des ersten Kapitels?

In ihrer groß angelegten Studie zu Paratext und Textanfang von 5 o Bildungsromanen aus den letzten drei Jahrhunderten ${ }^{23}$ reflektiert Annette Retsch zu

20 „So werden meine Werke auch gewiß in der Brust manches jungen geist- und gemütreichen Katers das höhere Leben der Poesie entzünden, und nimmt denn der edle Katerjüngling meine biographischen Belustigungen auf dem Dache vor, geht er ganz ein in die hohen Ideen des Buchs [sic] das ich so eben unter den Klauen habe, dann wird er im Entzücken der Begeisterung ausrufen: Murr, göttlicher Murr, größter deines Geschlechts, dir, dir allein verdanke ich alles, nur dein Beispiel macht mich groß -“ (Hoffmann, Werke, Bd. 5, S. 38 ).

21 Etwa Hoffmann, Werke, Bd. 5, S. 38 (ausführlicher zitiert in Kapitel IV.3.3) oder 44: „Genies werden den genialen Kater in seinen ersten Werken leicht erraten, und über die Tiefe, über die Fülle des Geistes, wie er zuerst aus unversiegbarer Quelle aussprudelte, erstaunen, ja ganz außer sich geraten. Damit die Welt sich dereinst nicht zanke über die Zeitfolge meiner unsterblichen Werke, will ich hier sagen [...]." Hinzu kommt hier: Auch Murr appelliert an die ,Gemeinschaft der Genies', die ihn verstehen würden - eine paradoxalerweise geteilte Originalität, ohne die der Absturz in den Wahnsinn droht; vgl. dazu ebenfalls Kapitel IV.3.3.

22 „Irgendwo [ein Asterisk verweist auf: „Fantasiestücke in Callots Manier. Neue Ausg. T. I. Seite 32.“, MG] heißt es von dem Kapellmeister Johannes Kreisler, daß seine Freunde es nicht dahin hätten bringen können, daß er eine Komposition aufgeschrieben und sei dies wirklich einmal geschehen, so habe er doch das Werk, so viel Freude er auch über das Gelingen geäußert, gleich nachher in's Feuer geworfen“ (Hoffmann, Werke, Bd. 5, S. 302).

23 Vgl. Retsch 2000, S. 13. 
Beginn ihres Kapitels zur „Beziehung zwischen Paratext und Textanfang“ zwar die Möglichkeit, dass "bestimmte Aufgaben des ,eigentlichen` Textanfangs“ bereits z. B. im Vorwort auftreten können, hält aber trotzdem daran fest, dass die „Textwelt“ eigentlich erst „mit dem ersten Satz des ersten Kapitels“ beginne und der Paratext lediglich "ein Signal für den, eigentlichen 'Textanfang“ sei. ${ }^{24} \mathrm{Im}$ Falle des hier untersuchten Romans ist jedoch der „Paratext", also die scheinbar rein metatextuellen Informationen zur Fiktion wie Autorangabe, Vorwort des Herausgebers etc., Teil der Fiktion, ${ }^{25}$ womit sich der „Eintritt in die Textwelt" folglich bereits mit dem Lesen des Titelblattes vollzieht. Remigius Bunia, der sich aus narratologischer Sicht mit der Typographie der Lebens-Ansichten des Katers Murr auseinandersetzt, stellt denn auch treffend fest:

Murrs und Kreislers Aufzeichnungen wechseln sich ab. Es ist dabei Teil der Fiktion, daß dieser Text durch einen Fehler des Setzers zustande gekommen ist. Während ein gewöhnlicher nicht-situativer Erzählerwechsel - das heißt ein Erzählerwechsel in der Stetigkeit des récit, der keine stetige Entsprechung in der histoire hat - von außerhalb der Fiktion bestimmt wird, Teil der Disposition eines Textes, nicht aber der Disposition der fiktiven Welt ist, ist der nicht-situative Erzählerwechsel in den Lebens-Ansichten eine fiktive Tatsache. ${ }^{26}$

Genau diese "fiktive Tatsache" ist Teil der Autorfiktion, die sich bereits im Titelblatt konstituiert: Während im Titelblatt die Angabe des Bandes, des Erscheinungsortes und -jahres sowie des Verlags (Erster Band/Berlin, 1820/bei Ferdinand Dümmler $)^{27}$ auf die ,reale Welt' verweisen, so gehört der gesamte Titel inklusive „herausgegeben von E. T. A. Hoffmann" bereits zur fiktiven Welt des Romans. Dies führt wiederum dazu, dass sich der vermeintlich eindeutige metatextuelle Hinweis auf den Verlag etc. ${ }^{28}$ mit der Fiktion zu vermischen beginnt. ${ }^{29}$ Im Vorwort des Herausgebers, in dem Hoffmann eine fiktive Herausgeberfigur darstellt, ist denn auch die Rede davon, dass ebendiese Figur sich mit Herrn Dümmler unterhalte, ${ }^{30}$ womit auch Herr Dümmler zu einer Figur

\footnotetext{
24 Vgl. ebd., S. 151.

25 Zum Beispiel: ein Kater als Autor, Hoffmann lediglich als Herausgeber, der Fehler des Setzers etc.

26 Bunia 2005, S. 382.

27 Vgl. das Titelblatt weiter unten resp. Hoffmann, Werke, Bd. 5, Abb. 1, zwischen S. 944 und 945 .

28 Nach Hausendorf/Kesselheim sind diese eine Untergruppe der Ganzheits- resp. Abgrenzungshinweise, nämlich die „Titel, bibliographische[n] und Impressums-Hinweise“ (Hausendorf/Kesselheim 2008, S. 47).

29 Vgl. dazu auch Wirth 2008, S. 388-391.

30 "[...] so lief er [der Herausgeber, MG] sofort, mit dem Manuskript in der Tasche, zu dem Herrn Dümmler unter den Linden, und proponierte ihm den Verlag des Katerbuchs. Herr Dümmler meinte, bis jetzt habe er zwar nicht unter seinen Autoren einen Kater gehabt,
} 
dieser Fiktion wird, was wiederum auch auf das Titelblatt zurückverweist, auf dem der Name des Besitzers Ferdinand Dümmler metonymisch ${ }^{31}$ für Druckerei und Verlag steht.

Damit wird deutlich, dass der Anfang des hier untersuchten Romans so konstruiert ist, dass er nicht am ", eigentlichen' Textanfang, der mit dem ersten Satz des ersten Kapitels beginnt", 32 verortet werden kann. Zumal sowohl der erste Murr-Teil des ersten Bandes mit einem Goethe-Zitat ${ }^{33}$ als auch der erste Kreisler-Teil des ersten Bandes mit einem Sterne- Zitat beginnt ${ }^{34}$ und damit jeweils sogleich eine Verweiskette eröffnet wird, die den eigentlichen Romananfang und dessen Lektüre über den Roman hinaus entortet. ${ }^{35}$ Sarah Kofman bringt den entortenden Sog dieser intertextuellen Verweise wie folgt auf den Punkt:

Der ganze Text des Katers ist durchsetzt von Zitaten, die hier und da entlehnt sind, oft fehlerhaft; sie bewirken, daß das Buch nicht mehr endliches und festumrissenes Objekt ist, ruhend im geschlossenen Raum der Bibliothek. Der Kater, dieser Bücherwurm, nagt die Bände an, bricht ihre Begrenzungen auf und vollzieht damit den Mord am Autor als Vater des Werkes. ${ }^{36}$

Wobei jedoch zu ergänzen wäre, dass Murr, selbst Autor seines Werkes, nach Kofmans Argumentation vor allem auch Selbstmord „vollzieht“. ,Ausstellt‘ wäre deshalb wohl treffender als „vollzieht“, denn der Vollzug des ,Todes des Autors' ist Möglichkeitsbedingung einer jeden Verwendung zeichenhafter Kommunikation und nicht auf das krallenbewehrte Kompilieren Murrs beschränkt.

Selbst wenn man Annette Retschs Definition des „eigentlichen“ Textanfangs trotz der bislang beobachteten Verfahren einer Verweigerung eines solchen folgen würde, bliebe noch immer der Umstand, dass der Roman ein

wisse auch nicht, daß irgend einer seiner werten Kollegen mit einem Mann des Schlages bis jetzt sich eingelassen, indessen wolle er den Versuch wohl machen“ (Hoffmann, Werke, Bd. 5, S. 11).

31 Zu den weiteren Metonymien im Titel und deren im Zuge der Lektüre ausgelösten Übertragungsbewegungen siehe weiter unten.

$32 \quad$ Retsch 2000, S. 151 .

33 Aus dem Egmont; vgl. Ende 1.1.3.

34 Spannend ist hierbei, was Annette Retsch mit Bezug auf die textlinguistische Forschung zum eigentlichen Textanfang schreibt: „Das Ende des Textanfangs kann auch durch den Übergang zur a) ,direkten Rede', b) ,indirekten Rede‘ und c) ,erlebten' Rede signalisiert werden“ (dies. 2000, S. 150). Dies wäre nämlich ein weiterer Hinweis darauf, dass der eigentliche Anfang des hier untersuchten Romans verwischt wird, da sowohl das erste Kapitel Murrs als auch der erste Kreisler-Teil mit direkter Rede beginnen.

Vgl. Liebrand 1996, S. 213-217; Kofman 1985, S. 107 f.

$36 \quad$ Kofman 1985 , S. 105. 
doppelter ist. Es wäre demzufolge nicht nur ein Anfang des (Doppel-)Romans, sondern konsequent und paradoxal zugleich zwei Anfänge desselben zu bestimmen. Wobei den Anfang der Kreisler-Biographie festzumachen, sich als noch schwieriger erweist als im Falle der vermeintlich so chronologisch beginnenden Autobiographie Murrs - oder wo wollte man den Anfang einer fragmentarischen, nur in Makulaturblättern zufällig überlieferten Biographie verorten?

Immerhin mag auf der Suche nach dem Anfang die Tatsache Unterstützung bieten, dass sowohl Murrs Autobiographie als auch die fragmentarische Kreisler-Biographie auf materialer Ebene zwischen denselben zwei ${ }^{37}$ Buchdeckeln gebunden sind, die über ihre materiale Geschlossenheit jene beiden Biographien als Einheit, als ein Buch, versprechen. Selbst diese Ebene der Materialität wird jedoch bereits im Untertitel und insbesondere im Vorwort des Herausgebers als prekär beschrieben - und trotzdem: Angesichts der behandelten Schwierigkeiten scheint auf der Suche nach dem Anfang der Weg über die von der Materialität des Buches (und dem kulturell geschulten Umgang damit) suggerierte Ordnung dessen, was seine Buchdeckel umschließen, noch der einzig gangbare zu sein.

Hält man also, noch immer auf der Suche nach dem Anfang des Romans, scheinbar ganz banal Ausschau nach dem ersten Buchstabengebilde, das einem der Roman in dieser Ordnung zu lesen gibt, so ergibt sich daraus folgender Ablauf: Man nimmt das Buch zur Hand - es wird hier von der Erstausgabe des ersten Bandes ausgegangen -, schlägt unterbewusst geleitet vom Text- und Weltwissen des abendländischen Kulturraumes den illustrierten Buchdeckel zurück, ${ }^{38}$ stößt auf das Titelblatt, das man ebenfalls aufgrund seines Textwissens überhaupt sogleich und weitgehend unbewusst als solches erkennt, ${ }^{39}$ und beginnt von oben links nach unten rechts zu lesen: ${ }^{40}$

37 Ganz streng genommen wären es gar vier Buchdeckel, es handelt sich ja um einen in zwei Bänden erschienenen Fortsetzungsroman.

38 Selbstverständlich ließe sich bereits das Titelbild mit seiner Bildsprache und den zahlreichen darin enthaltenen Anspielungen als Text (im weiteren Sinne) lesen. Im vorliegenden Rahmen kann jedoch nicht auf die Umschlagbilder des Originals eingegangen werden. Im Zusammenhang von Dekonstruktion von Autor und Buch als Ganzheitshinweisen für einen Text böte Kofmans Feststellung, das Titelbild diene als letzte Garantie, den Leser hinsichtlich der "Identität [des Autors, MG] zu beruhigen“ (Kofman 1985, S. 118), einen interessanten, aber kritisch aufzugreifenden Ansatzpunkt für eine Auseinandersetzung mit dem Titelbild des ersten Bandes.

39 Vgl. dazu auch Hausendorf/Kesselheim 2008, S. 35 f. und $39 \mathrm{f}$.

40 Natürlich ist es möglich, mitten im Titelblatt mit dem Lesen zu beginnen (die Schriftgröße von „Katers Murr“ etwa provoziert dies geradezu), was aber nichts daran ändert, dass ein jeder Text im lateinischen Alphabet den Leser zu einer gewissen Linearität zwingt. Auch wenn man mitten in einem Buch zu lesen beginnt, so ist man - sofern 


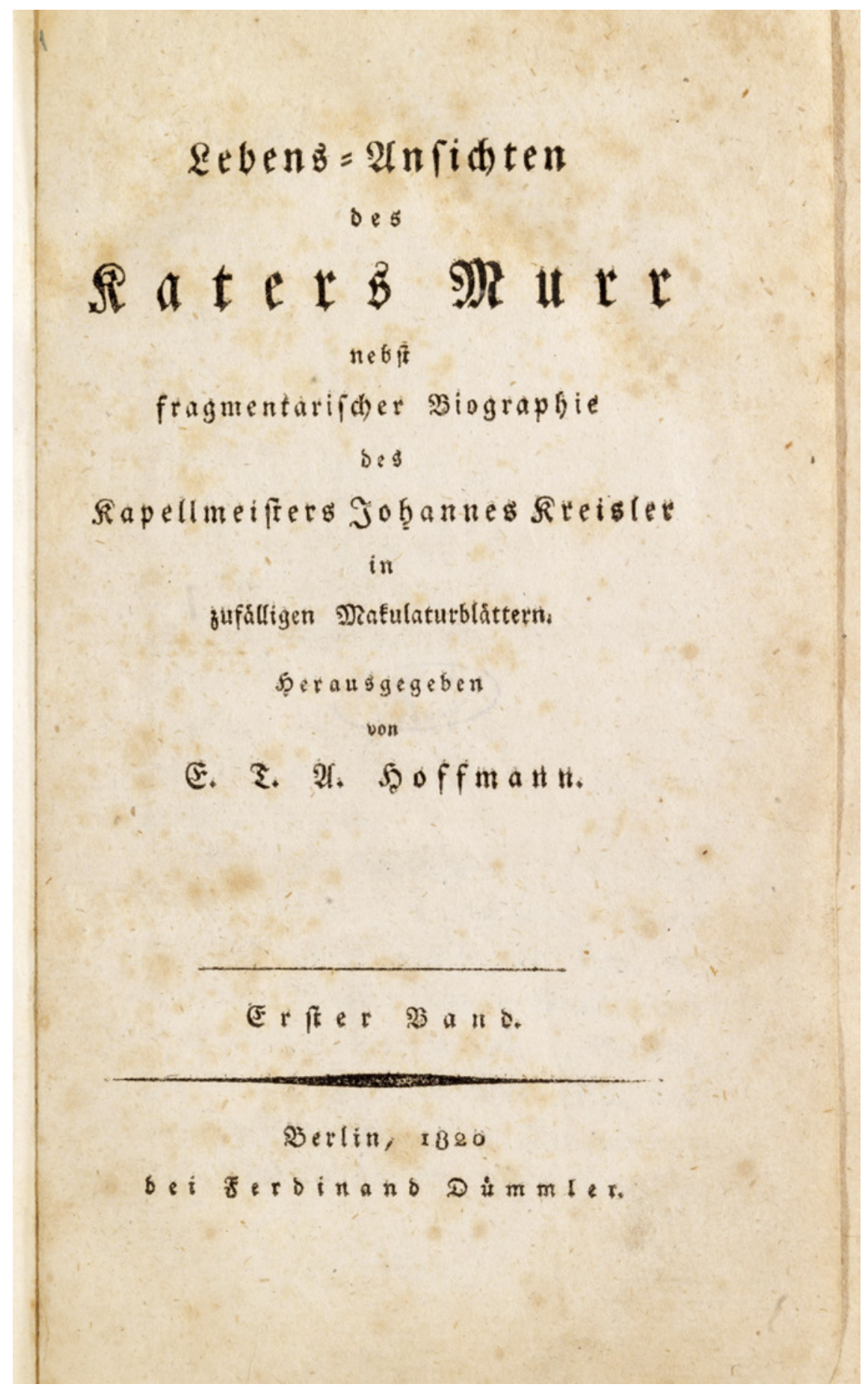

Abb. 1 Titelblatt der Erstausgabe; Staatsbibliothek Bamberg, Sigle Sel.229-1. 
Intuitiv möchte man also antworten, der Roman beginne mit dem ersten Wort des Titels: Lebens-Ansichten. An diesem Punkt nun sei dem Folgenden eine These vorangestellt, die sodann in den Abschnitten a) bis c) verifiziert werden soll. Die These lautet:

Der vermeintliche Anfang von Hoffmanns Titel, nämlich das Kompositum Lebens-Ansichten, stellt in nuce sowohl auf morphologischer und semantischintertextueller als auch auf lautlicher Ebene den Anfang des Romans als nicht exakt verortbar aus.

a) [Morphologische Ebene:] Kaum vermeint man, den Anfang des Romans im ersten Wort des Titels gefunden zu haben, so stellt sich das nächste Problem. Denn bei diesem ersten Wort ist wiederum eine Doppelung zu beobachten: Genau genommen handelt es sich nämlich um zwei mittels Fugen-s und Bindestrich(en) verbundene Wörter, um das Kompositum Lebens-Ansichten. Beginnt der Roman nun also mit dem Wort Leben oder mit dem Kompositum Lebens-Ansichten?

b) [Lautliche Ebene:] Das Wort ,Leben' bildet in der deutschen Sprache bekanntermaßen ein Minimalpaar mit ,Lesen'. In ,Lebens-Ansichten` vermag demnach auch ,Lesens-Ansichten' mitzuklingen. So wirft bereits der Titel die hermeneutischen Fragen auf, ob die Lektüre des Romans (und von Texten im Allgemeinen) mit dem Lesen oder mit den Ansichten über das Lesen und zu Lesende beginnt oder mit beidem zusammen und danach, wie Lesen und Ansichten miteinander in Verbindung stehen.

c) [Semantisch-intertextuelle Ebene:] Auch auf der semantischen Ebene gerät man in Schwierigkeiten, will man den Anfang des Titels genau festmachen. Denn der erste Titelteil Lebens-Ansichten des Katers Murr ${ }^{41}$ zitiert mindestens ${ }^{42}$ auch Sternes Romantitel Life and Opinions of Tristram Shandy, Gentleman. Der Anfang des Titels und damit die ersten Wörter des Romans verweisen demnach auf den Anfang eines anderen Titels, sind Zitat und somit

man nicht willkürlich einzelne Buchstaben , herauspickt sogleich wieder der Linearität unterworfen, indem man die einzelnen Buchstaben von links nach rechts zu einem Wort zusammenfügt.

41 Selbst der Name Murr scheint über Jean Pauls Leben Fibels ein Zitat eines Zitates des Namens eines Gelehrten aus Augsburg, Christian Gottlieb von Murrs, zu sein (vgl. Wirth 2008, S. 415, Anm. 247).

42 Zusätzlich zitiert der Titel wohl auch Ernst Wagners Romantitel Wilibald's Ansichten des Lebens (vgl. Retsch 200o, S. 67). Auch Murrs Vorrede des Autors weist Parallelen zum Vorwort in Wagners Roman auf (vgl. ebd., S. 9o). Zur Anlehnung an die typische Bildungsromantitelgebung (Geschichte und Personenname) des 18. Jahrhunderts und zur an barocke Praktiken erinnernden, titelblattfüllenden Gestaltung des Titels siehe ebd., S. 67 . 
ein Zweites, werden zur Mitte innerhalb einer intertextuellen Verweiskette. ${ }^{43}$ (Hinzu kommt natürlich, dass es sich beim Verweis des Untertitels auf den Kapellmeister Kreisler letztlich ebenfalls um ein Zitat handelt, nämlich um das Zitat einer literarischen Figur aus anderen Schriften Hoffmans. $)^{44}$

Bemerkenswert ist dabei auch die Abweichung des ersten Teils von Hoffmanns Titel gegenüber dem Titel bei Sterne. Bettina Schäfer schreibt dazu:

Jedoch bereits der Titel ,Die Lebens-Ansichten des Katers Murr impliziert in dieser Operation von Variation und Imitation des englischen Titels eine Hindeutung auf das Gestaltungsprinzip des Sterne-Textes in seiner Modifikation durch Hoffmann. Aus den Substantiven ,Leben` und ,Meinungen' wird bei Hoffmann das Kompositum ,Lebens-Ansichten', und dies durch einen Bindestrich verbunden. Gibt es im ,Tristram Shandy' korrespondierend mit der Zweiteilung des Titels zwei Erzählbewegungen, Fortschreiten im Erzählfluss und $A b s c h w e i f e n$ vom Erzählfluss, so scheint doch im ,Kater Murr' schon in der Titelgebung die Betonung auf dem Segment des Erzählflusses zu liegen. [Hervorhebungen, MG] ${ }^{45}$

Zu der von Schäfer genannten „Variation“ resp. zur „Betonung des Erzählflusses" sei je ein Punkt genannt:

1. Indem Hoffmann Sternes Titel imitiert und zugleich variiert, vermag sein Titel über den Verweis auf denjenigen Sternes Schreiben und Lesen poetologisch als „Imitation“ eines Textes bei gleichzeitiger "Variation“ desselben auszustellen. Dies wird besonders deutlich, wenn man das oben behandelte Minimalpaar Leben - Lesen sowohl auf die wörtliche Übersetzung von Sternes als auch auf Hoffmanns Titel bezieht, wobei man folgende Titel(teile) erhält: $L e[\mathrm{~s}]$ en und Ansichten resp. Le[s]ens-Ansichten. Dadurch, dass Hoffmann also den Begriff Leben für das Leben Murrs, das eben nur als Gerade-gelesenWerdendes zu haben ist, mit dem Wort Ansichten zu einem Kompositum verbindet, verhandelt sein Titel im Gegensatz zu demjenigen Sternes auch den hermeneutischen Umstand, dass Lesen und Ansichten (nach Gadamer „Vorurteile“) eben nicht klar voneinander zu trennen sind, sondern vielmehr in einer engen Beziehung zueinander stehen.

2. Mit „Betonung auf dem Segment des Erzählflusses“ meint Schäfer offenbar das vom Kompositum implizierte Erzählen von (Lebens-)Ansichten im

43 So meint denn auch Kofman mit Blick auf die Anfänge des ersten Murr-Teils und des ersten Kreisler-Teils des ersten Bandes: „Jedes ,Beginnen“ ist also ein ,Zitieren“ (Kofman 1985, S. 107), jedoch ohne auf das Sterne-Zitat im ersten Kompositum des Titels hinzuweisen. Zur Intertextualität im Kater Murr vgl. das Kapitel „Beobachtungen zur ,penetranten Intertextualität' der Lebens-Ansichten“ in Wirth 2008, S. 399-409.

44 Vgl. Liebrand 1996, S. 195.

45 Schäfer 2001, S. 120. 
Gegensatz zu dem bei Sternes Titel implizierten Erzählen eines Leben(s), von dem die Darlegung von Ansichten abschweife. Widersprüchlicherweise folgt bei Schäfer auf die oben zitierte Stelle ein von ihr nicht weiter kommentiertes Zitat Hartmut Steineckes, welches das „Fragmentarische“ bei Hoffmann gegenüber dem „zusammenhängenden Erzählfluss bei Sterne“ betont. ${ }^{46}$ Vielleicht möchte sie damit sagen, die „Betonung auf dem Segment des Erzählflusses“ mache es überhaupt erst möglich, mit fragmentarischem Erzählen zu spielen und dieses auszustellen. Dies ließe sich mit Bezug auf die Titel bei Hoffmann und Sterne wie folgt weiterziehen: Während Sternes Titel mit Life ein grammatikalisch eindeutig abgrenzbares erstes Wort besitzt, betont der Titel Lebens-Ansichten zwar die Verschmelzung von Leben und Ansichten, doch sein erstes Wort Lebens ist aufgrund des -s zugleich fragmentarisch. ${ }^{47}$ Man könnte also sagen, Hoffmanns Titel figuriert auch, dass ein jedes noch so zusammenhängend scheinendes Erzählen eine Zusammensetzung aus zitierten Fragmenten darstellt, die letzten Endes willkürlich ist, ${ }^{48}$ im Grunde weder Anfang noch Ende besitzt und deshalb ständig bedroht ist, selbst als Fragment aufzubrechen und als solches erkannt zu werden (vgl. dazu auch Kapitel II.3.3 zur Fragmentästhetik).

Zum Anfang des Titels lässt sich somit zusammenfassend festhalten: Hoffmanns Titel(variation) lehrt uns, dass es in hermeneutischer Hinsicht grundsätzlich gar kein Lesen (kein Leben zu lesen) gibt, das in Lesen (ein gelesenes Leben) und Ansichten (in Ansichten über dasselbe) zu trennen wäre. Es gibt höchstens Lesens-Ansichten, höchstens die potenziell endlose (und anfangslose) Verschmelzung von gelesenem Leben mit den Ansichten über und durch die Lektüre desselben. Murrs gesamte Autobiographie stellt dieses hermeneutische Problem aus, denn gerade die vermeintlich so genialen Lebens-Ansichten des Katers - und dies ist natürlich auch die große Parodie auf Goethes Dichtung und Wahrheit resp. die Genieästhetik der vorangegangenen Jahrzehnte im Allgemeinen ${ }^{49}$ - entpuppen sich letztendlich als nichts anderes als seine Lesens-Ansichten, als von ihm andernorts gelesene

\footnotetext{
46 Ebd.

47 Betrachtet man „Lebens“ isoliert, so ist es entweder Genitivattribut, zu dem das Bezugsglied, oder Teil eines Kompositums mit Fugen-s, zu dem das zweite Glied (oder auch mehrere Glieder) fehlt bzw. fehlen.

48 Damit ist auch schon Murrs Schreibverfahren (zitieren, herausreißen, neu kombinieren, einfügen etc.) im Titel in nuce ausgestellt.

49 Die Parodie des Genies durch Hoffmann wird in Kapitel IV.3.3 zur Genieästhetik nochmals aufgegriffen.
} 
Ansichten fremder Federn. ${ }^{50}$ Das erste Kompositum des Titels nimmt vorweg, was der gesamte Roman zuweilen bis zum Äußersten zelebrieren wird: die Unverortbarkeit seines Anfangs und Endes und die damit einhergehende potenzielle Unendlichkeit seiner Lektüre, die, da dieses Potenzial von einem sterblichen Leser nicht ausschöpfbar ist, immer schon fragmentarisch gewesen sein wird.

Um vom Anfang des hier untersuchten Romans zu dessen Ende überzuleiten, sei noch eine letzte Beobachtung zum Titel angeführt: Beim ersten Titelteil Lebens-Ansichten des Katers Murr handelt es sich um eine Metonymie. Murr tut nämlich nicht nur seine Ansichten kund, sondern erzählt sein Leben, zu dem er Ansichten äußert. Die Lebens-Ansichten Murrs sind also im wörtlichen Sinne bloß ein Teil seiner Autobiographie. Aus textlinguistischer Sicht lässt sich dazu und zu metonymischen Titeln im Allgemeinen, deren zentrale Funktion in den Beispieltexten der vorliegenden Arbeit noch wiederholt zu beobachten sein wird, folgende These festhalten:

50 Vgl. dazu auch Kofman 1985, S. 108: „Man kann sogar sagen, dass das ganze ,Leben` des Katers, seine gesamte Erfahrung, ein einziges literarisches Zitat ist, eine Wiederholung dessen, was er in den Büchern gelesen hat (selbst wenn er manchmal am eigenen Leib erfahren muss, dass sich nicht immer alles so verhält, wie es in den Büchern steht). Der Text des Lebens und der der Schrift sind eng miteinander verschränkt.“

Bemerkenswert ist zudem Martin Swales Feststellung, Murrs Autobiographie basiere „auf dem Versuch, sowohl in philosophischer als auch literarischer Hinsicht einen Metadiskurs zum eigenen Leben zu finden." Wobei dieser Versuch jedoch misslinge, „die philosophisch anvisierte Transzendenz“ am „unabdingbaren Vorhandensein des Kreatürlich-Tatsächlichen" scheitere und sich „die künstlerische Transzendenz" als bloße Zitatwut entpuppe (Swales 1992-1993, S. 51). Des Weiteren schließt er seinen Aufsatz u. a. mit folgendem Fazit: „Kater Murr gehört in die Tradition des selbstreflexiven europäischen Romans der Neuzeit. Das überaus Wichtige an Hoffmanns Roman in diesem Kontext ist, glaube ich, dass sich das Selbstreflexive gleichzeitig potenziert und kritisch durchleuchtet. Die Sehnsucht nach Transzendenz, sowohl geistiger als auch literarischer Transzendenz, die etwa der romantischen Ironie innewohnt, wird als Formprinzip von Hoffmann aufs meisterhafte gehandhabt - aber daneben, mittels der Kater-Murr-Figur aufs intensivste hinterfragt, wie wir gesehen haben. Denn es wird die Möglichkeit aufgeworfen, dass der Prozess der ewigen erzählerischen Agilität, sprich romantischer Ironie, dank welchem die jeweilige Setzung einer fiktiven Welt relativiert wird, letzten Endes in den endlosen unentrinnbaren Leerlauf eines ewig sich reproduzierenden Meta-Diskurses [er scheint damit vor allem die oben erwähnte „Zitierwut“ Murrs zu meinen, MG] mündet“ (ebd., S. 55). Falls der Verfasser Swales richtig versteht, sei hier bei aller übrigen Zustimmung Folgendes ergänzt: ,Potenzierte Selbstreflexivität‘ lässt sich nicht nur und erst bei Hoffmann, sondern z. B. auch schon bei Novalis betrachten (vgl. Kapitel IV.1), ob sie selbst jedoch überhaupt ,kritisch durchleuchtet‘ und ,hinterfragt ${ }^{\star}$ werden kann, da sind Zweifel anzumerken (vgl. Kapitel IV.3.1). 
Der metonymische Titel dient als Ganzheitshinweis ${ }^{51}$ dazu, den Roman als ganzen Text ein- und abzugrenzen. Das Kompositum Lebens-Ansichten kann aber nicht nur im übertragenen Sinne metonymisch als Verweis auf ein Ganzes (die ganze Autobiographie Murrs) gelesen werden, sondern zugleich auch im ,eigentlichen', wortwörtlichen Sinne als Verweis auf einen Teil (eines gedachten/ konstruierten Ganzen). Damit unterläuft es den Ganzheitshinweis des Titels und stellt ihn als Konstrukt aus, das zwar für die Annahme eines Ganzen denknotwendig, aber eben letztlich nur ein Konstrukt ist.

Anhand des (vermeintlichen) Endes der Murr-Biographie lässt sich diese These besonders gut verifizieren. Murr schließt das vierte und letzte Kapitel (von ihm Vierter Abschnitt genannt) seiner Autobiographie mit folgendem Abschnitt ab:

Mein Meister mußte verreisen und fand es für gut, mich auf die Zeit seinem Freunde, dem Kapellmeister Johannes Kreisler in die Kost zu geben. Da mit dieser Veränderung meines Aufenthalts eine neue Periode meines Lebens anfängt, so schließe ich die jetzige, aus der du, o Katerjüngling! so manche gute Lehre für deine Zukunft entnommen haben wirst. $-{ }^{52}$

Der erste Satz dieses letzten Abschnittes lässt sich nicht als Ansicht Murrs im engeren Sinne bezeichnen, ist er doch lediglich eine Nacherzählung der Ereignisse, ohne dass er eine Meinung oder Ansicht dazu äußern würde..$^{53}$ Letzteres holt Murr dann im zweiten Satz des Abschnittes, der zugleich den (vermeintlich) letzten Satz der Murr-Biographie darstellt, nach, indem er darin die nicht

$5^{1}$ Dieser Ganzheitshinweis ließe sich denn auch noch genauer als „Titelhinweis“ bezeichnen, siehe dazu oben die einleitenden Bemerkungen zum Modell von Hausendorf/ Kesselheim.

$5^{2}$ Hoffmann, Werke, Bd. 5, S. 436.

53 Dabei wird klar, dass, würde Murrs Autobiographie nur aus Ansichten bestehen, sie sehr fragmentarisch(!) wäre, da diejenigen Dinge, Ereignisse etc., zu denen er seine Ansichten äußert, fehlen würden. Ein Beleg dafür ist auch die Nachschrift des Herausgebers: „Der Herausgeber findet es daher der Sache nicht unangemessen, wenn er in einem dritten Bande, der zur Ostermesse erscheinen soll, dies von Kreislers Biographie noch vorgefundene den geneigten Lesern mitteilt und nur hin und wieder an schicklichen Stellen das einschiebt, was von jenen Bemerkungen und Reflexionen des Katers der weiteren Mitteilung wert erscheint" (Hoffmann, Werke, Bd. 5, S. 457 f.). Der Herausgeber kündigt also die Edition weiterer Kreisler-Fragmente an, wobei er auf eine Fortsetzung von Murrs Autobiographie nur mit den beschreibenden Begriffen (und nicht mehr mit einem Ganzheit suggerierenden, metonymischen Titel) Bemerkungen und Reflexionen des Katers verweist. Dort also, wo Murrs Autobiographie nur noch Ansichten enthält, wird sie zum Fragment, das nun als in die Kreisler-Biographie eingeschoben (vgl. „einschiebt“) bezeichnet wird - und nicht mehr umgekehrt, wie es das "nebst“ im Titelblatt des ersten und zweiten Bandes noch suggeriert hat. 
unwesentliche Ansicht über sein Leben äußert, jene Ereignisse hätten eine neue „Periode“ seines Lebens eingeläutet - und damit die vorangegangene „Periode" beendet. Mit einer Ansicht über die Wirkung des vorangegangenen Kapitels der Autobiographie auf die Leser derselben - also einer LesensAnsicht - sucht Murr sodann performativ diesen zweiten Satz und damit das Kapitel zu schließen.

Bereits in diesem letzten Abschnitt wird so vorweggenommen, was im Zuge des Weiterlesens geschehen wird: Das Ich der Murr-Autobiographie wandert vom „Meister“ zum „(Kapell-)Meister“, kreiselt zu Kreisler. ${ }^{54}$ Und die „Lehre“, die dabei vermittelt wird, ist auf poetologischer Ebene eben auch, dass eine Autobiographie zu schreiben letztlich nicht möglich resp. ein unbeendbares Unterfangen ist, da das (Be-)Schreiben des eigenen Lebens zugleich auch dieses Schreiben selbst umfassen müsste und immer so fort. Die einzige Möglichkeit, dem gerecht zu werden, wäre folglich das unendlich oft zu potenzierende Schreiben über das biographische Schreiben und dessen Unmöglichkeit: etwa das Schreiben darüber, dass auf eine Satz-„Periode“ die nächste folgt, ohne dass das Ende der letzten Lebens-„Periode“ je von demjenigen, der sein eigenes Leben (be-)schreibt, in eine Satz-„Periode“ gefasst werden könnte. ${ }^{55}$

Was die Suche nach dem Ende des Romans betrifft, so lässt sich hier gleich anknüpfen: Jener letzte Satz - der wie bereits der Titel Lebens- und LesensAnsichten vereint - kann nicht eindeutig als Ende der Autobiographie Murrs verortet werden. Dies u. a. deshalb nicht, weil der fiktive Herausgeber im Nachwort eine Fortsetzung derselben ankündigt, ${ }^{56}$ weil das noch folgende letzte Kreisler-Fragment wie alle anderen Kreisler-Fragmente auch als Teil von Murrs Schreibakt betrachtet werden könnte und weil der letzte Murr-Teil ganz genau genommen nicht mit einer Lebens-Ansicht endet, sondern mit einem Gedankenstrich. ${ }^{57}$ Ist dieser Gedankenstrich nun als Gedanken- oder eine Art Pausenstrich zu lesen? Oder verweist er - die in der Chronologie des Romans

54 Vgl. auch Wirth 2008, S. 398. Es ist Wirth jedoch an dieser Stelle zu widersprechen, dass es logisch "gar nicht" möglich sei, dass der erste Kreisler-Teil des ersten Bandes, in dem Murr von Abraham an Kreisler übergeben wird, bereits gedruckt vorliegen könne, wenn im letzten Murr-Teil des zweiten Bandes diese Übergabe erst angekündigt werde. Dies wäre nur unmöglich, wenn Murr in ,Echtzeit' seine Biographie fortlaufend schreiben würde. So aber kann Murr seine Autobiographie lange nach den darin erzählten Ereignissen verfassen, auch noch nachdem Teile seines Lebens bereits in der Biographie eines anderen beschrieben worden sind.

55 Siehe dazu auch weiter unten; sowie Kapitel II.3; Letzteres dann auch u. a. mit Blick auf Jean Paul und dem Verweis auf seine Konjektural-Biographie.

$56 \quad$ Vgl. drei Anmerkungen weiter oben.

57 Zum Gedankenstrich bei Jean Paul vgl. Kapitel II.3.2.1; resp. Wieland 2013, S. 299-306; zum Gedankenstrich bei Kleist vgl. Nehrlich 2012, insbesondere S. 115-162. 
noch ausstehende Lektüre des Nachwortes wird es nahegelegt haben - auf einen Abbruch der Autobiographie? ${ }^{58}$ Für Letzteres spräche neben dem Nachwort, dass am Ende der drei anderen Kapitel resp. „Abschnitte“, wie sie in den Überschriften benannt sind, jeweils kein Gedankenstrich steht.

Welche Antwort man auch immer wählt, die soeben genannten Lesarten des Gedankenstriches zeigen vor allem eines: Die Lektüre der Autobiographie Murrs endet nicht mit jenem Gedankenstrich, sondern verschiebt sich sogleich aufs Nachwort, auf die Enden der drei vorangegangenen Kapitel/„Abschnitte“, und vor allem auf den nachfolgenden, vermeintlich letzten Kreisler-Teil, der noch vor dem Nachwort auf den letzten Murr-Teil folgt. Was nämlich für den Anfang des eigentlichen Romans gilt, gilt auch für dessen Ende: Es ist aufgrund der Tatsache, dass Murrs Autobiographie mit Fragmenten der KreislerBiographie durchsetzt ist, mindestens gedoppelt.

Hinzu kommt noch ein weiteres, grundsätzlicheres Problem, das sich ausführlich im Kapitel zu Lessings Miss Sara Sampson anhand des Sterbens in der Tragödie stellt und das auch der Gattung der Autobiographie als solcher inhärent ist: die Undarstellbarkeit des Todes durch denjenigen, der stirbt. ${ }^{59}$ Denn wenn Murr sein Leben (> bios) selbst (>autos) schreibt (> gráfein), wer schreibt dann seinen Tod? Als Auto-bio-graph kann Murr zwar die Geschichte seines Lebens selbst verfassen, aber nie deren Ende. Denn solange er dies noch tun kann, lebt er noch, und wenn er nicht mehr lebt, kann er nicht mehr schreiben, er sei tot. Den Tod des Autors (hier für einmal wortwörtlich gemeint $)^{60}$ einer Autobiographie vermag demnach nur eine zweite Person als Nachtrag zur Autobiographie festzuhalten, nicht aber der Autor selbst. Und

58 Zum Gedankenstrich im Allgemeinen vgl. Kammasch 2009; und Nehrlich 2012, S. 117-123.

59 Vgl. dazu auch Angehrn 2017, insbesondere S. 117-130.

6o An der Autobiographie wird aber auch der,Tod des Autors' im übertragenen Sinne Barthes' als Voraussetzung für die potenziell unendlich oft erfolgende ,Wiederauferstehung $/$ das ,Leben' seines Textes besonders deutlich: Gerade dadurch, dass der Autor einer Autobiographie nie das Ende seines Lebens (be-)schreiben kann, kann er als Figur ,seiner' Autobiographie auf inhaltlicher Ebene nie sterben (zur ästhetischen Nutzbarmachung eines ähnlichen Umstandes vgl. insbesondere die Ausführungen zum mittelhochdeutschen Tagelied unter II.2.1). Und dennoch endet ihr Leben als gelesener Text immer wieder, sobald ein Leser den Text nicht mehr liest. Selbst wenn nämlich nur ihr Leben und nicht ihr Tod in der Autobiographie beschrieben wird, so können diese Figur und ihr Leben nur im Zuge des Gelesenwerdens zum Leben erwachen. Kofman interpretiert denn die Stelle, wo Kreisler über Biographie und Biographen reflektiert und dabei davon spricht, er habe sich als „Leichnam, ausgestreckt auf der Tafel liegend, bereit zur biographischen Sektion“ (Hoffmann, Werke, 1992, S. 108), erblickt, auch wie folgt: „Kreisler vergleicht die ,authentischen' Biographien mit Seziertischen, auf denen Kadaver ausgebreitet liegen, und führt so die Biographie auf eine Thanatographie zurück“ (Kofman 1985, S. 89). 
in der Tat lautet die Antwort auf die soeben gestellte Frage denn auch: der Herausgeber, und zwar im Nachwort resp. in seiner Nachschrift:

Am Schluß des zweiten Bandes ist der Herausgeber genötigt den geneigten Leser eine sehr betrübte Nachricht mitzuteilen. - Den klugen, wohlunterrichteten philosophischen, dichterischen Kater Murr hat der bittre Tod dahin gerafft mitten in seiner schönen Laufbahn. ${ }^{61}$

Der Leser muss also über die Autobiographie und die darin enthaltenen Makulaturblätter hinaus bis zur Nachschrift des Herausgebers weiterlesen, um das Ende von Murrs Leben und des Lebens, das dieser in seiner Autobiographie beschreibt (und das noch frühzeitiger zu Ende ist als das tatsächliche Leben Murrs), zu erfahren. ${ }^{62}$ Dies heißt aber auch, dass die Lektüre über das Ende der Autobiographie und des darin beschriebenen Lebens hinausgeht. Wenn es also einem Autor einer Autobiographie verwehrt ist, das Ende seines Lebens festzuhalten, so folgt daraus, dass er sein Leben allein schon deshalb nie als ein Ganzes schreiben kann, weil seiner Biographie immer das Ende, der Tod, fehlen wird. Denn um tatsächlich ein Autobiograph zu sein, müsste er zugleich auch Autothanatograph (von altgriechisch thánatos, der Tod) ${ }^{63}$ sein können.

Hinzu kommt, dass auch jeder Anfang einer Biographie eine willkürliche Setzung ist: Beginnt man mit der Geburt, mit der Zeugung (wie etwa in Tristram Shandy), ${ }^{64}$ mit einer Ahnenreihe usw.? Ähnlich wie im Falle des Todes ist der Autobiograph, der sich weder an die eigene Zeugung noch an die frühste Kindheit erinnern kann, auf die Hilfe resp. die Informationen Dritter angewiesen. Murr fehlt sogar eine solche Informationsquelle, wodurch auf die willkürliche Setzung des Anfangs einer jeden (Auto-)Biographie sogar explizit verwiesen wird: „Ja! es ist nicht anders, auf einen [sic] Boden muß ich geboren sein! - Was Keller, was Holzstall - ich entscheide mich für den Boden!“65 Oder

61 Hoffmann, Werke, Bd. 5, S. 457 .

62 Da Murr am Ende seiner Autobiographie schreibt, seine Zeit bei Kreisler habe eine neue Periode dargestellt, muss man davon ausgehen, dass zwischen der Zeit, die seine Autobiographie umfasst, und dem Zeitpunkt der Niederschrift der Autobiographie ein größerer Abstand klafft, den zu schließen Murrs frühzeitiger Tod verhindert hat. Hierbei wird ersichtlich, dass die Autorfiktion quasi zu einer Dopplung von Murrs Leben führt: Erstens wird von einem lebenden Autor Murr ausgegangen, der eine Autobiographie samt Vorwort(en) verfasst. Zweitens präsentiert dieser ,reale‘ Murr sich selbst als Figur seiner Autobiographie, wobei das Leben dieser Autobiographiefigur nicht (völlig) dem des realen Murr gleichzusetzen, sondern ein (z. B. mit zahlreichen Topoi versehenes) Konstrukt eines Lebens ist.

63 Vgl. Kofman 1985, S. 89; resp. drei Fußnoten weiter oben.

64 Vgl. Sterne, Tristram Shandy, S. 11.

65 Hoffmann, Werke, Bd. 5, S. 23. 
aber Murr ignoriert eine solche Informationsquelle absichtlich, denn zumindest Meister Abrahams Erinnerung, die ,zufällig in der Kreisler-Biographie erhalten blieb, ${ }^{66}$ reicht zum Thema Murrs Kindheit weiter zurück als die vermeintliche Erinnerung von Murr selbst. Man könnte somit auch sagen, zumindest der frühste verbürgte Anfang von Murrs Autobiographie liege im ersten (resp. chronologisch letzten) Teil der Kreisler-Biographie, womit der Anfang des Romans durch eine weitere entortende Übertragungsbewegung verwischt wird.

Oben stehende Ausführungen haben also gezeigt, wie sehr die Vorstellung eines in einer Autobiographie festgehaltenen und von dieser als Ganzes suggerierten Lebens ein Konstrukt ist - ein Konstrukt, das der hier untersuchte Roman parodistisch und hoch reflektiert zugleich ausstellt. Doch damit nicht genug: Liest man nämlich über das Ende der Autobiographie Murrs hinaus und kommt dabei zum Ende des ,letzten' Kreisler-Teils, so muss man feststellen, dass auch dieser mit einem Gedankenstrich endet, ja gar mitten im Satz abbricht: 67

[...] Kommt nur lieber gleich auf der Stelle, wenn Ihr dies gelesen habt! Lauft was Ihr könnt. Bald seh' ich Euch. - Apropos! - Nehmt Euch doch vor den Pfaffen in Acht, aber den Abt lieb' ich sehr. - Adieu!

So kurz und so Inhaltsreich [sic] war dies Brieflein des alten Meisters, daß -68

Der mit "So kurz" beginnende und mit einem Gedankenstrich abbrechende resp. endende Abschnitt wird aber nicht mehr durch einen eindeutig identifizierbaren ,letzten' Absatz begrenzt. ${ }^{69}$ Gewissermaßen auf der Suche nach diesem Absatz gelangt der Leser über eine Leerzeile zu einem zentrierten Strich in der Mitte der übernächsten Zeile, der einen weiteren Abgrenzungshinweis darstellt, und von dort schließlich zum Titel Nachschrift des Herausgebers (in der Erstausgabe alles noch auf derselben Seite wie der ,Schluss' des Kreisler-Teils!). ${ }^{70}$ Spätestens mit dem ersten Buchstaben des ,Herausgebers` beginnt der Leser sodann, diesem und dessen Nachschrift seine Stimme zu leihen.

\footnotetext{
66 Vgl. ebd., S. 34.

67 Was rückwirkend die Lesart des Gedankenstrichs am Ende des Murr-Teils als Zeichen des Abbruchs stärkt.

68 Hoffmann, Werke, Bd. 5, S. 456.

69 Andernfalls würde die Nachschrift des Herausgebers sogleich nach einem Leerschlag an den Gedankenstrich anschließen.

70 Vgl. Kater Murr 1822, S. 405.
} 
Der scheinbare Abbruch des Romans war also - sofern der Leser das Buch nach dem „daß" nicht sofort zugeklappt hat ${ }^{71}$ - nur ein Verstummen des Kreisler-Biographen ${ }^{72}$ und nicht des Lesers und damit des Romans selbst. Liest der Leser nun weiter bis zum Ende der Nachschrift des Herausgebers, so endet diese wiederum, ohne durch einen weiteren Absatz resp. Abschnitt einund abgegrenzt zu werden. Die in der Erstausgabe zentrierte und mit größerer Schriftgröße gedruckte Formulierung „Ende des zweiten Bandes“73 scheint die Funktion einer solchen Eingrenzung zu übernehmen und ist denn auch durch ihre Typographie als Paratext gekennzeichnet. Das Problem hierbei ist aber, dass dies ein Paratext ist, der nicht den eigentlichen Text, sondern bereits einen anderen (vermeintlichen) Paratext, die Nachschrift des Herausgebers, begrenzt. Anstatt dass die Nachschrift selbst das Ende des Doppelromans klar ab- und eingrenzt, wird dieses Ende also - ähnlich wie bereits im Falle des Anfangs und seiner Vorworte - verwischt: Endet der Roman nun mit dem letzten Makulaturblatt und somit vor der Nachschrift; mit der Nachschrift des Herausgebers, die aber noch Teil der Fiktion ist; oder erst mit der (vermeintlich) performativen Formulierung Ende des zweiten Bandes, die dann zugleich die Nachschrift und das letzte Makulaturblatt einzugrenzen hätte?

Diese nicht abschließend zu klärenden Fragen führen den Leser wieder zurück zum vermeintlich letzten Kreisler-Teil, der jedoch auf der inhaltlichchronologischen Ebene nur der zweitletzte ist, denn der inhaltlichchronologisch erste Abschnitt des letzten Kreisler-Teils ${ }^{74}$ beginnt ja eigentlich mit dem ersten Makulaturblatt des ersten Bandes. ${ }^{75}$ Das Ende des letzten Abschnittes des letzten Kreisler-Teils des zweiten Bandes ließe sich also zu Beginn des ersten Makulaturblattes des ersten Bandes finden oder - die abwechselnden Biographieteile berücksichtigend - vor den ersten Worten in der

71 Selbst das „daß“ als Einleitung eines Konsekutivsatzes kann der Leser nicht ohne Bezug auf eine (mindestens gedachte) Fortsetzung des Textes lesen, und auch der Gedankenstrich lässt sich nur als ein Zeichen lesen, wenn man den vorliegenden Text um ein gedachtes Ganzes, den ,Rest' einer weiter gehenden Kreisler-Biographie, ergänzt und diese damit quasi in Gedanken weiterliest.

72 Genau genommen ist natürlich auch dieser nur die Erzählinstanz der Kreisler-Biographie und nicht der fiktive Biograph selbst.

73 Vgl. Kater Murr 1822, S. 406. Bemerkenswert ist an der Erstausgabe auch, dass unter dem Vermerk „Ende des zweiten Bandes“ noch ein durchgehender abgrenzender Strich steht, auf den ein Paratext mit einem (metonymischen) „Impressumshinweis“ auf die Druckerei folgt: „Berlin, gedruckt bei Conrad Feister“.

74 Der freilich selbst wiederum inmitten von Kreislers Leben, das eben nur fragmentarisch überliefert ist, beginnt.

75 Vgl. die schematische Darstellung unter II.1.1; sowie zusammenfassend Liebrand 1996, S. 198. 
Murr-Biographie. Letztere beginnt wiederum entweder mit dem von Murr verfälschten ${ }^{76}$ Egmont-Zitat „Es ist doch etwas schönes, herrliches, erhabenes um das Leben!" oder aber mit dem Titel des ersten Kapitels, wo es ausgerechnet (in der Erstausgabe in Sperrdruck) heißt: "Erster Abschnitt“.77 Damit hat - natürlich gemeinsam mit den inhaltlichen Verknüpfungen, die der Leser anstellt - die Lektüre des letzten Abschnittes des letzten Makulaturblattes den Leser zum ersten Abschnitt einer zweiten Lektüre geführt - einer Lektüre, deren potenzielle Unendlichkeit gerade auch in der Typographie des Textes angelegt ist.

Oder anders formuliert: Dadurch, dass einerseits sich die einzelnen Murr- und Kreisler-Teile zwar über beide Bände hinweg jeweils abwechseln, die Kreisler-Teile in der Chronologie ihrer Erzählung jedoch um einen verschoben mit dem letzten Teil beginnen, und andererseits das Ende des Doppelromans derart unverortbar ist, wird der Leser in eine potenziell ewig fortzusetzende Spirale der Lektüre geführt, ja mit höchstem Aufwand nahezu dazu gezwungen. Am Ende des zweiten Bandes wird ihm auf inhaltlicher, strukturell-kompositorischer und typographischer Ebene aufgedrängt, dass der vermeintlich erste Kreisler-Teil in der Chronologie der Erzählung der letzte ist, der Leser seine Lektüre der fragmentarischen Kreisler-Biographie also mit dem ersten Kreisler-Teil des ersten Bandes zu beenden hat. Doch tut der Leser dies, so hat er gewissermaßen bereits wieder mit Murrs Autobiographie begonnen, von deren erstem und zweitem Teil jener Kreisler-Teil gerahmt wird und deren Anfang nicht minder unverortbar ist. Man ist also versucht, mit Murr auszurufen, dass es nicht nur „etwas schönes, herrliches, erhabenes um das Leben" ${ }^{\text {"78 }}$ sei, sondern auch um das Lesen, im Zuge desselben Murrs und Kreislers Leben immer wieder von Neuem und immer wieder anders erweckt worden sein werden..$^{79}$

$7_{6}$ Vgl. Liebrand 1996, S. 213 f., die in einer Anmerkung auch auf die von Sabine Laussmann festgestellte zensurhistorische Brisanz des Zitates verweist.

77 Kater Murr 1820, S. 1. Was den Titel des Kapitels betrifft, so ist es mit Blick auf die zentrale Funktion von Absatz und Abschnitt sowie die autoreflexive, poetologische Lesart von „Abschnitt“ wohl kein Zufall, dass in den 16 von Retsch untersuchten Bildungsromanen des 19. Jahrhunderts ausgerechnet Hoffmanns Kater Murr und Tiecks Tischlermeister die einzigen sind, deren Kapitel mit „(Erster, Zweiter etc.) Abschnitt“ überschrieben sind, während ansonsten die Verwendung von "Capitel“ dominant ist (vgl. Retsch 2000, S. 206).

78 Hoffmann, Werke, Bd. 5 , S. 18.

79 Schäfers Kommentar zum Egmont-Zitat Murrs passt denn auch hervorragend zum Versuch, den Leser über den Tod des Katers und das vermeintliche Ende des Romans hinaus weiterlesen und damit Murr ,weiterleben' zu lassen: „Ein Zitat aus Goethes ,Egmont”, das am Ende eines Lebens, wohlgemerkt eines Lebens [gemeint ist Egmonts Leben, 
Mikroebene: Abgrenzungshinweise und ihre Eigendynamik Klammerbemerkungen, Absätze und (Lebens-)Abschnitte

Die fiktive Herausgeber-Figur ,E. T. A. Hoffmann' schreibt zu Beginn seines Vorwortes: „Keinem Buche, ist ein Vorwort nötiger, als gegenwärtigem, da es, wird nicht erklärt, auf welche wunderliche Weise es sich zusammengefügt hat, als ein zusammengewürfeltes Durcheinander erscheinen dürfte.“80 Den Grund für dieses „Durcheinander“ erfährt man im weiteren Verlauf des Vorwortes:

Als der Kater Murr seine Lebensansichten schrieb, zerriß er ohne Umstände ein gedrucktes Buch, das er bei seinem Herrn vorfand, und verbrauchte die Blätter harmlos teils zur Unterlage, teils zum löschen [sic]. Diese Blätter blieben im Manuskript und - wurden, als zu demselben gehörig, aus Versehen mit abgedruckt!

De- und wehmütig muß nun der Herausgeber gestehen, daß das verworrene Gemisch fremdartiger Stoffe durcheinander lediglich durch seinen Leichtsinn veranlaßt, da er das Manuskript des Katers hätte genau durchgehen sollen, ehe er es zum Druck beförderte, indessen ist noch einiger Trost für ihn vorhanden.

Für's erste wird der geneigte Leser sich leicht aus der Sache finden können, wenn er die eingeklammerten Bemerkungen, Mak. Bl. (Makulatur Blatt) und $M . f . f$. (Murr fährt fort) gütigst beachten will $[\ldots] .{ }^{81}$

Hierbei ergibt sich nun aber folgendes Problem: Die von ihren materialen Abgrenzungs- resp. Ganzheitshinweisen, nämlich den herausgerissenen Textträgern der ,Makulatur-Blätter', entledigten und auch in Schriftbild und Typographie zusammen mit der Murr-Biographie einheitlich abgedruckten Fragmente der Kreisler-Biographie teilen nun plötzlich ihrerseits Murrs Autobiographie in einzelne Fragmente. ${ }^{82}$ Dies sogar weitaus radikaler als noch im dem Verleger übergebenen Manuskript: Wo zuvor noch das (Makulatur-) Blatt einen materialen Abgrenzungshinweis verkörpert hat, würden sich nun

MG] einer literarischen Figur, steht, wird von Murr umgewandelt zum Beginn seines literarischen Unterfangens" (Schäfer 2011, S. 195).

8o Hoffmann, Werke, Bd. 5, S. 11.

81 Ebd., S. 12.

82 Die Murr-Fragmente ließen sich aber im Gegensatz zu den Kreisler-Fragmenten (abgesehen von den Gedankenstrichen) lückenlos wieder zusammenschließen. Dies führt gewissermaßen zu vielen kleinen Fortsetzungen, die im Kleinen die Fortsetzung des ersten Bandes in einem zweiten Band spiegeln - quasi ein Fortsetzungsroman im Fortsetzungsroman. Dabei ist es äußerst faszinierend, zu beobachten, dass, wenn man einen ganzen Text mit einem fragmentarischen kombiniert, plakativ ausgedrückt, nicht der fragmentarische nun eingebettet ganz, sondern der ganze fragmentarisch zu werden scheint. Die Fragmentierung von Murrs Autobiographie durch die Kreisler-Fragmente nimmt also vorweg, was zu Ende des zweiten Bandes offensichtlich wird: Auch die MurrAutobiographie ist letztlich ein Fragment. 
die Fragmente der Kreisler-Biographie ohne Abgrenzungshinweise (weder materiale, typographische noch begriffliche) an den Murr-Text anschließen. Dies sähe am Beispiel des ersten Wechsels zwischen Murrs Autobiographie und einem Fragment der Kreisler-Biographie wie folgt aus:

*[... ja wohl manchen Sperling haschen, und sogar hin und wieder ein Täublein erlauern. „Gewaltig ist die Liebe zu dir o Vaterland!“ -

Doch ich muß Rücksichts meiner und erinnern Sie sich gnädigster Herr! denn nicht des großen Sturms, der dem Advokaten, als er zur Nachtzeit über den Pontneuf wandelte, den Hut vom Kopfe herunter in die Seine warf? - Ähnliches steht im Rabelais $[\ldots] .^{83}$

Es wurde soeben der Konjunktiv II verwendet, weil eben dies offensichtlich nicht der Fall ist: Zum einen findet sich zwischen einem unterbrochenen MurrTeil und einem Kreisler-Fragment immer ein Absatz und zum anderen jeweils entweder der Hinweis (Mak. Bl.) oder (M.f.f.) sowie nach fast jedem Murr-Teil und nach der Klammerbemerkung eines jeden Kreisler-Teils (mindestens) ein Gedankenstrich. Die soeben zitierte Stelle lautet denn auch richtig:

[...] ja wohl manchen Sperling haschen, und sogar hin und wieder ein Täublein erlauern. „Gewaltig ist die Liebe zu dir o Vaterland!“ -

Doch ich muß Rücksichts meiner -

(Mak. Bl.) -- und erinnern Sie sich gnädigster Herr! denn nicht des großen Sturms, der dem Advokaten, als er zur Nachtzeit über den Pontneuf wandelte, den Hut vom Kopfe herunter in die Seine warf? - Ähnliches steht im Rabelais $[\ldots] \cdot{ }^{84}$

Das Weglassen materialer oder typographischer Abgrenzungshinweise führt also zu einer Eigendynamik des Fragments, die aber offensichtlich sofort mit neuen Abgrenzungshinweisen wieder eingedämmt werden muss. Die Frage dabei ist nur, wer ist für diesen erneuten Eingriff verantwortlich? Remigius Bunia schreibt gegen Ende seines die Lebens-Ansichten des Katers Murr behandelnden Aufsatzes Die Stimme der Typographie zusammenfassend:

Es sind ferner die Schriftverantwortlichen innerhalb der Diegese zu benennen; schriftverantwortlich ist, wer über Schriftzeichenfolgen entscheiden kann; in der fiktiven Welt der Lebens-Ansichten sind es Setzer, Herausgeber, Murr und Verleger - von Kreislers Biographen dagegen wird nicht erzählt. ${ }^{85}$

83 Vgl. Hoffmann, Werke, Bd. 5, S. 23.

84 Ebd.

85 Bunia 2005, S. 391. Letzteres ist in seiner etwas allgemein gehaltenen Formulierung zu ergänzen: Der Kreisler-Biograph kann zwar nicht die Anordnung der Murr- und KreislerBiographietexte beeinflussen, aber es gibt Texte innerhalb der Kreisler-Biographie, deren 
Das Buch, das man aber in der Wirklichkeit liest und sieht, zeigt weder Murrs Manuskript noch das fertige Druckwerk, das der Setzer hervorgebracht und der Herausgeber mit seinen Anmerkungen versehen hat, sondern es evoziert sie nur. ${ }^{86}$

Ergänzend sei hinzugefügt: Das Buch „evoziert“ sie - und löst dabei, wie oben dargelegt, eine Eigendynamik aus, die wiederum die Herausgeberund Autorfiktion unterläuft. Denn was Bunia hier indirekt anspricht, ist folgender Widerspruch: Der Herausgeber, der im Vorwort behauptet, er habe die Makulaturblätter nicht bemerkt und deshalb seien sie versehentlich mitabgedruckt worden, kann diese demzufolge gar nicht mit Anmerkungen ergänzt haben. Es ist denn auch weder im Vorwort noch sonstwo im Roman davon die Rede, dass der Herausgeber die Klammerbemerkungen eingefügt hat. Mit Blick auf die Ergebnisse zur Makroebene des Romans ist zudem die implizite Begründung des Herausgebers, weshalb er die Makulaturblätter übersehen habe, bemerkenswert: „[...] und da der Eingang der Historie ihm [dem Herausgeber, MG] ziemlich gut stylisiert schien, so lief er sofort, mit dem Manuskript in der Tasche, zu dem Herrn Dümmler unter den Linden, und proponierte ihm den Verlag des Katerbuchs.“87 Ausgerechnet der AutobiographieEingang Murrs mit den beiden Vorworten des Katers und der entortenden Intertextualität des eigentlichen Anfangs erschien dem Herausgeber so "gut stylisiert“, dass er offenbar nur die ersten paar Seiten der Biographie las, deshalb die Makulaturblätter übersah und in der Folge dieses Versehens mit seinem Vorwort den entortenden Stil Murrs noch potenzierte. Oder anders gesagt: Der Herausgeber scheint der erste Leser der Autobiographie Murrs gewesen zu sein, der sich in der potenzierten Entortungsbewegung ihres Anfangs verloren hat.

Es bleibt also beim oben genannten Widerspruch: Entweder der Herausgeber bemerkt das ,Versehen' rechtzeitig, und aus der Autobiographie Murrs wird keine Doppelbiographie, oder er bemerkt es nicht rechtzeitig, und das Manuskript wird ohne die Anmerkungen des Herausgebers - z. B. nach Murrs ,unterdrücktem' Vorwort - und ohne die Abgrenzungs- und

Abfolge er durchaus bestimmt. Im Falle des Briefes von Kreisler an Meister Abraham tut er dies sogar ganz explizit, indem er diesen dem Leser zu lesen gibt, noch bevor ihn Meister Abraham überhaupt erst geöffnet hat: „Hat aber nun auch Meister Abraham des Kapellmeisters Brief verschlossen in seinen [sic] Schreibepult oder Schreibtischkasten und ist er auch spazieren gegangen in den Park, doch soll der geneigte Leser den Inhalt sogleich buchstäblich erfahren. - Johannes Kreisler hatte folgendes geschrieben: [...]“ (Hoffmann, Werke, Bd. 5, S. 270).

86 Bunia 2005, S. 389.

87 Hoffmann, Werke, Bd. 5, S. 11. 
Gliederungshinweise - (Mak. Bl.), (M.f.f.), Absätze und Gedankenstriche zwischen den Biographieteilen gedruckt. ${ }^{88}$ Uwe Wirth hat bereits auf dieses Paradoxon hingewiesen ${ }^{89}$ und stellt diesbezüglich fest:

Der im Vorwort-Ensemble in Szene gesetzte performative Widerspruch wird als synekdochisches Vorspiel zur Selbstdarstellung jenes poetischen Konzepts [ebenjenes performativen Widerspruchs, des Ausstellens der Fiktion als Fiktion, MG], das dem gesamten Roman zugrunde liegt. ${ }^{90}$

Beim Versuch, diesen Widerspruch zu lösen, schreibt Wirth von einer

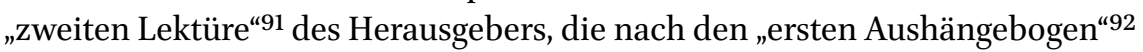
korrigierend eingegriffen habe. Doch bei Hoffmann wird nirgends erwähnt, wer die korrigierenden Klammerbemerkungen eingefügt hat. Zudem stellte sich bereits Claudia Liebrand die Frage: Wenn der Herausgeber schon korrigierend

88 Auch folgender, bemerkenswerter Einschub des Herausgebers im zweiten Band unterläuft die rahmende Herausgeberfiktion des Vorwortes:

„[...] und kein finstrer Geist vermochte den Himmel ihrer Liebe zu trüben. -

- Hier hat, wie der Herausgeber es dem geneigten Leser bemerklich machen muß, der Kater wieder ein Paar Makulaturblätter ganz weggerissen, wodurch in dieser Geschichte voller Lücken wiederum eine Lücke entstanden. Nach der Seitenzahl fehlen aber nur acht Kolumnen, die eben nichts besonders wichtiges enthalten zu haben scheinen, da das Folgende sich im Ganzen noch so ziemlich an das Vorhergegangene reiht. Also weiter heißt es:

- - - nicht erwarten durfte. Fürst Irenäus war überhaupt ein abgesagter Feind von allen ungewöhnlichen Vorfällen [...]“ (Hoffmann, Werke, Bd. 5, S. 405).

Der Herausgeber schaltet sich hier zum ersten und einzigen Mal zwischen zwei Kreisler-Teilen ein (vgl. Czezior 20o8, S. 146 und 149 f.), und ebenfalls zum ersten und einzigen Mal befindet sich damit - streng genommen - zwischen zwei Kreisler-Teilen kein Murr-Teil. Der Einschub zeugt davon, dass der Herausgeber die Makulaturblätter in Murrs Manuskript nicht nur gelesen, sondern sogar noch mit einer ausführlichen Notiz versehen hat. Zufälligerweise beträgt die Anzahl der Zeilen in der Edition der „Bibliothek deutscher Klassiker“ wie die Zahl der „Kolumnen“ (freilich nicht Zeilen) ebenfalls acht, was den performativen Akt des Herausgebers, der mittels seines Hinweises auf die Lücke überhaupt erst eine Lücke in der Kreisler-Biographie (wieder-)herstellt, noch ein wenig verstärkt (zu dieser Stelle vgl. auch Wirth 2008, S. 405, Anm. 200). In der Erstausgabe beträgt der Einschub des Herausgebers jedoch zehn Zeilen (vgl. Kater Murr 1822, S. 312). Diese unscheinbare Textstelle kann also noch mehr zu lesen geben als die Ironisierung des Herausgebers, „der auch hier das Wesentliche vom Unwesentlichen nicht trennen kann" (Steinecke 2004, S. 508).

89 Ebd., S. 386-389.

$90 \quad$ Wirth 2008 , S. 387.

91 Ebd., S. 382.

92 Hoffmann, Werke, Bd. 5, S. 12. 
eingreift, weshalb entfernt er dann die Kreisler-Fragmente nicht oder gibt sie in einem eigenen Band heraus? ${ }^{93}$

Es sieht also ganz danach aus, als ob man es - zumindest bei fiktiven Metatexten wie z. B. (Mak. Bl.), (M.f.f.) und der Nachschrift zu Murrs unterdrücktem Vorwort ${ }^{94}$ - letztlich mit einem unbekannten "Schriftverantwortlichen" zu tun hat, während die Schriftverantwortlichkeit des Herausgebers plötzlich infrage gestellt ist. ${ }^{95}$ Uwe Wirth selbst beantwortet die Frage nach

93 Ihre Antwort fällt dabei wie folgt aus: „Die Fiktion will offenbar auf ihre Scheinhaftigkeit hin durchschaut werden. Ihr geht es nicht um die Suggestion von Wahrheit, Realität, Authentizität, sondern um die Etablierung eines literarischen Spielfeldes“ (Liebrand 1996, S. 203). Uwe Wirth hingegen begegnet dieser Frage vorerst damit, dass sich dabei "dem Leser der Verdacht auf[drängt], dass dem vermeintlichen Zufallsarrangement die Strategie eines impliziten Herausgebers zugrunde liegt" (ders. 2008, S. 386).

94 Auch beim unterdrückten Nachwort Murrs ist der Schriftverantwortliche nicht zu klären, obwohl dieses mit „d. H.“ (Hoffmann, Werke, Bd. 5, S. 17), also wohl mit „der Herausgeber“, signiert ist (vgl. auch Wirth 2008, S. 386-388). Interessant ist hier ebenfalls, dass es sich bei „d. H.“ - wie schon bei der Klammerbemerkung (Mak. Bl) - um eine Abkürzung handelt, bei der auf das Vorwort zurückgegriffen werden muss, um sie im Zuge einer Entortungsbewegung aufzulösen und damit erst den vollständigen Signifikanten zu erhalten.

95 Zu beachten ist in diesem Zusammenhang auch David G. Kropfs These, die Textanfänge zwischen den einzelnen Biographieteilen würden weitere herausgeberische Eingriffe provozieren, indem sie z. B. sehr oft mit einer Rede begännen, was zahlreiche Herausgeber späterer Editionen dazu gebracht habe, Anführungszeichen einzufügen, die in der Erstausgabe nicht vorhanden gewesen wären und welche die Herausgeberfiktion des Vorwortes massiv unterlaufen würden (vgl. Kropf 1994, S. 221). Man könnte also sagen, die Stellen, an denen die Schriftverantwortlichkeit nicht geklärt ist, übten eine besondere Anziehungskraft auf die Leser aus (davon zeugt auch das vorliegende Kapitel), an welche die Schriftverantwortlichkeit delegiert ist. Ist der Leser gar ein späterer Herausgeber, so übernimmt er die Schriftverantwortlichkeit derart geflissentlich, dass er in den Text eingreift, und zwar besonders in den Fällen, wo es um eine Ab- und Eingrenzung von Text geht, wie eben im Falle der Anführungszeichen. Bemerkenswert ist dabei, dass selbst in der Erstausgabe an einer Stelle dem Ende eines Makulaturblattes ein doppeltes Anführungszeichen ,beigefügt' ist: „Mit zwei Worten, sprach die Benzon [sic] erkläre ich alles. Als ich mich vor fünf Jahren in -“ (Hoffmann, Werke, Bd. 5, S. 69; resp. Kater Murr 1820, S. 96). Zu beachten ist hier zudem weiter, dass der Einschub des Erzählers „sprach die Benzon“ nicht durch ein vorangehendes Schluss- und ein nachfolgendes Anführungszeichen von der direkten Rede, ausgeklammert wird'. In Anlehnung an Müller Nielabas Überlegungen zum doppelten Anführungszeichen könnte man dazu sagen: Dadurch, dass ein doppeltes Anführungszeichen nur in Relation zu einem zweiten doppelten Anführungszeichen überhaupt als solches gelesen werden kann (vgl. ders. 2009, S. 148 f.), sah man sich an dieser Textstelle offenbar gezwungen, den Ort des für die Figuration des ersten doppelten Anführungszeichens denknotwendigen zweiten doppelten Anführungszeichens resp. Schlusszeichens nicht einfach nur dem Verstehensprozess des Lesers zu überlassen. Man druckte das Schlusszeichen deshalb ab, um ihm damit vermeintlich einen festen Ort zu geben, was jedoch wiederum gerade dadurch ad absurdum geführt wird, dass so die 
der Schriftverantwortlichkeit damit, dass dem "Drucker die Funktion“ zukomme, „die äußerste Rahmungsinstanz“ zu sein, „die bis zuletzt eine Möglichkeit zum Eingreifen und Modifizieren des Textes“ besitze. „Dadurch wird die Instanz des Druckers zur anonymen Personifikation jenes überpersönlichen ,typographischen Dispositivs', das im Rahmen der technischen Reproduktionsverfahren gleichermaßen für das Gelingen wie für das Scheitern der Verkörperungsbedingungen verantwortlich ist. ${ }^{46}$ Wenngleich Wirth damit die rahmende Funktion der Typographie betont und den Drucker als deren Personifikation bezeichnet, so ist zu ergänzen, dass von diesem Drucker im Vorwort des Herausgebers letztlich nicht die Rede ist. Es finden sich lediglich die Begriffe „Setzern“ (im Plural) und „Setzer“97 (zweimal), die höchstens metonymisch - also erneut über eine Übertragungsbewegung - für ,den Drucker stehen können. Zudem kommen sie allesamt in ein und demselben Abschnitt vor, der gar nicht direkt von dem Setzer des zur Diskussion stehenden Romans handelt, sondern von den "Setzern“ im Allgemeinen und je von dem "Setzer“ der Nachtstücke und des Fräulein Scudery (wobei die Erwähnung dieser beiden Werke wiederum mit der Identität des mit „E. T. A. Hoffmann ${ }^{498}$ signierenden fiktiven Herausgebers spielt).

Hoffmanns Doppelroman entzieht sich also letztlich jedem Versuch einer Fest-Setzung(vgl.,,Setzer"); seiner potenziellunendlichenEntortungsbewegung vermag kein Rahmen eines Autors, Herausgebers, Drucker-Setzers, von Buchdeckeln oder eines Blattes Einhalt zu gebieten.$^{99}$ Genau dies lässt sich letztlich auch an Wirths weiterer Argumentation beobachten, wenn sie der Chronologie der Vorworte folgend über das Verzeichnis der Druckfehler auf das unterdrückte Vorwort des Autors stößt:

Dieser offene Angriff des Herausgebers [der sich über die Fehler der Setzer lustig macht, $\mathrm{MG}^{100}$ ] wird vom Drucker-Setzer performativ beantwortet: Gegen den Willen des Herausgebers wird das unterdrückte Vorwort des Autors abgedruckt. Unklar bleibt dabei, wer die Kennzeichnung "Unterdrücktes des Autors" vornimmt. [...] In jedem Fall kann man sagen: Die Lebens-Ansichten des Katers

Herausgeberfiktion unterlaufen und die Entortungsbewegung an der Textgrenze letztlich nicht angehalten, sondern im Gegenteil weiter verstärkt wird.

96 Wirth 2008, S. 387.

97 Hoffmann, Werke, Bd. 5, S. 12 f.; resp. Kater Murr 182o, S. VII-VIII.

98 Ebd., S. 14.

99 Zu der in der Forschung lange Zeit dominanten Betrachtungsweise von Hoffmanns Doppelroman, die interpretatorisch ,jene ,Einheit' zu stiften [sucht], die der Text verweigert“, vgl. Liebrand 1996, S. 199, zu den „Integrationsvorschlägen und (Auf-)Lösungen“ der Forschung S. 199-202.

Vgl. Hoffmann, Werke, Bd. 5, S. 12 f. 
Murr thematisieren ex negativo die parergonale Kraft der Funktion Drucker durch eine Inszenierung editorialer Fehlschläge. Die Konsequenzen dieser Fehlschläge werden durch die Struktur des Textes verkörpert. So ist die in der Nachschrift zum Vorwort - „das ist zu arg!“ - zum Ausdruck kommende Ohnmacht des Herausgebers nicht nur ein Indiz für die Eigensinnigkeit der Technik, sondern auch ein Indiz dafür, daß es hinter der literarischen Szene ein übergeordnetes, unsichtbares editoriales Dispositiv gibt. Dieses editoriale Dispositiv sorgt mit einem gehörigen $\mathrm{Ma}$ an performativer Ironie dafür, daß die Instanz des Druckers den unzuverlässigen Herausgeber in einen ohnmächtigen Herausgeber transformiert. ${ }^{101}$

Nach der Logik dieser Argumentation müsste der Herausgeber nicht nur eine „zweite Lektüre“ vorgenommen haben, sondern in Auseinandersetzung mit dem Setzer auch eine dritte, die wiederum vom Setzer gekontert werden könnte usw. - ganz gemäß (früh-)romantischer sich potenzierender Ironie $^{102}$ - ad infinitum. An Uwe Wirths Lektüre selbst wird also ersichtlich, dass die Rahmungsversuche der Herausgeberfiktion Anlass zu einer potenziell unendlichen Kette interpretativer Aufpfropfungen geben, womit in gewissem Sinne eine von Wirths Kernthesen ${ }^{103}$ sowohl von ihm selber als auch von dem vorliegenden Kapitel performativ bestätigt wird.

Wirths Ergebnisse, die auf die „Konfusion von Rahmen“ und die dadurch autoreflexiv bewirkte „erhöhte Aufmerksamkeit für Rahmungen“104 hinweisen, werden hier also weitergeführt, indem aufgezeigt wird, dass Rahmenkonfusion eine potenziell unbeendbare Eigendynamik nach sich zieht, die gerade auch strategisch für den Versuch eingesetzt werden kann, den Leser zu einer (potenziell) unendlichen Lektüre zu zwingen. Oder mit anderen Worten: Sowohl die Rahmenkonfusion als auch die auf der Makroebene beobachtete Kreisstruktur des Doppelromans und die exzessiven intertextuellen Verweise lassen sich unter der Operation zur Ewigkeitsattribuierung von Schriftzeichen Unendliche Lektüre fassen, wobei es im Falle der Rahmenkonfusion auch zur Überschneidung mit der komplementären Operation Unendliches Verstummen kommt (siehe dazu das betreffende Kapitel II.2).

Aus all den Widersprüchen, in die sich der Herausgeber selbst, aber auch noch der aufmerksamste Leser verstricken kann resp. geradezu muss, geht die

\footnotetext{
101 Vgl. Wirth 2008, S. 388.

102 Vgl. dazu auch Wellenberger 1986, dessen Monographie Der Unernst des Unendlichen jedoch trotz vielversprechendem Titel für die vorliegende Fragestellung kaum Ergiebiges beinhaltet.

103 Vgl. zusammenfassend Wirth 2008, S. 419-421.

104 Ebd., S. 416.
} 
These hervor, die es für die folgenden Ausführungen dieses Kapitels im Hintergrunde immer mitzudenken gilt:

Durch das komplexe Spiel mit vom Leser normalerweise weitestgehend nicht bewusst wahrgenommenen ${ }^{105}$ Abgrenzungs- und Gliederungshinweisen entfaltet der hier untersuchte Roman eine Eigendynamik, die das stetige, potenziell unendliche Verschieben von Anfang und Ende eines Textes und dessen Bedeutungen ausstellt, das jene Hinweise anzuhalten resp. festzusetzen vorgeben.

Es sei nun in einem letzten Schritt noch einmal auf die Klammerbemerkungen (Mak. Bl.) und (M.f.f.) zurückgekommen, die von Uwe Wirth auch als "Links" bezeichnet worden sind. ${ }^{106}$ Die Bezeichnung der Klammerbemerkungen als Links hat, insbesondere mit Blick auf die heutigen digitalen Medien, etwas für sich. Sie macht aber vor allem dann Sinn, wenn bloß eine der beiden Klammerbemerkungstypen, (Mak. Bl.) oder (M. f.f.), als Link betrachtet wird, denn andernfalls läge konsequenterweise nur eine Aneinanderreihung von Links vor. Damit wird deutlich, dass die Klammerbemerkungen im Grunde letztlich doch keine einzelnen, in ihrer verweisenden Funktion für sich stehenden Links sind, sondern sich ihre ab- und eingrenzende Funktion nur in Relation zueinander konstituiert: Ohne eingeschobene Makulaturblätter würde Murr nicht unterbrochen werden, hätte also auch keinen Grund, explizit fortzufahren, und ohne den Text Murrs müssten die Makulaturblätter nicht eigens als solche abgegrenzt werden. Die fiktiven Metatexte $(M . f . f$. verweisen also sowohl darauf, dass die Murr-Biographie weitergeht, als auch vor und zurück auf die Makulaturblätter, die einen solchen Verweis überhaupt nötig machen - und umgekehrt. Oder anders formuliert: Die Klammerbemerkungen (M.f.f.) bilden nicht eigenständig einen Rahmen resp. Klammern um einen Murr-Text, wozu eine zusätzliche Bemerkung wie „Murr wird bald weiter fortfahren" am Ende eines Murr-Teils nötig wäre. Sie sind deshalb auf den zu Beginn des jeweils nächsten Kreisler-Teils folgenden Hinweis (Mak. Bl.) angewiesen - und vice versa. Die Klammerbemerkungen funktionieren somit ähnlich wie Absätze, die einen Abschnitt nur in Bezug auf einen weiteren, zweiten Absatz eingrenzen können. ${ }^{107}$

105 Vgl. Hausendorf/Kesselheim 2008, S. 21.

106 Vgl. Wirth 2002, Performative Rahmung, S. 426; sowie ergänzend Wirth 2007. Ebenfalls dazu, dass die Klammerbemerkungen auch immer auf den gewaltsamen Bruch in der Abfolge der beiden Biographietexte verweisen, den sie zugleich zu überbrücken suchen, vgl. Wirth 2004, insbesondere S. 429 .

$107 \mathrm{Zu}$ einer abstrakten, sprachphilosophischen Auseinandersetzung mit dem Bereich der Interpunktion vgl. etwa den für die Analyse der Mikroebene resp. der Typologie inspirierenden Sammelband: Abbt/Kammasch 2009. 
Als Absatz stehen sie aber immer zwischen zwei, durch sie erst voneinander abgegrenzten Abschnitten und figurieren sowohl das Ende des vorangehenden als auch den Anfang des folgenden Abschnittes. (M.f.f.) und (Mak. Bl.) sind somit als Zeichen für den Anfang und das Ende eines Textes weder eindeutig am Anfang noch am Ende eines Textes zu verorten, sondern werden im Zuge ihrer Lektüre vielmehr Anfangen und Enden gewesen sein. Dass die Klammerbemerkungen nach Wirth „typographische Anker" seien, kann hier somit keine Zustimmung erfahren.

Hinzu kommt sogar, dass die Klammerbemerkungen (M.f.f.) und (Mak. Bl.) sowie die typographischen Absätze zwischen den Kreisler- und Murr-Teilen immer sowohl Absätze als auch - in Bezug auf die Absatzfunktion der jeweils anderen Absatzart - Teil eines Abschnittes sind. Oder mit anderen Worten: Liest man die Klammerbemerkungen als Absätze, so wird der zwischen den beiden Biographieteilen liegende typographische Absatz Teil des von den Klammerbemerkungen hergestellten Abschnittes - und umgekehrt.

Dies führt dazu, dass die von der einen Absatzart gebildeten Abschnitte in die Abschnitte der anderen hineinreichen (jeweils dort, wo sich in der unten stehenden Darstellung Rot und Blau überlagern). In einer schematischen Darstellung der ersten drei Wechsel zwischen den beiden Biographien des ersten Bandes sieht dies folgendermaßen aus (typographische Abschnitte rot, durch die Klammerbemerkungen gebildete Abschnitte blau):

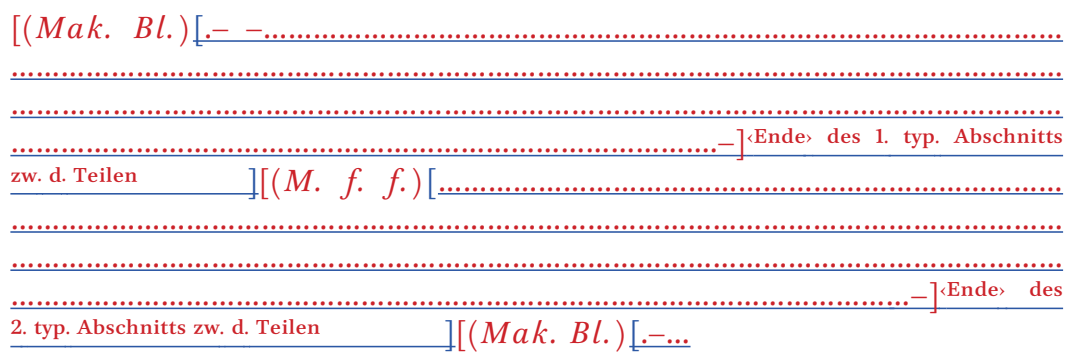

An dieser schematischen Darstellung wird nun auch ersichtlich, dass die beiden Absatzarten ebenso immer um eine Position versetzt angeordnet sind wie im gesamten Roman die inhaltlich-chronologische Reihenfolge der Makulaturblätter im Verhältnis zur chronologischen Reihenfolge der MurrAutobiographie. Verbindet man diese Beobachtung zur Mikrostruktur mit den oben dargelegten Ergebnissen zur Makrostruktur, so ergibt sich folgender Befund:

Die unendliche Lektüre, welche durch die chronologische Anordnung der Makulaturblätter innerhalb des Doppelromans erzwungen wird, steht in einem 
Ähnlichkeitsverhältnis zur potenziell unbeendbaren Übertragungsbewegung an den Grenzen der einzelnen Biographie- und Autobiographieteile. Das Strukturprinzip des gesamten Romans spiegelt sich so im Kleinen in der Doppelung in typographische Abschnitte einerseits und Abschnitte, die durch die Absatzfunktion der Klammerbemerkungen figuriert werden, andererseits.

Die so zustande kommende Situierung eines Abschnittes in einem Abschnitt schafft denn auch die Voraussetzung für eine autoreflexive Wendung der Lektüre auf die Konstituenten des jeweiligen Abschnittes und von Abschnitten im Allgemeinen. Die Überlagerung der Abschnitte macht nämlich deutlich, dass es für die Figuration eines Abschnittes - ob typographisch oder wie im Ausnahmefall des hier untersuchten Romans mittels einer Absatzfunktion von Klammerbemerkungen - immer zweier Absätze bedarf. Ähnliches gilt für die verschriftlichte direkte Rede, die immer nur durch zwei doppelte Anführungszeichen figuriert werden kann. ${ }^{108}$ Die Absätze können jedoch im Gegensatz zu den doppelten Anführungszeichen nur als solche auftreten, wenn sie ihrerseits von zwei Abschnitten begrenzt resp. figuriert werden, von denen sie in einem Fall das Ende, im anderen Fall den Anfang kennzeichnen, und dies jeweils wiederum nur in Bezug auf einen nachfolgenden oder vorangegangenen Absatz $^{1}$ - und immer so fort in einer potenziell unendlichen Bewegung, im Zuge derer die Bedeutung des Absatzes von einer weißen Absatzfläche zur nächsten vor und zurück übertragen wird. ${ }^{109}$

Nach der oben gezeigten schematischen und vereinfachten Darstellung soll nun abschließend eine besonders bemerkenswerte Folge von Übergängen zwischen Murr- und Kreisler-Teilen genauer untersucht werden. Hierbei geht es auch darum, aufzuzeigen, wie eng die typographische Ebene des Romans nicht nur mit dessen Makrokomposition, sondern auch mit dessen Inhalt verknüpft ist. Bei den genannten Übergängen handelt es sich um diejenigen zwischen dem je zweiten und dritten Murr- und Kreisler-Teil sowie den Übergang vom dritten Kreisler- zum vierten Murr-Teil des ersten Bandes. Wie schon oben steht Rot dabei für die typographischen Abschnitte, hier jedoch nur im Falle der Murr-Teile, Blau im Falle der Kreisler-Teile für die durch die Absatzfunktion der Klammerbemerkungen eingegrenzten Abschnitte. Die schwarz gehaltenen typographischen Abschnitte innerhalb der Murr-Teile helfen aufzuzeigen, dass die rot gehaltenen typographischen Abschnitte zu Beginn

108 Vgl. Müller Nielaba 2009, S. 148 f. Zum potenziell unendlichen Prozess der Figuration vgl. Müller Nielaba/Schumacher/Steier 2011.

109 Mit dem weißen „Zwischenraum“ von Texten hat sich auch Thomas Fries auseinandergesetzt, dessen Beobachtungen hiermit beizupflichten und zu ergänzen sind (vgl. Fries 2009, insbesondere S. 175). 
und zu Ende des hier mittleren Murr-Teils jeweils durch einen Kreisler-Teil unterbrochen werden. Die Klammerbemerkungen (Mak. Bl.) sind ebenfalls in Schwarz gehalten, es wird damit suggeriert, dass diese nicht zu den durch die Absatzfunktion der Klammerbemerkungen gebildeten Abschnitten und damit als metatextuelle Informationen nicht zum eigentlichen Text gehören:110

[...] Sprang wirklich ein Heldengedicht unter meinen Klauen hervor, beide hätte kein Mensch mehr gelesen.

Ich komme jetzt auf die -

(Mak. Bl.) - zum besseren Verständnis doch nötig sein, dir, geneigter Leser das ganze Verhältnis der Dinge klar und deutlich aus einander zu setzen. [es folgt nun der weitere Inhalt dieses Makulaturblatts, der mitten in einem Abschnitt mit den Worten endet, MG] Denn außerdem daß -

$(M . f . f$.$) - merkwürdige Begebenheit die, um mich des gewöhnlichen$ Ausdrucks geistreicher Biographen zu bedienen, einen Abschnitt in meinem Leben machte [kursive Hervorhebung, MG].

- Leser - Jünglinge, Männer, Frauen, unter deren Pelz ein fühlend Herz schlägt, die ihr Sinn habt für Tugend - [es folgt nun der weitere Inhalt dieses Murr-Teils, der mit einem neuen typographischen Abschnitt und mit folgenden Worten endet, MG]

So schließe ich diese Episode meines Lebens die -

(Mak. Bl.) - - nichts verdrießlicher für einen Historiographen oder Biographen, als wenn er, wie auf einen wilden Füllen reitend hin und her sprengen muß, über Stock und Stein, über Äcker und Wiesen, immer nach gebahnten Wegen trachtend, niemals sie erreichend. So geht es dem, der es unternommen für dich, geliebter Leser, das aufzuschreiben, was er von dem wunderlichen Leben des Kapellmeisters Johannes Kreisler erfahren. ${ }^{111}$ [es folgt nun der weitere Inhalt dieses Makulaturblattes, der mit den Worten Benzons mitten in einem

110 Dieser Eindruck entsteht jedoch nur, weil um der besseren Übersichtlichkeit willen nicht jede mögliche Lesart der typographischen Absätze und jeder Klammerbemerkung als Absatz miteinbezogen wurde. Dazu müsste man diese Darstellung mit der oben stehenden schematischen verbinden - eine Verbindung, die dann aber praktisch unlesbar wäre.

111 Es ist hier nicht möglich, auch die inhaltlichen Korrespondenzen zwischen den einzelnen Teilen der Murr- und Kreisler-Biographie ausführlich zu untersuchen, aber es ist kaum ein Zufall, dass der Anfang des dritten Murr- und Kreisler-Teils eine Leseransprache beinhaltet. Zudem liest sich der Beginn des dritten Kreisler-Teils wie ein Kommentar zum hier untersuchten unterbrochenen Lebensabschnitt Murrs, denn der Kreisler-Biograph beklagt ja, dass er gezwungen sei, hin und her zu springen. Ein Hin-und-her-Springen, das er in der Kreisler-Biographie natürlich an den Leser weitergibt und das, wie gerade beobachtet, sich aufgrund der Unterbrüche der Makulaturblätter ebenfalls auf die MurrAutobiographie überträgt. Vgl. dazu auch Wirth, der von einer doppelten Rahmung spricht, die zum einen von den rahmenden Eingriffen und Bemerkungen des fiktiven Herausgebers ausgeht, zum anderen aber auch von einer inhaltlichen Spiegelung (vgl. ders. 2008 , S. 405 f.). 
Abschnitt endet, MG] „Mit zwei Worten, sprach die Benzon erkläre ich alles. Als ich mich vor fünf Jahren in -“

$(M . f . f$.$) - mich überzeugte, daß in einem echten tiefen Dichtergemüt$ auch kindliche Tugend wohnt und Mitleid mit dem Bedrängnis der Genossen.

Eine gewisse Schwermut, wie sie oft junge Romantiker ${ }^{112}$ befällt, wenn sie den Entwicklungskampf der großen erhabenen Gedanken in ihrem Innern bestehen, trieb mich in die Einsamkeit. $[\ldots]^{113}$

Es sticht nun besonders ins Auge, wie stark die Abgrenzung der einzelnen Romanteile durch typographische Abschnitte einerseits sowie durch mittels Klammerbemerkungen hergestellte Abschnitte andererseits das Zur-MitteWerden des Textes ausstellt und mitkonstituiert: Ein Kreisler-Teil kommt jeweils inmitten zweier Murr-Teile zu liegen; der eigentliche Lebensabschnitt Murrs, in dem er seine Mutter trifft, wird zwischen den diesen inhaltlichen Lebens-Abschnitt performativ rahmenden typographischen Abschnitten erzählt, die wiederum von den Kreisler-Teilen unterbrochen werden usw. In den Ausführungen zur Makrostruktur wurde bereits anhand des ersten Kompositums des Titels Lebens-Ansichten auf die enge Verknüpfung zwischen Leben und Lesen hingewiesen. Genau diese Verknüpfung lässt sich auch an der soeben zitierten Stelle beobachten:

Erstens anhand der Formulierung „einen Abschnitt in meinem Leben“, also, wie Murr explizit hervorhebt, anhand „des gewöhnlichen Ausdrucks geistreicher Biographen“. Dadurch, dass das im übertragenen Sinne gebrauchte Wort „Abschnitt“ innerhalb eines typographischen Abschnittes steht, ${ }^{114}$ geht die Rede vom Lebens-Abschnitt ein Ähnlichkeitsverhältnis mit dem typographischen Lesens-Abschnitt ein. So erhält sie zugleich etwas Performatives: Es wird nicht nur darüber geschrieben, wie etwas in Murrs Leben „einen Abschnitt [...] machte“, sondern es wird gerade durch dieses Schreiben (und Lesen) ein Abschnitt gemacht resp. geschrieben - und zwar ein typographischer. Ein typographischer Abschnitt, der als solcher über zwei Absätze immer nur in Relation zu mindestens zwei anderen Abschnitten resp. zwei Absätzen figuriert wird. Und auch hierin besteht eine Parallele zu den hinsichtlich der Makrostruktur behandelten Verknüpfungen zwischen der

\footnotetext{
112 Der Verweis auf (die) „Romantiker“, die "großen erhabenen Gedanken“, das „Innere“ und die „Einsamkeit“ ausgerechnet am Ende einer Stelle potenzierter Reflexion über Leben und Lesen bis in die graphische Ebene von Schrift und Text hinein ist wohl kein Zufall; vgl. dazu Kapitel IV.3.1. Zur dem Genie stets drohenden radikalen Einsamkeit vgl. IV.3.3.

113 Hoffmann, Werke, Bd. 5, S. 44-69.

114 Auch der typographische Abschnitt ist letztlich eine Metapher und damit der Lebensabschnitt bereits eine Metapher einer Metapher.
} 
Konstitution von Murrs Leben resp. Autobiographie in Relation zu anderen Leben resp. anderen Texten.

Zweitens lässt die Abfolge ,Abschnitt in meinem Leben macht. - Absatz Gedankenstrich - Leser! - Gedankenstrich' die Stimme Murrs am Absatz verstummen und sie alslediglich vom Leser geliehene bewusst werden. Die Stimme des Lesers wird im Weiß des Absatzes, wo keine Erzählinstanz oder eine Figur spricht, so gewissermaßen , auf sich selbst zurückgeworfen', während sich am Gedankenstrich zusätzlich die (freilich vor- und zurückführende, horizontale) Linearität resp. Sequenzialität eines jeden Lesens von in lateinischer Schrift gehaltenen Texten ausstellt.

Drittens kommt hinzu, dass im Falle des hier mittleren Murr-Teils der erste typographische Abschnitt mit „Leben machte“ endet, während der zweite ausgerechnet mit der Leseransprache " - Leser" beginnt (Hervorhebungen, MG).

Die Homonymie des Wortes „Abschnitt“ ist also Teil einer extrem komplexen Verschachtelung und vereint in ihrer Semantik Lesen und Leben. Besonders faszinierend ist nun, dass bei dieser für das vorliegende Unterkapitel zentralen Textstelle der typographische Abschnitt, in dem Murr neben der Überschrift des ersten Kapitels zum ersten Mal explizit von einem Lebensabschnitt spricht, durch einen Kreisler-Teil unterbrochen wird. Mehr noch: Murr wird nicht nur in demjenigen typographischen Abschnitt unterbrochen, wo er die Erzählung dieses Lebensabschnittes explizit eröffnet, sondern auch in demjenigen, wo er sie explizit beendet. ${ }^{115}$ In der oben verwendeten Farbgebung gesprochen heißt dies: Die beiden roten typographischen Abschnitte der Murr-Biographie werden je durch die zwei blauen, durch die Klammerbemerkungen abschnitthaft figurierten Kreisler-Teile unterbrochen. Sowohl diese typographischen Abschnitte der Murr-Teile als auch Murrs inhaltlicher Lebensabschnitt sind nur über die beiden unterbrechenden Kreisler-Teile zu lesen. Ihr Anfang und Ende und damit Anfang und Ende jenes "Abschnitt[s] in meinem Leben“ sind dadurch nicht exakt zu verorten. Dies alles lässt sich in folgenden zwei Befunden komprimieren:

Die typographischen sowie die durch die Klammerbemerkungen konstituierten Abschnitte der beiden Biographien überschneiden sich ebenso, wie inhaltlich gewisse Abschnitte in Murrs und Kreislers Leben ineinanderragen. ${ }^{116}$

115 Er benutzt dabei die folgenden, performativ gebrauchten Verben: , auf etwas zu sprechen kommen' und ,(eine Episode) schließen'.

116 Zusammenfassend zu den inhaltlichen Verknüpfungen zwischen Murr- und KreislerTeilen sowie zum inhaltlichen Abdruck, den der Murr-Text auf den als Löschpapier verwendeten Makulaturblättern hinterlässt, vgl. Wirth 2008, S. 411-414, inklusive Anm. 240; sowie Liebrand 1996, S. 196 f. 
Oben stehende farbliche Markierung veranschaulicht und verdeutlicht zudem die bisherigen Beobachtungen insofern, als dass ausgerechnet dort, wo vom "Abschnitt“ die Rede ist - wo er nicht nur begrifflich verortet werden soll, sondern auch performativ hergestellt wird -, sich die ultimative Potenzierung der Entortung dieses Abschnittes findet. Eines Abschnittes, der als Lebensabschnitt, als typographischer Abschnitt und als durch die Absatzfunktion der Klammerbemerkungen figurierter Abschnitt ein mindestens dreifacher Lesensabschnitt ist, dessen drei Lesarten im Zuge der Lektüre jedoch nie gleichzeitig zu haben sind. Eines Abschnittes, an dem selbst dessen performative Herstellung als eine an die Lektüre gebundene, nicht als bleibendes Produkt zu habende, aber unendlich weiterzuführende, potenziell unbeendbare ausgestellt wird.

\subsubsection{Zusammenführung der Ergebnisse}

In E. T. A. Hoffmanns Doppelroman, dem die Ein- und Abgrenzung von Text und Textteilen als ein zentrales, wenn auch weitgehend implizites Thema dient, kommt der typographischen Ebene eine entscheidende Rolle zu. Dabei sind es gerade auch die meist unbeachteten Absätze und Abschnitte, die auf der Mikroebene des Textes wesentlich am Versuch beteiligt sind, den Leser in eine unendliche Lektüre fortzuführen. Ein Versuch, der auf der Makroebene am prominentesten durch die chronologisch versetzte resp. verschränkte Anordnung der Murr- und Kreisler-Teile unternommen wird und zu dem auch zahllose intertextuelle Verweise und Verschachtelungen ${ }^{117}$ sowie die Konzeption als Fortsetzungsroman ${ }^{118}$ beitragen.

Wenn Sabine Laussmann zu den Lebens-Ansichten des Katers Murr schreibt, „[i]n fast postmoderner Weise feiert das erste Vorwort bereits den autorlos autonomen Text und seine Teilhabe an der unendlichen Bibliothek eines zeitlosen intertextuellen Universums", ${ }_{119}$ so ist ihr also zuzustimmen und weiterführend zu ergänzen: Es ist kein Zufall, dass sie mit ihrer bildlichen Formulierung einer „unendlichen Bibliothek eines zeitlosen intertextuellen Universums" auf die implizite Ewigkeitsbehauptung ${ }^{120}$ gegenüber Schriftzeichen verweist. Die in den Lebens-Ansichten des Katers Murr geradezu exzessiv eingesetzte Intertextualität dient nämlich auch dem Versuch, Unendlichkeit und Zeitlosigkeit zu erschreiben. Oder mit anderen Worten: Das erste Vorwort "feiert" hier nicht nur implizit behauptend die „Teilhabe“ an

117 Vgl. dazu auch Laussmann 1993, insbesondere S. 16o f.; und Wirth 2008, S. 406.

118 Auf den Aspekt des Seriellen und den Cliffhanger „Kreislers Hut, an dem blutige Spuren befindlich“ (Hoffmann, Werke, Bd. 5, S. 234) kann im vorliegenden Rahmen nicht näher eingegangen werden; man vgl. dazu insbesondere Fröhlich 2015.

119 Laussmann 1993, S. 161.

120 Vgl. dazu die betreffenden Kapitel in der Einführung. 
einer vermeintlich existierenden textuellen Unendlichkeit und Zeitlosigkeit, sondern versucht zugleich, diese Ewigkeitsbehauptung gegenüber Schriftzeichen mittels Operationen zur Ewigkeitsattribuierung überhaupt erst wahr werden zu lassen.

Im Falle der Absätze und Abschnitte kommt letztlich nicht nur die Operation Unendliche Lektüre zum Einsatz, sondern zusätzlich die Unteroperation Poetische Performativität (siehe zu dieser Operation Kapitel III), und zwar über die Analogie von typographischem Abschnitt und Lebensabschnitt, die dem jeweiligen vergänglichen Lebensabschnitt einen ewigen Abschnitt aus Schrift zu stiften sucht. Doch gerade die entortende, potenziell unendliche Bewegung der Figuration von Absatz und Abschnitt wird in Hoffmanns Doppelroman auf eine Weise ausgestellt, die jedes zeichenhaft erzählte oder gedachte Leben als ein textuell konstruiertes und strukturiertes, als solches gelesenes und zu lesendes zu enttarnen vermag. Oder anders formuliert: Unendliche Lektüre ist in den Lebens-Ansichten des Katers Murr diejenige der Operationen zur Ewigkeitsattribuierung von Schriftzeichen, die gegenüber den anderen Operationen, aber auch in einem ästhetischen, den Doppelroman auf formaler Ebene strukturierenden, rahmenden und zugleich entrahmenden Sinne dominant ist. Die Operation Poetische Performativität hingegen nimmt dort eine wichtige Rolle ein, wo nicht nur von einem Lebensabschnitt die Rede ist, sondern zugleich ein Abschnitt einer Bio-Graphie, einer Lebens-Schrift, erschrieben resp. gelesen wird. Gerade der exzessive Einsatz der Operation Unendliche Lektüre (inkl. Überschneidungen mit der komplementären Operation Unendliches Verstummen, siehe Kapitel II.2) zwingt den Leser fast schon dazu, auf einer Metaebene über Anfang und Ende von Texten, die Möglichkeitsbedingungen und Aporien eines verschriftlichen Lebens und damit auch die Ewigkeitsbehauptung gegenüber der Gattung der (Auto-)Biographie sowie von Schriftzeichen im Allgemeinen nachzudenken. Damit aber bedient sich der Doppelroman letztlich in nicht unbedeutendem Maße auch der Grundoperation Reflexivität, die in Kapitel IV behandelt wird.

$\mathrm{Zu}$ Letzterem ist hier besonders hervorzuheben, dass E. T. A. Hoffmann sowohl in der Autobiographie Murrs als auch in der fragmentarischen Biographie Kreislers die Versuche der Verewigung des Genies und seiner Werke mittels Schriftzeichen inhaltlich thematisiert. Er tut dies auf den ersten Blick mittels parodistischer und ironischer Distanz zu diesen Versuchen. Aber trotz oder eben gerade wegen aller ironischen Reflexion auf Text, „unsterbliche Werke ${ }^{\text {"121 }}$ und die ,Göttlichkeit ${ }^{\text {‘22 }}$ des Genies experimentiert Hoffmann mit

121 Unter anderem Hoffmann, Werke, Bd. 5, S. 38 oder 44.

122 Vgl. dazu den oben zitierten Ausruf "göttlicher Murr“ (Hoffmann, Werke, Bd. 5, S. 38). 
den semiotisch beschränkten Möglichkeiten, Leben mittels Schriftzeichen zu verewigen. Vielleicht könnte man sogar so weit gehen und sagen, dass Hoffmann die Bestrebungen der ,Weimarer Klassik', die mit ihrem Einsatz von Operationen zur Ewigkeitsattribuierung von Schriftzeichen vor allem auf die Autonomie des Verschriftlichten abzielte, ${ }^{123}$ einerseits zwar parodiert, andererseits aber zugleich zu integrieren und mit Operationen, die vor allem auf eine unendliche Aktualisation abzielen, zu kombinieren sucht. Vieles deutet zumindest darauf hin und ließe sich auch verknüpfen mit Claudia Liebrands Makroperspektive auf die Ästhetik Hoffmanns und deren Entwicklung ${ }^{124}$ sowie der Beobachtung, ,die negative Ästhetik, an der die KreislerTeile noch entlanggeschrieben sind“, würde erzählstrukturell „mit einem Affirmativen ästhetischen Entwurf (den Kateraufzeichnungen) kontrastiert und kontaminiert". ${ }^{125}$

Was die Figur Murr aber mit größtmöglichem Selbstvertrauen für eine Qualität hält, die sich von seiner göttlichen Genialität selbstverständlich auf seine „unsterblichen Werke“126 überträgt, das muss Hoffmann mit allen Mitteln überhaupt erst herzustellen versuchen: die Unsterblichkeit eines Werkes. Ja, es deutet alles darauf hin, dass Hoffmann gerade durch das als Herausgeber vermeintlich bescheidene - und von Murrs unterdrücktem Vorwort bereits autoreflexiv infrage gestellte - Zurücktreten hinter den "göttliche[n] [Autor] Murr", 127 durch die Parodie der Göttlichkeit und Unsterblichkeit des Genies, seiner Werke und der in der Genieästhetik angelegten engen Verknüpfung von göttlich-unsterblichem Werk und Leben ${ }^{128}$ mit unglaublich komplexem Aufwand sich (selbstironisch) als das inszeniert, was er parodiert: als göttlichunsterbliches Genie. Und zugleich zeigt er auf, dass das Leben eines Genies so verhandelt es die Biographie Kreislers eindrücklich - in seiner vermeintlich göttlichen Einheit stets in Wahnsinn auseinanderzufallen droht; ${ }^{129}$ dass das Werk eines Genies - dies zeigt wiederum die potenzierte Entortung von Anfang

\footnotetext{
123 Vgl. die Kapitel II.3.x, III.1 und IV.2.

124 Vgl. Liebrand 1996, u. a. S. 234 und - in Bezug zur Genie- und Autonomieästhetik zusammenfassend $-\mathrm{S} .13 \mathrm{f}$.

125 Ebd., S. 194.

126 Hoffmann, Werke, Bd. 5 , S. 38 oder 44.

127 Ebd., S. 38.

$128 \mathrm{Zu}$ den "Paradoxien des Genies" in Hoffmanns Roman vgl. Seidler 2005, insbesondere S. 6 of.

129 Diese Gedankengänge werden wieder aufgegriffen in Kapitel IV.3.3 zur Genieästhetik; und in Kapitel II.3.
} 
und Ende des Romans und seiner Teile - stets davon bedroht ist, das zu werden, was es im Grunde immer schon gewesen sein wird: fragmentarisch. ${ }^{130}$

\subsection{Miss Sara Sampson}

Lessings (nicht Fragment gebliebene) Trauerspiele tragen allesamt einen metonymischen Titel, sind benannt nach ihren jeweils auf den letzten Seiten dem Tod geweihten Hauptfiguren: Miss Sara Sampson, Philotas, Emilia Galotti. Der Tod, das Ende der Hauptfiguren, rückt damit in ein Similaritätsverhältnis zum Ende des jeweiligen Trauerspiels; wo etwa die Figur Sara Sampson stirbt, hat auch das Trauerspiel Miss Sara Sampson nicht mehr lange zu leben.131 Dieses durch den metonymischen Titel bedingte Similaritätsverhältnis - das in abgewandelter Form schon bei den Lebens-Ansichten des Katers Murr zu beobachten war - gibt Anlass zur Hypothese, die genannten Trauerspiele handelten nicht nur vom Ende ihrer titelgebenden Protagonist(inn)en, sondern auch vom Ende jener Trauerspieltexte selbst sowie des Trauerspiels im Allgemeinen.

Dass sich diese Hypothese als zutreffend erweist, hat Daniel Müller Nielabas Aufsatz „Schlafes Bruder zu Wort gekommen: Wie Lessing enden lässt" ${ }^{132}$ ausführlich belegt. Die Kernthese dieses Aufsatzes stellt eine Überführung des Schreckensmomentes des Todes im zeitgenössischen Trauerspiel, des Endes der Hauptfigur in ein von der Protagonistin resp. vom Protagonisten ersprochenes Enden fest. Diese Überführung des Endes in ein Enden wiederum ermöglicht überhaupt erst, dass angesichts des Todes auf der Bühne die Zuschauer nicht gemäß der bis anhin geltenden und auch von Gottsched vertretenen Aristoteles-Übersetzung ${ }^{133}$ Mitleid und Schrecken überkommt,

130 Vgl. dazu auch, was Claudia Liebrand zu einem allfällig geplanten dritten Band des Romans geschrieben hat: „Offenbar hingen die Schwierigkeiten Hoffmanns, an die beiden ersten Bände der Lebens-Ansichten einen dritten, einen Schlussband zu fügen, damit zusammen, daß eine inhaltliche Auflösung der Doppelstrukturen, die das ,vollendete ' Werk postuliert hätte, weit hinter das in den ersten beiden Bänden ästhetisch Erreichte zurückgefallen wäre. Stattdessen hat sich Hoffmann entschlossen, den Text offen zu lassen und ihn zu schließen - hat er ein (wie Singer es treffend genannt hat), in sich vollendetes Fragment' geschaffen [...] “ (dies. 1996, S. 198; resp. Singer 1963, S. 327). Zum Fragmentarischen als die Kombination der Unteroperationen Unendliche Lektüre und Unendliches Verstummen vgl. Kapitel II.3.4 sowie Kapitel 1.1 des Schlussteils.

131 Vgl. dazu auch Müller Nielaba 1999, S. 286, Anm. 3 o.

132 Vgl. Müller Nielaba 1999.

133 „Sie [die Tragödie, MG] konnte in diesem ihrem Zustande gar wohl ein Trauerspiel heißen: weil sie zu ihrer Absicht hatte, durch die Unglücksfälle der Großen, Traurigkeit, Schrecken, Mitleiden und Bewunderung bey den Zuschauern zu erwecken“ (Gottsched, Versuch einer critischen Dichtkunst, S. 6o6). Und: „Diese Fabel [der Tragödie, MG] ist nun geschickt, Schrecken und Mitleiden zu erwecken, und also die Gemüthsbewegungen 


\section{sondern Mitleid und Furcht. ${ }^{134}$ Ausführlicher zusammengefasst heißt es bei Müller Nielaba:}

Lessing lässt individuell und konkret genau so enden, wie er abstrakt und allgemein den Tod, das Ende des Endens sieht. ${ }^{135}$ Seine Bühnenfiguren, zumal Sara und Emilia, erliegen ursachenmäßig der Kทp [Ker, gewaltsamer Tod, MG], welche sie aber in der Sterbensdarstellung zum Өavaros [Thanatos, Tod, MG] wandeln. Lessing also verleiht dem konkreten, „so und so" verlaufenden Enden seiner einzelnen Bühnenfiguren in der dramatischen Darstellung selber genau

der Zuschauer, auf eine der Tugend gemäße Weise, zu erregen. Das erstere erregen seine Schandthaten, und die unverhoffte Entdeckung derselben: dieses aber, die Betrachtung, daß er sie unwissend begangen hat" (ebd., S. 612). Nach heutigem Forschungskonsens unter den Altphilologen übersetzte Lessing falsch (falls man mit dem Maßstab einer reinen Übersetzungsabsicht und -leistung an dessen einschlägige Textstellen herantritt); heute werden Aristoteles' Begriffe mit: "Jammer und Schaudern“ (Aristoteles, Poetik, 6 resp. ders. Poetik, S. 19) übersetzt.

134 So heißt es im 75. Stück der Hamburgischen Dramaturgie: „Man hat ihn [Aristoteles, MG] falsch verstanden, falsch übersetzt. Er spricht von Mitleid und Furcht, nicht von Mitleid und Schrecken; und seine Furcht ist durchaus nicht die Furcht, welche uns das bevorstehende Übel eines andern, für diesen andern, erweckt, sondern es ist die Furcht, welche aus unserer Ähnlichkeit mit der leidenden Person für uns selbst entspringt; es ist die Furcht, daß die Unglücksfälle, die wir über diese verhänget sehen, uns selbst treffen können; es ist die Furcht, daß wir der bemitleidete Gegenstand selbst werden können. Mit einem Worte: diese Furcht ist das auf uns selbst bezogene Mitleid“ (Lessing, Werke, Bd. 6, S. 556 f.; vgl. u. a. auch das 74. Stück). In ebendiesem 75. Stück verweist Lessing darauf, dass er sich bei seiner Neuinterpretation auch auf Stellen im zweiten Buch von Aristoteles' Rhetorik (also nicht nur die Poetik) gestützt habe, eine davon lautet denn auch: „[...] kurz gesagt, furchterregend ist alles, was Mitleid erweckt, wenn es anderen zustößt oder droht“ (Aristoteles, Rhetorik, S. 91). Bemerkenswert ist, dass auch Gottsched sich zur Erregung des Mitleids auf ein Ähnlichkeitsverhältnis beruft, das durch die Wahl und das Leid von Menschen „mittlerer Gattung“, die sowohl tugend- wie lasterhafte Züge haben, zustande kommen soll (vgl. Gottsched, Versuch einer critischen Dichtkunst, S. 6o7).

135 Zuvor hat Müller Nielaba aus Lessings Schrift Wie die Alten den Tod gebildet (1769) folgende Stelle zitiert: „Tot sein, hat nichts Schreckliches; und insofern Sterben nichts als der Schritt zum Totsein ist, kann auch das Sterben nichts Schreckliches haben. Nur so und so sterben, eben itzt, in dieser Verfassung, nach dieses oder jenes Willens, mit Schimpf und Marter sterben: kann schrecklich werden und wird schrecklich. Aber ist es sodann das Sterben, ist es der Tod, welcher das Schrecken verursachte? Nichts weniger; der Tod ist von allen diesen Schrecken das erwünschte Ende ..." Lessing fährt im Original unmittelbar fort: „und es ist nur der Armut der Sprache zuzurechnen, wenn sie beide diese Zustände, den Zustand, welcher unvermeidlich in den Tod führet, und den $\mathrm{Zu}$ stand des Todes selbst, mit einem und eben demselben Worte benennet" (Lessing, Werke, Bd. 6, S. 76o f.). Lessing argumentiert sodann weiter, dass jene „Armut der Sprache“ oft zur Quelle des Pathetischen werde. Eine solche Art des Pathetischen solle aber vermieden und ihr durch klare begriffliche Trennung vorgebeugt werden, die Lessing bei

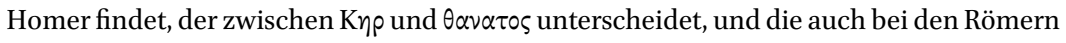
(lethum vs. mors) vorkomme (vgl. ebd.). Vgl. dazu auch Leventhal 1993, S. 312-218. 
diejenige ästhetische Qualität, die er zuvor als die allgemeine Eigenschaft des Todes, des Endes vom Enden erarbeitet hat. - Das bedeutet: Nach Maßgabe seines ästhetischen Gehalts [...] macht Lessing das Enden selber zum Ende, gestaltet er also das Ende als sein eigenes ,Davor‘. Der Tod als Übergang, so hatte es

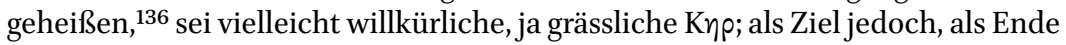
des Endens sei er stets schöner, erlösender $\theta \alpha \nu \alpha \tau \circ \varsigma$. Das ,schöne' Enden Saras und Emilias macht ästhetisch den Weg zum Ziel, gestaltet die Knp als $\theta \alpha \nu \alpha \tau \circ \varsigma$.

Wenn das vermeintlich gesicherte Ende aber, durch seine ästhetische Qualität, ins Enden eingeht, d. h., wenn das Ende selber zu jenem Prozess wird, der auf es hinzuführen scheint, dann ,ist' kein Ende mehr. Wenn ,Schlafes Bruder zu Wort kommt bei Lessing, schrecklos und schön, dann fängt das Ende an zu sprechen, über sich selbst und darüber hinaus. [...] Das Drama Lessings offeriert dem Publikum jene Leiche, die es erwartet. Es zeigt ihm aber zugleich an sich selber als Text, daß das Ende nicht dort sich befindet, wo gewaltsam geendigt wird, daß dieses vermeintliche Ende vielmehr der Beginn eines gemeinsamen Nach- und Neudenkens des Gezeigten sein muß. ${ }^{137}$

Im Folgenden wird der Fokus vor allem darauf liegen, die Ergebnisse dieses Aufsatzes ergänzend weiterzudenken und in den größeren Kontext der hier untersuchten Operationen zur Ewigkeitsattribuierung von Schriftzeichen einzuordnen. Ein erster Ansatz zu einer solchen Einordnung sei als These den unten stehenden Ausführungen bereits vorangestellt:

Lessings angestrebte Transformation des Trauerspiels des Mitleids und Schreckens hin zu einem Trauerspiel, das das Mitleid - gerade auch das selbstbezogene ${ }^{138}$ Mitleid der Furcht - ganz ins wirkungsästhetische Zentrum stellt, war nur zu erreichen durch eine gleichzeitig vorgenommene Betonung der Dauer (des Mitleidens) gegenüber dem (Schreckens-)Moment.

Die einschlägigen Aussagen Lessings dazu finden sich im 74. und 77. Stück der Hamburgischen Dramaturgie, wo es heißt:

Es ist wahr, das [sic] Schrecken ist eine Gattung der Furcht; es ist eine plötzliche, überraschende Furcht. Aber eben dieses Plötzliche, dieses Überraschende, welches die Idee desselben einschließt, zeiget deutlich, daß die, von welchen sich hier die Einführung des Wortes Schrecken, anstatt des Wortes Furcht, herschreibet, nicht eingesehen haben, was für eine Furcht Aristoteles meine. ${ }^{139}$

Aber er [Aristoteles] wollte uns zugleich lehren, welche Leidenschaften, durch die in der Tragödie erregten, in uns gereinigt werden sollten; und in dieser

$136 \quad$ Siehe die vorangehende Fußnote.

137 Müller Nielaba 1999, S. 287.

138 Zur Operation der Spiegelung, die analog zum Paradigmenwechsel in der zeitgenössischen Philosophie dieser Neuinterpretation des aristotelischen phóbos zugrunde liegt, vgl. das Ende dieses Kapitels II.1.2; und insbesondere das Kapitel zur Reflexionsphilosophie IV.3.1.

139 Lessing, Werke, Bd. 6, S. 553. Lessing setzt diese Stelle dann unmittelbar mit dem berühmten „kleinen Ausschweif“ fort, der seine Dramentheorie entfaltet. 


\begin{abstract}
Absicht mußte er der Furcht insbesondere gedenken. Denn obschon, nach ihm, der Affekt des Mitleids, weder in noch außer dem Theater, ohne Furcht für uns selbst sein kann; ob sie schon ein notwendiges Ingredienz des Mitleids ist: so gilt dieses doch nicht auch umgekehrt, und das Mitleid für andere ist kein Ingredienz der Furcht für uns selbst. Sobald die Tragödie aus ist, höret unser Mitleid auf, und nichts bleibt von allen den empfundenen Regungen in uns zurück, als die wahrscheinliche Furcht, die uns das bemitleidete Übel für uns selbst schöpfen lassen. Diese nehmen wir mit; und so wie sie, als Ingredienz des Mitleids, das Mitleid reinigen helfen, so hilft sie nun auch, als eine vor sich fortdauernde Leidenschaft, sich selbst reinigen. ${ }^{140}$
\end{abstract}

Das Mitleid(en) und die Furcht als das auf sich selbst bezogene Mitleid(en $)^{141}$ sind also nicht nur auf das Element der Dauer innerhalb des Stückes angewiesen, sondern sie sorgen dafür, dass das Stück und ebenso diese Leidenschaften selbst, die es hervorruft, über das eigentliche Ende des Stückes fortdauern. ${ }^{142}$ Oder hinsichtlich des Fokus der vorliegenden Arbeit anders ausgedrückt: Der Schrecken korrumpiert als das Flüchtige die Ewigkeitsattribuierung des Trauerspiels. ${ }^{143}$

Diese Betonung der Dauer trifft, wie aus den Ausführungen Müller Nielabas $\mathrm{zu}$ entnehmen ist, insbesondere auf das Ende der Protagonist(inn)en zu. Ein Ende, das in seinem Enden bei den Trauerspielen Lessings nicht zufällig immer mit einem Gedankenstrich schließt. ${ }^{44}$ (Das vorangegangene Kapitel hat gezeigt, dass 65 Jahre später E. T. A. Hoffmann diesen Einsatz von Geviertresp. Gedankenstrichen an den Übergängen resp. Enden zwischen den einzelnen Murr- und Kreisler-Teilen geradezu zelebriert.) ${ }^{145}$ Darauf, dass Lessings

140 Ebd., S. 566.

141 Vgl. Schulz 1988, S. 274-279.

142 Siehe unten, insbesondere zu Ende des Kapitels 1.2.2. Zur zunehmenden Wichtigkeit der Furcht innerhalb von Lessings dramatischem Schaffen, gerade aufgrund ihrer potenziellen Dauer über die jeweilige Theateraufführung hinaus, vgl. Schulz 1988, S. 276, zusammenfassend S. 297.

143 Vgl. dazu auch das historisch-kontextualisierende Kapitel II.3.

144 Vgl. Müller Nielaba 1999, S. 288; resp. das folgende Unterkapitel 1.2.1. In Gottscheds Sterbender Cato beispielsweise stirbt die titelgebende Hauptfigur (zumindest in dem dem Verfasser zugänglichen Nachdruck der zweiten Auflage von 1736) nicht mit einem Gedankenstrich, sondern mit einem Ausrufezeichen: „Der Beste [man denke an die weiter oben in den Anmerkungen zitierte Maxime des Menschen von „mittlerer Gattung“; vgl. Gottsched, Versuch einer critischen Dichtkunst, S. 6o7] kann ja leicht vom Tugendpfade wanken. / Doch ihr seyd voller Huld. Erbarmt euch! - - Ha!“ (Gottsched, Sterbender Cato, S. 113).

$145 \mathrm{Zu}$ den Gedankenstrichen und Jean Paul, der diese schon vor E. T. A. Hoffmann virtuos einsetzte, sowie generell Lessings Einfluss auf ästhetische Verfahren späterer Jahrzehnte vgl. Kapitel II.3. Zum sprunghaften Anstieg von Gedankenstrich und Ausrufezeichen in 
mit Miss Sara Sampson angestrebte Transformation hin zu einem Trauerspiel, in dessen Zentrum das Mitleid(en) steht, sich im Drama des 18. Jahrhunderts nicht durchgesetzt hat, sondern für die nachfolgenden bürgerlichen Trauerspiele insbesondere die Maxime der „Poetischen Gerechtigkeit" ${ }^{\text {“46 }}$ galt, die dem Mitleid(en) mindestens ebenso verbunden war wie dem Schrecken, ist später zurückzukommen. ${ }^{147}$

Im folgenden Unterkapitel sei nun vor dem soeben dargelegten Hintergrund auf den Anfang und das Ende(n) von Miss Sara Sampson. Ein bürgerliches Trauerspiel, in fünf Aufzügen (1755), Lessings erstem bürgerlichem Trauerspiel, eingegangen, und zwar unter besonderer Berücksichtigung des Gedankenstrichs.

\subsubsection{Tödliche Gedankenstriche des Mitleidens}

Die ersten Gedankenstriche des Stücks finden sich bereits gleich zu Beginn des ersten Aufzugs:

SAMPSON Hier meine Tochter? - Hier in diesem elenden Wirtshause?

WAITwE LL Ohne Zweifel hat Mellefont mit Fleiß das allerelendeste im ganzen Städtchen zu seinem Aufenthalte gewehlt [sic]. Böse Leute suchen immer das Dunkle, weil sie böse Leute sind. Aber was hilft es ihnen, wenn sie sich auch vor der ganzen Welt verbergen könnten? Das Gewissen ist doch mehr, als eine ganze uns verklagende Welt. - Ach, Sie weinen schon wieder, schon wieder, Sir! Sir! ${ }^{148}$

der zweiten Hälfte des 18. Jahrhunderts vgl. die am Schluss dieses Kapitels zur Miss Sara Sampson erwähnte These Andrea Polascheggs.

146 Vgl. Mönch 1993, insbesondere S. 340-350.

147 Vgl. Kapitel II.3.4.

148 Lessing, Werke, Bd. 3, S. 433. Die Stellen aus Miss Sara Sampson werden hier zitiert nach der Ausgabe der „Bibliothek deutscher Klassiker“, die im Gegensatz zu den übrigen Editionen dem Erstdruck von 1755 folgt (vgl. ebd., S. 1202). Die von Herbert G. Göpfert herausgegebene Edition, die Müller Nielaba verwendet, und ebenso die Reclam-Ausgabe folgen direkt oder indirekt (Letztere stützt sich auf die von Muncker überarbeitete Edition Lachmanns 1886) der von Lessing revidierten Ausgabe letzter Hand von 1772. Hier zitierte Stellen aus Müller Nielabas Aufsatz können also Zitate aus der Ausgabe von 1772 enthalten; Müller Nielabas zentrale Feststellung, dass alle Protagonisten in Lessings Trauerspielen mit einem Gedankenstrich sterben, trifft (auch im Falle der beiden anderen Trauerspiele) ebenso auf die Erstausgabe zu. „Die Änderungen [der Ausgabe letzter Hand, MG] gegenüber dem Erstdruck betreffen fast ausschließlich Zeichensetzung, Wortstellung und Rechtschreibung und sind im Grunde marginal. [...] Markante Änderungen sind die Tilgung des Epithetons ,bürgerliches' im Titel [und ganz am Ende, MG] des Stücks (es heißt jetzt nur noch: ,ein Trauerspiel') sowie die durchgehende Korrektur von ,Sir Sampson' in ,Sir William' [Lessing, Werke, Bd. 3, S. 1202 f.]." Der Rückgriff auf die Erstausgabe ist dadurch zu begründen, dass der Gedankenstrich sowohl bei Müller Nielaba als auch in den folgenden Überlegungen alles andere als "marginal“ und wesentlich an der Akzentuierung der Dauer des Mitleidens gegenüber dem Moment des Schreckens beteiligt ist, die Lessings 
Der Fokus liegt im Folgenden auf dem zweiten Gedankenstrich:149 Der Satz zu seiner Linken handelt von der gewaltigen Macht des Gewissens (vor der sich niemand verbergen könne). „Das Gewissen“ und das Mitleid sind eng miteinander verknüpfte Gefühlsregungen: Oft stellt sich das (schlechte) Gewissen erst als Folge des Mit-Leidens - z. B. mit einer Person, an deren Leid man (mit-)schuldig ist - ein. Der Satz rechts des Gedankenstrichs handelt denn auch nicht zufällig vom Weinen, das die physische, sichtbare Folge von Mitleid darstellt und dadurch den Beweis liefert, dass die weinende Person auch tatsächlich des Mitleids fähig ist. ${ }^{150}$ Vergleicht man nun die Thematik dieser beiden Sätze, so lässt sich Folgendes feststellen: Während der linke Satz in einem theoretischen Gestus von der Macht des Gewissens spricht, fasst der rechte das auf der Bühne stattfindende, von Waitwell beobachtete und dem Publikum vermittelte ${ }^{151}$ Weinen in Worte. Es bleibt jedoch die Frage, wie sich hier der Wechsel zwischen theoretischem Sprechen über das durch Mitleid ausgelöste (schlechte) Gewissen hin zum Kommentieren einer sich gerade in diesem Augenblick auf der Bühne (resp. im Lesedrama über den Verweis „weinen“) zeigenden, sichtbaren Folge von Mitleid vollzieht. Die Antwort, die sich aufdrängt, lautet: über den Gedankenstrich.

Der Gedankenstrich ist es nämlich, der zwischen den beiden Sätzen Raum und (als Pause in der Rede auch) Zeit schafft, wo sich das Mitleid entfalten kann. ${ }^{152}$ Waitwell wird in seiner kurzen Redepause, als die der Gedankenstrich gelesen werden und die er dabei zugleich performativ schaffen kann, vom Theoretiker zum Zuschauer, vom Sprecher über Mitleid zum Mitleidenden. Offensichtlich ist er ein Zuschauer, der des Mitleids fähig ist, denn das erste Wort nach dieser Pause ist der Ausruf des Mitleids schlechthin: „Ach [...]!" Bekanntlich klingt in jedem ,Ach auch ein Ich mit, und zugleich ist gerade das Mitleid ein Gefühl, das sich im Individuum vollzieht, und zwar insbesondere in Bezug - und dabei über eine Similaritätsbeziehung - auf ein anderes Individuum. Das von Waitwell ausgestoßene „Ach“ klingt demnach in seiner Ähnlichkeit zum Ich an die an der Schwelle zur sogenannten Moderne

Transformation des Trauerspiels einleitet - und dies schon 1755 und nicht erst 1772. Einzig Saras Vater wird im Zuge der Argumentation nach der Ausgabe letzter Hand als ,Sir William' bezeichnet, da sich dieser Name etabliert hat.

149 Dieser wird in der Fassung letzter Hand von $177^{2}$ - wohl kaum zufällig - der erste sein.

15 O Vgl. auch Schulz 1988, S. 178 f., der bemerkt, dass im betreffenden Stück zwar das Mitleiden mittels Tränen gezeigt werden kann, nicht jedoch das Selbstleiden.

151 Wobei vor allem das Lesepublikum, das im Gegensatz zu den Theaterbesuchern Sir William und sein Verhalten nicht physisch vor sich sieht, auf diese Vermittlung angewiesen ist.

$152 \mathrm{Zu}$ Gedankenstrichen im Allgemeinen vgl. Kammasch 2009; und Nehrlich 2012, S. 117-123. 
sich vollziehende Erfindung des (bürgerlichen) Individuums als Bedingung für einen Paradigmenwechsel im Trauerspiel (vom Schrecken hin zu einer stärkeren Betonung des Mitleids) an, während es zugleich metonymisch auf die Gefühlsregung des Mitleids selbst verweist. Das „Ach“ Waitwells steht also als symbol (nach Peirce) für einen Seufzer, indexikalisch für das Mitleid, während es quasi als icon (sowohl graphisch als auch lautlich) ${ }^{153}$ eine Ähnlichkeitsbeziehung zum Ich generiert, das die Voraussetzung von Mitleid und Seufzer ist. Die Figur des Waitwell, die zum Zuschauer wird, thematisiert somit über ihre Similaritätsbeziehung mit den vor der Bühne anwesenden Zuschauern poetologisch die (erwünschte) Reaktion des Theaterpublikums, das ja dazu gebracht werden soll, Mitleid zu empfinden, und zwar ebenfalls dadurch, dass es mit den Figuren auf der Bühne in ein (zeichenhaft konstituiertes) Ähnlichkeitsverhältnis tritt.

Nimmt man die beiden Wörter in den Blick, die der Gedankenstrich (scheinbar) voneinander trennt, so lässt sich Folgendes beobachten: Der Gedankenstrich steht zwischen "Welt“ und "Ach“. Das Mitleid, das sich im Raum und in der Sprechpause, die der Gedankenstrich schafft, stumm entfaltet, um dann im "Ach“ indirekt/indexikalisch hörbar zu werden, wäre demnach das Bindeglied zwischen der Welt und dem Individuum, dem Ich, das im "Ach“ nachklingt. Zwischen „Welt“ und dem Individuum des „Ach“ steht der Gedankenstrich, bewegt sich das Mitleid. Damit wird an dieser Stelle in nuce poetologisch das Programm des bürgerlichen Trauerspiels erfasst: Weltzugriff des Individuums qua Similarität über einen Prozess des Mitleidens anstelle einer zeitgenössischen metonymischen Repräsentationsästhetik, die vor allem auf den Moment des Schreckens resp. Schauderns abzielt. Die Gegenüberstellung von "Welt" (als totum) und „Ach“/,Ich“ (als pars) würde noch für diesen metonymischen Weltzugriff (der Held, der König, die Märtyrerin etc. leidet stellvertretend für die übrigen Menschen) stehen, den die zeitgenössische Tragödie französisch-Gottsched'scher Prägung vermittelt. Doch der Gedankenstrich, der Raum und Zeit für die Entfaltung von Mitleid sowohl zu lesen geben als auch performativ schaffen kann, setzt "Welt" und "Ach“ an die Pole eines Prozesses des Mitleidens, der über Ähnlichkeitsbeziehungen Welt und Individuum miteinander verbindet. Weltzugriff durch Mitleiden.

Nach dieser Auseinandersetzung mit dem Anfang des Trauerspiels sei nun das Ende(n) Saras in den Blick genommen, ein Ende(n), bei dem Gedankenstriche wiederum keine unwesentliche Rolle spielen. Saras letzte Rede lautet nämlich:

153 Vgl. Peirce 1955. 
SARA Die bewährte Tugend muß Gott der Welt lange zum Beispiele lassen, und nur die schwache Tugend, die allzu vielen Prüfungen vielleicht unterliegen würde, hebt er plötzlich aus den gefährlichen Schranken - Wem fließen diese Tränen, mein Vater? Sie fallen als feurige Tropfen auf mein Herz; und doch doch sind sie mir minder schrecklich, als die stumme Verzweiflung. Entreißen Sie sich ihr, Mellefont! - Mein Auge bricht - Dies war der letzte Seufzer! - Noch denke ich an Betty, und verstehe nun ihr ängstliches Händeringen. Das arme Mädchen! Daß ihr ja niemand eine Unvorsichtigkeit vorwerfe, die durch ihr Herz ohne Falsch, und also auch ohne Argwohn der Falschheit, entschuldiget wird. der Augenblick ist da! Mellefont - mein Vater -

MELLEFont Sie stirbt! - Ach! $[\ldots]^{154}$

Ähnlich wie schon beim ersten Sprechen Waitwells ist es hier der erste Gedankenstrich, der zur Dauer beiträgt, die das Mitleid benötigt, um sich zu entfalten - und wieder steht er an der Stelle, wo der Redegegenstand wechselt, wo sich die Rede dem Weinen (wiederum demjenigen von Sir William) zuwendet. „Dies war der letzte Seufzer!“ ruft Sara aus und vollzieht dabei einen performativen Selbstwiderspruch, denn solange sie im Tempus der Vergangenheit ihren letzten Atemzug redend kommentiert, wird sie noch nicht den „letzte[n] Seufzer“ ausgestoßen haben. Und so folgt auf diesen „Seufzer“, wie könnte es anders sein, ein weiterer Gedankenstrich, der Saras Rede und das Hören und Lesen derselben fortführt: ein Lesen, das auch ihr zuvor geäußerter Ausruf „Mein Auge bricht“ unterläuft, der selbst schon wieder von einem Gedankenstrich unterbrochen resp. aufgeschoben worden ist, um erneut anzuklingen kurz vor dem Ende ihrer Rede: „- der Augenblick ist da!“ Nicht der "Augenblick“ ihres Todes ist das, was da ist - ihr Sprechen geht ja weiter -, sondern offenbar der Blick der Augen derjenigen, die gerade dabei sind, Saras Enden lesend weiter zu aktualisieren, es wortwörtlich weiterzulesen, und zwar im Stück Miss Sara Sampson, das den Tod seiner titelgebenden Figur, wenn auch nur um etwa zwei Seiten, im Zuge jeder (linearen, von Gedankenstrichen weitergetriebenen und potenziell unendlich oft wiederholbaren ${ }^{155}$ Lektüre überdauert haben wird.

\footnotetext{
154 Lessing, Werke, Bd. 3, S. 524 f.

155 Was Müller Nielaba zu einer Stelle in der Hamburgischen Dramaturgie schreibt, an der Lessing die schauspielerisch-gestische Umsetzung im Augenblick von Saras Tod durch die Schauspielerin Hensel lobt, findet sich im Dramentext zu jenem „Augenblicke“ Saras somit eindrücklich bestätigt resp. trifft für ebendiese Stelle im Dramentext genauso zu: „Was Lessings Beschreibung eines szenischen Todes versprachlicht, die Darstellung jenes ,Augenblick[s], da die Seele [weicht]', hört genau da auf, ,Augenblick` zu sein, wo es verschriftlicht und das heißt: wiederholbar wird“ (Müller Nielaba 1999, S. 271).
} 
Die bereits von Müller Nielaba festgestellte Überführung des schrecklichen "Augenblick[es]" des Todes in ein denselben immer weiter hinauszögerndes Reden schafft im Falle von Saras letztem Auftritt nicht nur den ,zeitlichen Raum', in dem sich das Mitleiden des Publikums mit Sara entfalten kann, sondern stellt dies zugleich aus, indem Sara selbst diese Zeit für das Entfalten ihres eigenen Mitleidens benötigt: Ihre Rede endet immer weiter, über das Brechen der Augen, den „letzte[n] Seufzer“, den „Augenblick“ hinaus, nicht um Sara schrecklich immer weiter leiden, sondern um sie weiter mitleiden zu lassen: mit ihrem Vater, Mellefont und schließlich auch mit ihrer Dienerin Betty.

Es sei nun noch einmal zurückgeblickt zum ersten Gedankenstrich in Saras letzter Rede sowie von dort weiter voraus zur Reaktion Mellefonts, zu dessen eigenem Enden und dem Enden des Trauerspiels selbst: Im Unterschied zu Waitwell zu Beginn des Stücks lässt Sara die Frage folgen („Wem fließen diese Tränen, mein Vater?“), die sich nicht nur bezüglich Sir Williams, sondern poetologisch auch für Lessings neue Konzeption eines Trauerspiels des Mitleidens aufdrängt: Wem gelten die Tränen? Stehen sie metonymisch für das empfundene Mitleid gegenüber einem anderen Individuum, oder gelten sie dem (Mit-)Leiden des eigenen Ichs? Eines Ichs, das in Mellefonts "Ach!“ aufschreit, welches wiederum auf einen Gedankenstrich folgt, der den Gedankenstrich am Ende von Saras Rede gewissermaßen bereits schon zitiert, damit deren Ende erneut verschiebt und in ein weiteres Enden überführt, das letztlich auch das Enden Mellefonts gewesen sein wird. Denn die Frage, wer im Zentrum des eigenen Mitleidens steht, scheint Mellefont tatsächlich über sein „Ach!“ mit ,Ich!' zu beantworten. Und wie Waitwell ganz am Anfang des Stücks Sir Williams Tränen dem (schlechten) „Gewissen“, also letztlich dem Selbstmitleid(en) des Vaters, zugeschrieben hat, so führt dieses "Gewissen“ Mellefont dazu, sich für eine selbst zugesprochene Schuld mit dem Tod zu bestrafen: „Es steht bei mir nicht, das Geschehene ungeschehen zu machen; aber mich wegen des Geschehenen zu strafen - das steht bei mir! er ersticht sich, und fällt an dem Stuhle der Sara nieder." ${ }^{156}$

In einem aber folgt Mellefont Saras, in ihrer letzten Rede geäußertem Wunsch, nämlich darin, sich der "stumme [n] ${ }^{157}$ Verzweiflung “ $z_{\text {, }}[\mathrm{e}]$ ntreißen“. Wie Sara spricht er sein Ende herbei und darüber hinaus: „MELLEFONT sterbend:158 Ich fühl es - daß ich nicht fehlgestoßen habe! - Wollen Sie mich

$15^{6}$ Lessing, Werke, Bd. 3, S. $5^{26 .}$

157 Hervorhebung MG.

$15^{8}$ Hervorhebung MG. 
nun Ihren Sohn nennen, ${ }^{159}$ Sir [...] - Gnade, o Schöpfer, Gnade! - "160 Sir William selbst hingegen (wie später Odoardo, der Vater Emilia Galottis) widersteht sowohl dem "Gewissen" als auch dem Selbstmitleid und ersticht sich nicht „wie" in „eine[r] schaale[n] Tragödie“, wie es bei Odoardo autoreferenziell heißen wird. ${ }^{161}$

Das Empfinden der Schuld seitens Mellefonts aber scheint ausgerechnet durch das Mitleiden Sir Williams verstärkt zu werden, das erneut über einen Gedankenstrich repräsentiert wird resp. durch diesen überhaupt erst Raum und Zeit in Mellefonts Rede und dem Dramentext erhält: ,- Was ist das? Ich will nicht, daß Sie einen barmherzigen Blick auf mich werfen sollen!" ${ }^{162}$ Noch mehr: Es ist gerade das Mitleiden Sir Williams, das Mellefont in den eigenen Tod sich reden lässt: Mangels eines strafenden Urteils seitens des Vaters der Geliebten sieht sich Mellefont offenbar gezwungen, sich in der rhetorisch beispielhaft gestalteten Beweisführung gegen sich selbst so lange immer weiter zu überbieten, bis diese, da Sir William nicht vom Mitleiden zum (schrecklichen) Strafen übergeht, unweigerlich im Selbstmord enden muss. Ja, ,schal' ist es bestimmt nicht, das Trauerspiel Miss Sara Sampson, und im Enden Mellefonts mag es Zuschauer und Leser gar mehr schaudern lassen als manch andere Tragödie vor ihm:

Denn am Selbstmord Mellefonts - so die These - wird deutlich, dass Lessings Trauerspiel Miss Sara Sampson bei aller Transformation der Tragödie weg von

159 Müller Nielaba schreibt dazu:„Daß die Selbstmörder Mellefont und Philotas beide explizit als ,Söhne' agieren, ist nicht ohne Belang. Vielmehr beweist es, daß Lessings Darstellung der ,Gewalt gegen sich' alles andere als eine Affirmation der heroischen Selbstnegation ist" (ders. 1999, S. 275). Bemerkenswert ist nun aber, dass auch Sara und Emilia explizit als Töchter in der Anrufung ihrer Väter sterben: „mein Vater -“ sind nämlich beider letzte Worte.

160 Lessing, Werke, Bd. 3, S. 526.

161 „Sie erwarten vielleicht, daß ich den Stahl wider mich selbst kehren werde, um meine Tat wie eine schaale Tragödie zu beschließen? - Sie irren sich!“ (Lessing, Werke, Bd. 7, S. 371; vgl. dazu auch Müller Nielaba 1999, S. 285). Wobei im „Sie“ natürlich nicht nur der Prinz, sondern auch das damit direkt angesprochene Publikum mitschwingt. Besonders bemerkenswert ist hier auch die Auseinandersetzung von Georg-Michael Schulz mit ebendiesem Satz Odoardos. Schulz wirft nämlich die Frage auf, „in welchem Maße die Verführung zum Erhabenen, der Emilia und Odoardo erliegen, von der poetischen Vermittlung ebendieses Erhabenen ausgeht, ob also bei dem hier dargestellten Ausweg in den Tod nicht vielleicht auch die Poesie in einer verhängnisvollen Weise ihre Gewalt unter Beweis stellt“ (Schulz 1988, S. 296). Freilich wäre erst zu präzisieren, ob diese ,Gewalt der Poesie' auf der Ebene der Fiktion oder auf der Ebene der Ko- und Kontexte von Lessings Schreiben ausgeübt wird (oder auf beiden); danach aber könnte ein Vergleich mit dem Verhandeln des tötenden Aspekts des Mitleids am Ende von Miss Sara Sampson (vgl. den folgenden Abschnitt) äußerst spannend sein.

162 Lessing, Werke, Bd. 3, S. 525 . 
einer Ästhetik des Schreckens hin zu einer Ästhetik des Mitleidens zugleich aufzeigt, dass erschreckenderweise auch das Mitleid tödlich sein kann.

1.2.2 Anfang - Mitte - Mitte und die Verewigung im Mitleid(en)

Im Vergleich mit dem Kapitel zu Hoffmanns Doppelroman lässt sich das bislang Festgestellte wie folgt zusammenfassen: Wie bei den Lebens-Ansichten des Katers Murr ermöglichen bereits im Falle des knapp 65 Jahre früher verfassten Trauerspiels Miss Sara Sampson der metonymische Titel und der an entscheidenden Stellen vorgenommene Einsatz von Gedanken- resp. Geviertstrichen eine Verwischung sowie eine poetologische Thematisierung von Anfang und Ende von Text. Und sowohl gegen Ende der Autobiographie Murrs als auch gegen Ende des Trauerspiels Miss Sara Sampson stellt sich das Problem der Darstellbarkeit des Todes der jeweils titelgebenden Protagonisten. Im Unterschied zu Hoffmanns Roman zwingt das hier untersuchte Stück den Leser (und letztlich auch die Zuschauerin) nicht über die chronologisch versetzte Anordnung einzelner Teile in eine potenziell endlos zu praktizierende Re-Lektüre, aber sucht doch das Ende seines Gelesen- und Gespieltwerdens immer weiter aufzuschieben, es zu überführen in ein Enden, das das Ende nahezu wortwörtlich überdauern soll. Dabei spielt der Gedankenstrich wie in allen drei Trauerspielen Lessings - die Theatermetapher scheint angebracht eine zentrale Rolle, die Müller Nielaba wie folgt beschreibt:

,Wie Lessing enden lässt': Emilia, nicht anders als Sara, Mellefont, Philotas, endet im Gedankenstrich - „Ah - mein Vater -“ (II, 204) -, in einem Zeichen also, dessen Funktion gerade darin besteht, darzustellen, daß kein Ende des Denkens dort ist, wo das Sprechen abbricht. Der Text, in der Darstellung des Endens, erweist sich als eine Darstellung seiner eigenen endlosen Dynamik, als vorbehaltlose Öffnung auf seine „Nachkommenschaft“. ${ }^{163}$

Es lässt sich also festhalten:

Der von Lessing durch seine Neuinterpretation von Aristoteles' Begriff phóbos angestrebte Paradigmenwechsel innerhalb der zeitgenössischen Gattung des Trauerspiels von einer Betonung des Schauderns/Schreckens hin zum Mitleid(en) ging nicht nur einher mit einer Priorisierung der Dauer des Mitleidens gegenüber dem schrecklichen Augenblick, sondern führte zugleich zur Auflösung einer anderen zentralen Begrifflichkeit in Aristoteles' Poetik, nämlich der für die Tragödie geforderten Dreieinigkeit von Anfang, Mitte und Ende. Dies insofern, als

163 Müller Nielaba 1999, S. 288. Mit „Nachkommenschaft“ wird eine Stelle aus Lessings Schrift Wie die Alten den Tod gebildet zitiert, siehe dazu weiter unten. 
bei Lessing das Ende in ein Enden überführt und damit zur Mitte wird. ${ }^{164}$ Lessing, so scheint es, ist damit auch ein entscheidender Wegbereiter für die gegen Ende seines Jahrhunderts erfolgende Ästhetisierung des Fragments, steht vielleicht sogar am Anfang jenes an der Schwelle zurModerne einsetzenden Infragestellens der Ganzheit eines Werkes (siehe dazu ausführlich II.3), wie sie dann beispielsweise in einem Roman wie den Lebens-Ansichten des Katers Murr richtiggehend zelebriert wird.

Der Gedankenstrich, der bei Lessings Trauerspielen sowohl auf den Tod als auch das Mitleid verweisen kann resp. im Zuge der Lektüre performativ erst die Dauer (mit-)erschafft, in dem sich das Mitleiden, aber auch das Reden und Denken über den Tod und über den Text hinaus und wieder zurück, ${ }^{165}$ entfaltet, wird dabei zum Zeichen der Mitte. Der Gedankenstrich stellt in nuce aus, woran er selbst entscheidend beteiligt ist: das Zur-Mitte-Werden des Endes.

Der Gedankenstrich als Graphem ist zudem ein Zeichen, das wie wohl kaum ein anderes die Frage nach der szenischen Darstellbarkeit eines Dramentextes aufwirft. Auch wenn er im Falle von Lessings Trauerspielen an vielen Stellen der Schaffung von Dauer dient, in der Mitleid sich entfalten kann, so ist im Allgemeinen die Lesart oder die szenische Umsetzung eines Gedankenstrichs als eine Pause bereits eine Interpretation. Als eines der wenigen Schriftzeichen der deutschen Sprache, das phonetisch stumm ist und zugleich keine eindeutige Vorgabe der Intonation (wie etwa ein Fragezeichen) nahelegt, ist der Gedankenstrich sogar das einzige Schriftzeichen, das auf einen Leerschlag folgt und dem zugleich auch ein Leerschlag nachfolgt. ${ }^{166}$ Umgeben von zwei Leerschlägen rückt es diese damit in den Blick wie kein anderes Schriftzeichen und

164 Es sei dafür bloß das in diesem Kapitel und in Müller Nielabas Aufsatz Erarbeitete mit der Stelle in Aristoteles' Poetik verglichen, dessen Definition der Mitte genau auf das Enden von Lessings Trauerspielen zutrifft: „Wir haben festgestellt, dass die Tragödie die Nachahmung einer in sich geschlossenen und ganzen Handlung ist, die eine bestimmte Größe hat; es gibt ja auch etwas Ganzes ohne nennenswerte Größe. Ein Ganzes ist, was Anfang, Mitte und Ende hat. Ein Anfang ist, was selbst nicht mit Notwendigkeit auf etwas anderes folgt, nach dem jedoch natürlicherweise etwas anderes eintritt oder entsteht. Ein Ende ist umgekehrt, was selbst natürlicherweise auf etwas anderes folgt, und zwar notwendigerweise oder in der Regel, während nach ihm nichts anderes mehr eintritt. Eine Mitte ist, was sowohl selbst auf etwas anderes folgt als auch etwas anderes nach sich zieht" (Aristoteles, Poetik, S. 25). Bemerkenswert ist hierbei auch, dass Aristoteles selbst seine Definition des Ganzen nicht mit der Definition des Endes schließt, sondern auf diese die Definition der Mitte folgen lässt.

165 Der waagrechte Strich zeugt von beiden möglichen Leserichtungen, ohne sich wie der Pfeil für eine zu entscheiden.

166 Diese Beobachtung verdankt der Verfasser der Diskussion seiner Überlegungen zum Gedankenstrich mit Daniel Müller Nielaba. Als einzige weitere, jedoch äußerst selten verwendete Zeichen, die ebenfalls von zwei Leerschlägen umgeben sind, kämen noch 
schafft so eine auch beim bloßen Überfliegen eines Textes ins Auge springende weiße Fläche - eine weiße Fläche, die einerseits eine Analogie bilden kann zu einer größeren Dauer, die zwischen der Lektüre der Zeichen vor und nach dem Gedankenstrich und den ihn umgebenden Leerschlägen vergehen soll. Eine weiße Fläche, die aber andererseits auch den Schrecken des Nichts, des leeren, unbeschriebenen Blattes, in Analogie zum ungewissen menschlichen Zustand vor der Geburt und nach dem Tode in Erinnerung zu rufen vermag. Somit ist es auch aus dieser semiologischen Mikroperspektive kein Zufall, wenn sowohl Lessings titelgebende Trauerspielfiguren als auch der Autobiograph der Lebens-Ansichten des Katers Murr nicht mit irgendeinem Schriftzeichen, sondern mit einem Gedankenstrich enden. Vielmehr zeigen sich am Gedankenstrich selbst, und wie er bei Lessing und Hoffmann eingesetzt wird (zu Jean Paul vgl. Kapitel II.3), letztlich die beiden komplementären Unteroperationen der Grundoperation Unendliche Aktualisation, nämlich Unendliche Lektüre und Unendliches Verstummen.

Es seien deshalb noch einige letzte und schließlich zur in Kapitel II.2 behandelten Operation Unendliches Verstummen überleitende Bemerkungen zu Dauer und ewigem Überdauern erlaubt. Dazu sei nochmals zurückgekehrt zum vorletzten Abschnitt und zum Zitat aus Müller Nielabas Aufsatz: Das am Ende jenes Abschnitts zitierte Wort „Nachkommenschaft“ stammt aus Lessings Schrift Wie die Alten den Tod gebildet, die den Totenglauben der ,Alten' beschreibt. Dieser Totenglaube unterteilt nach Lessing die Seelen der Verstorbenen in Lares, die ihrer Nachkommenschaft (also den noch lebenden Verwandten) wohlgesonnen sind, und in zur Strafe für begangene Verbrechen herumirrende Larvae. ${ }^{167}$ Es kann hier nicht weiter auf diese Stelle in Wie die Alten den Tod gebildet eingegangen werden, dafür jedoch auf das Ende des Stückes Miss Sara Sampson, wo zwar nicht von der "Nachkommenschaft", aber doch von einem „Vermächtnis“ die Rede ist:

SAMPSON [...] Laß mich nicht länger, Waitwell, bei diesem tötenden Anblicke verweilen. Ein Grab soll beide umschließen. Komm, schleunige Anstalt zu machen, und dann laß uns auf Arabellen denken. Sie sei, wer sie sei; sie ist ein Vermächtnis meiner Tochter! Sie gehen ab, und das Theater fällt zu.

Ende des bürgerlichen Trauerspiels ${ }^{168}$

vokalische Ausrufe oder Anreden infrage, so etwa ,O König“ resp. „o Katerjüngling!“ (Hoffmann, Werke, Bd. 5, S. 436).

${ }_{167}$ Vgl. Lessing, Werke, Bd. 6, S. 765 .

168 Lessing, Werke, Bd. 3, S. $5^{26 .}$ 
In Anlehnung an die in der Einleitung zitierte Rede Diotimas in Platons Symposion scheint am Ende des Stücks Marwood das dereinstige Fortdauern in ihrem biologischen Kinde (Arabella) abgesprochen und als "Vermächtnis“ Saras der Linie Sir Williams und seiner „Tochter“ zugesprochen zu werden. Umso bitterer für Marwood, dass nicht nur Lessing sie - wie auch Marinelli und den Prinzen in Emilia Galotti - nicht enden lässt, ${ }^{169}$ sondern dass Sara sie bereits um ihr schriftliches ,Kind" gebracht hat, indem sie deren „Zettel“ ${ }^{470}$ keiner Lektüre würdigt und ihn zerreißt:

[Mellefont:] Dies schreibet Marwood. er lieset: ,Wenn Sie diesen Zettel lesen werden, Mellefont, wird ihre Untreue in dem Anlasse derselben schon bestraft sein. [...] Ich sah es [das Giftpulver, MG] ihr geben, und gieng triumphierend fort. Rache und Wut haben mich zu einer Mörderin gemacht; ich will aber keine von den gemeinen Mörderinnen sein, die sich ihrer Tat nicht zu rühmen wagen.

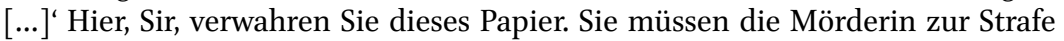
ziehen lassen, und dazu ist es ihnen unentbehrlich. - Wie erstarrt er da steht!“ SARA Geben Sie mir dieses Papier, Mellefont. Ich will mich mit meinen eigenen Augen überzeugen. er giebt es ihr, und sie sieht es einen Augenblick an: Werde ich so viel Kräfte noch haben? sie zerreißt es.

Daniel Müller Nielaba hat diese Stelle bereits wie folgt treffend analysiert:

Doch Marwoods vermeintlicher Triumph ist keiner: Jenes [auf dem „Zettel“ formulierte, MG] Lob der eigenen Tat, in dem Lessing hier die Medea des Euripides zitiert, verliert genau dadurch seine Kraft, daß es keine eigene Stimme hat, bloße Schrift ist, der der Getroffene selber die Zunge leihen muß, damit es überhaupt vernehmlich wird. Das Ungeheuerliche an Medeas Kommentierung ihres Racheaktes besteht ja genau darin, daß sie, nachdem sie die Nebenbuhlerin, deren Vater und die eigenen Kinder getötet hat, das ganze Grauen dem ungetreuen Ehemann Jason persönlich ins Gesicht sagen kann [...]. Die einzige, allerdings radikale Schmähung, die das Opfer der Täterin hier seinerseits antut, besteht darin, daß Sara bloß „Papier“ ansieht, wo es Schrift zu lesen gäbe, daß sie die Lektüre des eigenen Todesurteils und in diesem die Präsenz der sich „rühmen[den]“ Mörderin verweigert. Das „Papier“, welches in Anbetracht der Unsichtbarkeit des Giftes der einzige Beleg wäre für die Gewaltsamkeit ihres Todes und die Fremdbestimmung, der dieser Tod unterliegt: Sara "zerreißt es“ [...] und befreit durch dieses unwiderrufliche ,Zerreißen' ihr Sterben von allem Fremden und Äußerlichen und entzieht es damit willentlich der Kausalkette von Marwoods Untat, auf welche diese ihren vermeintlichen Triumph gründet. ${ }^{171}$

169 Vgl. Müller Nielaba, S. 288.

170 Lessing, Werke, Bd. 3, S. 523. Bemerkenswert ist, dass in der Nichtlektüre Saras nochmals auf der Mikroebene der „Augenblick“ betont wird, der keinen Platz für ein Mitleiden mit Marwood aufkommen lässt.

171 Müller Nielaba 1999, S. 273. 
Wo in den Lebens-Ansichten des Katers Murr das Zerreißen in gewissem Sinne zum Überdauern von Kreislers Biographie führt, dient es hier offensichtlich der Zerstörung des Nachruhms, der damnatio memoriae Marwoods. Der unsterbliche Ruhm des Schreckens der Rachehandlung, mit der sich Medea verewigt hat, scheint Marwood also verwehrt zu werden. ${ }^{172}$ Es ließe sich hingegen einwenden, dass Marwoods Nachricht im Dramentext abgedruckt ist, obwohl sie später auf der Ebene der Fiktion von Sara zerrissen wird. Damit vollzieht sich ein performativer Widerspruch: Leser wie Schauspieler haben auf der Grundlage des realen Dramentextes die Möglichkeit, Marwoods Nachricht potenziell unendlich oft zu aktualisieren resp. Mellefont Marwoods Nachricht immer wieder vorlesen zu lassen. Die damnatio memoriae Marwoods vollzieht sich aber nicht nur auf der fiktiven Ebene, sondern reicht trotz dieses performativen Widerspruchs bis in die Realität hinein. Möglichkeitsbedingung dafür ist wiederum Lessings Verknüpfung von Mitleid und Dauer. Dazu sei zunächst aus einem Brief Lessings an Friedrich Nicolai zitiert: ${ }^{173}$

Wenn es also wahr ist, daß die ganze Kunst des tragischen Dichters auf die sichere Erregung und Dauer des einzigen Mitleidens geht, so sage ich nunmehr, die Bestimmung der Tragödie ist diese: sie soll unsre Fähigkeit, Mitleid zu fühlen, erweitern. Sie soll uns nicht bloß lehren, gegen diesen oder jenen Unglücklichen Mitleid zu fühlen, sondern sie soll uns so weit fühlbar machen, daß uns der Unglückliche zu allen Zeiten, und unter allen Gestalten, rühren und für sich einnehmen muß. ${ }^{174}$

Vielmehr als das Zerreißen des Zettels durch Sara fällt demnach ins Gewicht, dass Marwood das Mitleiden des Publikums dadurch verweigert wird, dass sie im Stück nicht stirbt, ${ }^{175}$ während das Mitleid(en) - das Saras sich selbst im Modus des Mitleidens vollziehendes Enden ${ }^{176}$ hervorruft - „zu allen Zeiten“ wirksam bleiben soll (und dadurch letztlich auch Sara selbst). Dies wiederum führt zu folgender These:

Ebenso wie seine Fabellehre (vgl. Kapitel IV.2.1) scheint auch Lessings Trauerspielkonzeption darauf abzuzielen, einem moralischen Kern des jeweiligen

\footnotetext{
172 Ebd., S. $272 \mathrm{f}$.

173 Zum Briefwechsel über das Trauerspiel zwischen Lessing, Mendelssohn und Nicolai vgl. Schulz 1988, S. 197-207.

174 Briefwechsel über das Trauerspiel, Brief Lessings an Friedrich Nicolai vom November 1756 (Lessing, Werke, Bd. 3, S. 671).

175 Müller Nielaba 1999, S. 272 f.

176 Sara leidet mit Mellefont, mit Betty etc. mit, siehe oben unter 1.2.1.
} 
epischen oder dramatischen Textes - bei den Fabeln der moralische Satz, bei den Trauerspielen das Mitleid - die Dauer über "alle[] Zeiten" hinweg zu sichern. ${ }^{177}$

Zusammenfassend lässt sich jedoch aus den in diesem Unterkapitel angestellten Beobachtungen der Befund ableiten, dass der Versuch Lessings, dieses Ziel zu erreichen, im Falle seiner Trauerspielkonzeption letztlich in einen faszinierenden Zirkelschluss münden muss:

Das Mitleid, das nur als Mitleiden zu haben und deshalb im Gegensatz zum Schreckensmoment auf eine zumindest relative Dauer angewiesen ist, soll nach Lessing wiederholbar ausgelöst werden können durch ein Konservieren des Mitleidanlasses in einem Trauerspieltext, dessen Überdauern durch einen Modus garantiert werden soll, der selbst wiederum der des Mitleidens ist.

Dies ist vonseiten Lessings freilich ein Zirkelschluss, der gerade dadurch, dass er einer ist, eine potenziell endlose Bewegung lostritt. Oder anders formuliert: Gerade dadurch, dass das Mitleiden des Lesers nicht in einem absoluten Sinne dauerhaft festgehalten werden kann, birgt es in Lessings Konzeption eine gewisse abstrakte Dauerhaftigkeit durch jene Verschränkung von Dauer und Mitleid in einem potenziell unendlichen Prozess des Mitleidens.

Von hier aus bietet es sich nun an, überzuleiten zum nächsten Kapitel: Mitleid ist also auf Dauer angewiesen, die in Lessings Trauerspielen den Tod hinausschiebt und ihn zugleich zu überwinden sucht durch ein verewigendes Mitleiden. Eng damit verknüpft ist das Problem der (Un-)Darstellbarkeit des Todes, ${ }^{178}$ das bereits bei den Lebens-Ansichten des Katers Murr zu beobachten war, so Müller Nielaba:

Der „Augenblick, da die Seele“, die eigene, ,weicht': Saras Sprechen antizipiert ihn als das, was der Text selber nur in der sprechenden Leere eines Gedankenstrichs darstellen kann. Umgekehrt Mellefont: Demjenigen, was Sara, als ihr eigenes Ende, nur vorwegnehmend ausdrücken kann, jenem „Augenblick“, hinkt er, der Machtlose, um dieselbe entscheidende Zeitspanne hintennach. „Sie stirbt!" [...],

177 Interessant ist, dass hier ausgerechnet Gottsched eine ähnliche Meinung vertritt, jedoch jeweils ohne den Aspekt der Dauer: „Wie eine gute tragische Fabel [in diesem Zitat Gottscheds gemeint im Sinne von ,erzählte Handlung', nicht im Sinne der literarischen Gattung der Fabeln, MG] gemacht werden müsse, das ist schon im vierten Hauptstücke des ersten Theils einigermaßen gewiesen worden. Der Poet wählet sich einen moralischen Lehrsatz, den er seinen Zuschauern auf eine sinnliche Art einprägen will. Dazu ersinnt er sich eine allgemeine Fabel, daraus die Wahrheit eines Satzes erhellet. Hiernächst suchet er [...]" (Gottsched, Versuch einer critischen Dichtkunst, S. 611). Äußerst bemerkenswert ist zudem, dass Lessing in seinen Abhandlungen [über die Fabel] (nun Fabeln im Sinne der literarischen Gattung) Gottsched nahezu zitiert, was den moralischen Lehrsatz anbelangt, jedoch zusätzlich wiederum den Aspekt der Dauer betont (vgl. Kapitel IV.2.1 zu Lessings Fabel Der Phönix).

178 Vgl. dazu auch Leventhal 1993, S. 315 . 
muß er entsetzt feststellen, ohnmächtig darin, daß es diese "Sie“ als Sterbende [eher: Gestorbene, MG] genau dann bereits nicht mehr gibt, wo er sie als solche ansprechen kann. Der „Augenblick“ des Endes vom Enden ist sprachlich nicht zu fassen, bloß zu umschreiben, buchstäblich, in der gemeinsamen Verschränkung von vorwegnehmendem und nachfolgendem, Temporalität kontrahierendem und diese dehnendem Sprechen. - Ein letzter "gelinder Spasmus“, Sprache geworden. ${ }^{179}$

Mit Blick auf die in dieser Arbeit untersuchten Operationen zur Ewigkeitsattribuierung von Schriftzeichen lässt sich dazu ergänzend folgende These formulieren:

In Lessings Ästhetik des Endens wird die Unteroperation Unendliche Lektüre bemüht, um Dauer zu garantieren. Dabei spielt der Gedankenstrich eine entscheidende Rolle, der Raum und Zeit für die Entfaltung des Mitleidens schafft.

(Somit ergänzen und bestätigen das vorliegende Kapitel und die These Andrea Polascheggs einander eindrücklich; denn Letztere beobachtet, dass die in der zweiten Hälfte des 18. Jahrhunderts gewissermaßen zu ,Affektzeichen“ werdenden Satzzeichen - insbesondere die sprunghaft ansteigende Zahl der Gedankenstriche und Ausrufezeichen - einhergehen mit der Konstitution des modernen Individuums und der modernen Autorschaft. $)^{180}$

Der Gedankenstrich wird beiLessing des Weiteren gerade dorteingesetzt, wo der Tod, das Ende stehen müsste, was einem Verfahren entspricht, das komplementär zur Operation der Unendlichen Lektüre zugleich auch in Richtung der Operation Unendliches Verstummen tendiert. Zudem lässt sich in der Neuinterpretation des aristotelischen phóbos als Furcht im Sinne eines selbstbezogenen Mitleidens - in Einklang mit dem zeitgenössischen Paradigmenwechsel in der Philosophie ${ }^{181}$ eine Operation der Spiegelung beobachten, die der Grundoperation Reflexivität zugrunde liegt.

Wie das Problem der (Un-)Darstellbarkeit des Endes auch ästhetisch produktiv genutzt werden kann, damit beschäftigt sich nun das folgende Kapitel II.2 zum potenziell unendlich oft erfolgenden Verstummen von Schriftzeichen.

\footnotetext{
179 Müller Nielaba 1999, S. $274 \mathrm{f}$.

180 Vgl. Polaschegg 2012, insbesondere S. 16o-162 und 181 f. Dazu passen ebenso eindrücklich die Ergebnisse Uwe Wirths weiterführender Beobachtungen zum Zusammenhang zwischen Ewigkeitsattribuierung, Herausgeberfiktion und Konstitution der modernen Autorschaft, wie sie weiter unten in Kapitel II.3.3 dargelegt werden.

181 Vgl. insbesondere Kapitel IV.3.1.
} 


\section{Unteroperation Unendliches Verstummen}

\subsection{Der Spinnerin Nachtlied}

\section{Der Spinnerin Nachtlied ${ }^{182}$}

Es sang vor langen Jahren, Wohl auch die Nachtigall, Das war wohl süßer Schall

[1-4] Da wir zusammen waren

Ich sing' und kann nicht weinen Und spinne so allein, Den Faden klar und rein

[5-8] So lang der Mond wird scheinen.

$\mathrm{Da}^{183}$ wir zusammen waren

Sang süß ${ }^{184}$ die Nachtigall

Nun mahnet mich ihr Schall

[9-12] Daß du von mir gefahren

So oft der Mond mag scheinen, Gedenck ich ${ }^{185}$ dein allein, Mein Herz ist klar und rein,

[13-16] Gott wolle uns vereinen.

Seit du von mir gefahren Singt stets die Nachtigall Ich denk bei ihrem Schall

[17-20] Wie wir zusammen waren

Gott wolle uns vereinen Hier spinn ich so allein, Der Mond scheint klar und rein, [21-24] Ich sing' und mögte weinen.

182 Zitiert nach der Fassung im Brief an Achim von Arnim vom 6. September 1802 (Brentano, Werke, Bd. 29, S. 498), Abweichungen einzelner Worte (nicht der Orthographie und nicht der Interpunktion) gegenüber den Varianten des Gedichts in den beiden Fassungen der Chronicka eines fahrenden Schülers sind mit Fußnoten vermerkt.

183 "Als" anstelle von „Da“ wird bloß im kritischen Apparat zur Fassung des Liedes innerhalb der Chronicka eines Fahrenden Schülers (1. Fassung) als Variante angegeben (vgl. Brentano, Werke, Bd. 19, S. 527).

184 In der Chronicka eines fahrenden Schülers (1. und 2. Fassung): „Da sang die ...“ (ebd., S. 96 und 200).

185 In der Chronicka eines fahrenden Schülers (1. Fassung): „So denck ich ...“" (ebd., S. 96 und 527). 
Die Überlieferung des Liedes gestaltet sich komplex. Es wurde wohl im Sommer 1802 verfasst und (noch ohne Titel) in einem Brief vom 6. September 1802 an Achim von Arnim mitgeteilt. ${ }^{186}$ Als Kompositions- und von der Forschung angenommener Erstdruck erschien es ca. 1806 (terminus ante quem: 16. Juni 1806) erstmals kontextfrei. Entstanden ist es aber ursprünglich „[im] Zusammenhang mit der Chronicka eines fahrenden Schülers" und wurde 1818 dann auch als Teil dieses Erzählfragments abgedruckt. „[D]och hat es Brentano in wenigstens einer (undatierten) Abschrift selbst aus dem Prosakontext gelöst und ihm die Überschrift Der Spinnerin Nachtlied gegeben." ${ }^{187}$ Der nicht originale Titel Der Spinnerin Lied, der einem zuweilen noch begegnet (etwa bei Alewyn), ${ }^{188}$ stammt von den Herausgebern der $185^{2}$ postum erschienenen Gesammelten Schriften. ${ }^{189}$ Dass diese ausgerechnet das Bestimmungswort Nacht- strichen, mutet äußerst seltsam an, stellt der Titel doch gerade dadurch einen impliziten Bezug zu den mittelhochdeutschen Tage-Liedern her, ${ }^{190}$ der nach Kenntnis des Verfassers in der Forschung aber bislang keine Beachtung

186 Vgl. Brentano, Werke, Bd. 29, S. 498 f.

187 Das Lied wird hier außerhalb jenes Prosakontextes untersucht; zum Lied in seinem unmittelbaren Kontext der Chronicka eines fahrenden Schülers vgl. u. a. Frühwald 1994, S. 275 und 277-279; Schrimpf 1976, S. 384-386; und vor allem Kirchberger 1975, S. 420-424.

188 Vgl. den Titel seines 1971 erstmals erschienenen Aufsatzes; Alewyn 1974, S. 198.

189 Vgl. Frühwald 1994, S. 269 f.

190 Brentanos Wissen und seine Verdienste um die mittelhochdeutsche Lyrik, darunter natürlich auch Tagelieder, sind allgemein bekannt. An dieser Stelle sei als Exempel bloß aus der Einleitung der Edition des Königsteiner Liederbuches zitiert, das zu etwa zwei Dritteln aus Sehnsuchtsklagen besteht (vgl. Sappler 1970, S. 5) und vielleicht den Entstehungskontext von Der Spinnerin Nachtlied ergänzen mag: „Ein Tinteneintrag auf dem vorderen Pergamentspiegelblatt verso gibt über die Vorbesitzer Auskunft: ,Codex olim Clementis Brentanonis. Postea fratrum Grimmiorum. ' [...] Clemens Brentano scheint die Handschrift aus Neigung für die ältere deutsche Literatur gekauft zu haben; auf die Erwerbung könnte folgende Stelle aus einem Brief an Arnim vom August 1802 [also etwa einen Monat vor dem Brief, der Der Spinnerin Nachtlied enthält, MG] hindeuten: ,Ich bin fünf baare Wochen in Koblenz gewesen und habe unter andern viele seltene alte Bücher und einige Manuscripte spottwohlfeil gekauft: [...] Zwei Tagelieder der Sammlung (Nr. 6 und 40) gelangten im gleichen Jahr [1805, MG] in den ersten Band des ,Wunderhorns“" (ebd., S. 28). Diesen Hinweis verdankt der Verfasser seiner Bürogenossin und Expertin für mittelalterliche Handschriften, Dr. Lena Ötjens. 
gefunden hat. ${ }^{191}$ Man hat lediglich auf die Parallelen zu Friedrich Spee ${ }^{192}$ und Hans Jakob Christoffels von Grimmelshausen Nachtigallen-Lied aus dem Simplicissimus $(\mathrm{I}, 7)$ verwiesen, ${ }^{193}$ die jedoch selber wiederum Elemente des Tageliedes resp. der mittelhochdeutschen Lyrik aufgreifen. Der Bezug zum mittelhochdeutschen Tagelied ist - wie sich zeigen wird - vor dem Hintergrund dieser Arbeit jedoch von zentraler Bedeutung und dient deshalb für das vorliegende Kapitel als Ausgangslage, das denn auch gattungspoetologischen Aspekten des Gedichtes besondere Aufmerksamkeit schenkt. mittelhochdeutschen Tagelieder

Die mittelhochdeutschen weltlichen Tagelieder ${ }^{194}$ besingen - oft verknüpft mit den Elementen des Weckens und Wachens - die drohende Trennung eines Liebespaares (meist einer höhergestellten adligen Herrin und ihres Geliebten) bei Tagesanbruch, das im Falle einer Entdeckung Tod und Schande fürchten muss. ${ }^{195}$ Über u. a. das Auftreten mehrerer Sängerinstanzen (wozu auch Singvögel wie die Nachtigall zählen können) und die mehrdeutige Deixis der Pronomen handeln sie aber auch und nicht minder gattungskonstitutiv - so hat der Verfasser in einer Studie von 44 solcher Tagelieder gezeigt ${ }^{196}$ - von den Möglichkeitsbedingungen des Singens eines Textes, wobei sie das Verstummen des Liedes ästhetisch und poetologisch produktiv nutzen. Die zentrale Bedeutung der Tageliedszene für die in diesem Kapitel (und auch in Teilen von Kapitel II.3) entfaltete Argumentation mag folgendes, etwas längeres Selbstzitat jener Studie rechtfertigen:

191 Frühwald erwähnt zwar, dass der Schlussvers des Gedichtes „in Anlehnung an den Eingangsvers eines Tageliedes des Meisters Walther von Breisach (Ich singe und sollte weinen) gebildet“" (Frühwald 1994, S. 277) sei, ohne aber dem ganzen Lied die Nähe zur Gattung der Tagelieder zuzusprechen. Bei Walther von Breisach ist es der Wächter, dem im Falle der ersten Strophe die Stimme geliehen wird und der sich nicht erinnert, sondern vor dem Tagesanbruch warnt. In der zweiten Strophe des Liedes berichtet dann eine erzählende Instanz, dass die Geliebte aufgrund des Singens des Wächters weint: „ir leides hûsgenôz, / der trehene flôz, / begôz ir beider wengel dô vil gar“ (Tagelieder 2011, S. 166).

192 Zu Brentano und seiner Rezeption von Friedrich W. Spees Trutz-Nachtigall resp. des barocken Echogedichtes vgl. Menke 200o, insbesondere S. 496-499.

193 Darauf, dass Brentanos Lied eine Antwort auf Achim von Arnims Nachtigallenlied Dichterlohn sei (vgl. Frühwald 1995, S. 407).

194 Vgl. die bestehenden Anthologien: Tagelieder des deutschen Mittelalters ${ }^{3}$ 2011; Hausner 1983; Deutsche Tagelieder 1983; Texte zur Geschichte des deutschen Tageliedes 1947. Die einzige Anthologie geistlicher Tagelieder stammt von Schnyder 2004.

195 Zum Tageliedstoff in der mhd. Literatur außerhalb der Tageliedgattung vgl. Hausner 1983; und Mohr 1971. Für den englischen Sprachraum vgl. zudem Honegger 1999.

196 Vgl. Gut 2014. 
Der Zeitpunkt, in dem das Singen der allermeisten Sänger-Instanzen auf semantischer Ebene stattfindet, befindet sich fast immer zwischen Tag und Nacht. Insbesondere das Ende des Tageliedes ist erreicht, bevor es tatsächlich helllichter Tag geworden wäre, und fast nie erzählt eine weitere, letzte Strophe die scheinbar logische Folge des Weckens des Liebespaares, nämlich eine tatsächlich erfolgte Trennung der Liebenden. Damit vollzieht sich ein Widerspruch zwischen der semantischen Ebene, in der vom Wecken des Paares und der unmittelbar bevorstehenden Trennung die Rede ist, und dem Ende des Liedes, das genau dieses Wecken wirkungslos macht, indem es ein (Weiter-) Singen von einer tatsächlich erfolgten Trennung schlicht unterlässt. In der fiktiven (semantischen) Welt des Liedes kann somit gar keine Trennung des Paares erfolgen, da im Lied von keiner erfolgten Trennung die Rede ist. Kurz gefasst lässt sich also sagen: Die allermeisten der untersuchten Tagelieder thematisieren den performativen Widerspruch, den sie - durch den Zeitpunkt, in dem ihre ,Erzählung‘ abbricht - generieren.

Dieser Zeitpunkt aber ist ein Dazwischen: ein ,Graubereich' (Morgengrauen) zwischen Nacht und Tag. Aus diesem Dazwischen auf semantischer Ebene und der Spannung zwischen Tag und Nacht, zwischen Wach-Sein und Schlafen, zwischen Zusammensein und drohender Trennung, entfaltet sich die Gattung des Tagelieds, und selbst Variationen des klassischen Tagelied-Stoffes kommen kaum umhin, in irgendeiner Form darauf Bezug zu nehmen. [...]

Aber das Tagelied spricht nicht nur von einem Werden, sondern ,ist' zugleich auch immer ein Werden: Als Geflecht aus Sprachzeichen, das nur zu einem Lied wird, wenn jemand es singt, ist es als solches immer gerade im Begriff, gesungen zu werden. Der semantische Fokus auf ein Werden (des Tages) und auf das damit verbundene Wecken ermöglicht somit, dass das Lied vollzieht, wovon es als ganzes Lied (und nicht nur in einzelnen Passagen) spricht. Auf poetologischer Ebene wird das Werden des Liedes, auf semantischer Ebene das Werden des Tages behandelt. Der Zeitpunkt des Liedendes ist auf semantischer Ebene fast immer so gewählt, dass ebendiese semantische Ebene mit der poetologischperformativen Ebene (insbesondere genau in diesem Ende[n]) zusammenfällt.

Es gibt also eine verblüffende Ähnlichkeitsbeziehung zwischen dem Tagesanbruch auf semantischer Ebene und dem Gesungen-Werden des Liedes. Dass diese Ähnlichkeitsbeziehung gerade auch in Variationen des Tagelied-Stoffes nicht nur oft beibehalten wird, sondern z. T. sogar das zentrale produktive Element, aus dem sich die Variation entfaltet, darstellt, zeigt [innerhalb des untersuchten Korpus, MG] Morungens Tagelied. ${ }^{197}$

Es kann also kaum für einen Zufall gehalten werden, wenn Brentano die Tageliedszene ausgerechnet mit der auf poetologischer Ebene mythologisch und literaturgeschichtlich höchst aufgeladenen Szene am Spinnrad ${ }^{198}$ kombiniert. Denn als Tagelied-Spinnrad-Hybrid stellt Brentanos ,Nachtlied“ genau eine jener „Variationen des Tagelied-Stoffes“ (und umgekehrt betrachtet natürlich

197 Ebd., S. 279-282; vgl. dazu auch Mertens Fleury 2018, insbesondere S. 196 f.

198 Frühwald 1994, S. 272. 
auch eine Variation des Topos vom Weben $)^{199}$ dar. Dies gibt methodisch den Anlass dazu, die folgende Argumentation systematisch aus den wichtigsten Elementen von Brentanos Variation der Tageliedszene zu entwickeln. Diese sind, in der Reihenfolge ihrer unten stehenden Behandlung:

a) die Kombination der Spinnrad- mit der Tageliedszene

b) der Gesang/Klang einer weiteren Sängerinstanz (in diesem Fall der Nachtigall) hat eine erinnernde und keine weckend-warnende Funktion

c) die Zukunft wird als wiedervereinende erhofft, während sie im typischen mittelhochdeutschen Tagelied die Trennung herbeiführt

d) die explizite Bezeichnung des Liedes als ein Nacht- anstelle eines Tageliedes

$\mathrm{Zu}$ a), die Kombination der Spinnrad- mit der Tageliedszene: Wolfgang Frühwald erwähnt, dass Brentano

eine im späten 18. und 19. Jahrhundert häufige lyrische Szene thematisch und formal weitergebildet [hat]: das Lied des auf den Geliebten wartenden Mädchens am Spinnrade; er hat in der Form des Liedes die starke Affektbetonung dieser Lieder mit der Monotonie der Arbeit am Spinnrad konfrontiert, in der sich die Qual des Wartens sinnbildlich erneuert. ${ }^{200}$

Auf diese ,Erneuerung resp. die Iteration wird sogleich eingegangen, zuerst sei aber auf die komplexe Symbolik des Spinnens hingewiesen: Das Metzler Lexikon literarischer Symbole führt unter dem Eintrag "Gewebe/Faden“, der auch das Schlagwort "Spinnen“ abdeckt, neun verschiedene Symboliken, wovon in Brentanos Gedicht mindestens sechs in hohem Maße mitschwingen: „2. Symbol des Schicksals und der Zeit“, „3. Symbol der Kunstfertigkeit und des Darstellungsvermögens“, „4. Symbol des Singens und mündlichen Erzählens“, "7. Symbol emotionaler Beziehung und persönlichen Andenkens“,201 „8. Symbol von Struktur und Textur" und in 8 schon mitschwingend: "9. Symbol des Dichtens bzw. Textens. “202 Bemerkenswert ist nun, dass die symbolischen Bedeutungen 4 (teilweise auch 3 und 7) und vor allem 8 und 9 sich mit der Tageliedszene und deren (poetologischen) Bedeutungsebenen überschneiden und diese dadurch noch verstärken, wohingegen Symbolik 2 eine zusätzliche Ebene ins Spiel bringt, die sich jedoch - auch dies ist höchst bemerkenswert mit dem Fokus der geistlichen Tagelieder deckt (siehe unten Punkt c).

199 Nichtsdestotrotz ist das Gedicht betitelt als Nachtlied einer Spinnerin und nicht als ein Spinnlied einer des Nachts Singenden. Die Titelgebung akzentuiert also stärker die Kombination des Tageliedstoffes mit dem Topos des Webens als umgekehrt.

200 Frühwald 1994, S. 272.

201 Vgl. dazu auch ebd.

202 Metzler Lexikon literarischer Symbole 2012, S. 149-151. 
Das Similaritätsverhältnis zwischen der inhaltlichen Ebene des Spinnens und der auf Wiederholung und Verschränkung beruhenden Form von Brentanos Lied und die dadurch sich eröffnende poetologische Lesart desselben wurden in der Forschung bereits ausführlich behandelt. Stellvertretend dafür sei hier Hans Magnus Enzensberger zitiert, der dies, was die Strophen und Verszeilen anbelangt, auch schematisch schön vor Augen führt:

Wenn man die ersten acht Verszeilen mit den Ziffern 1-8 bezeichnet und von den kleinen, aber bedeutungsvollen Veränderungen absieht, ${ }^{203}$ denen sie wiederkehrend unterworfen werden, so erhält man das folgende Bild:

Strophe i 1234 Strophe ii 5678

iii $4234 \quad$ iv 8675 vi234 vi 5678

Jede der beiden Strophenarten (a- und ei-Strophen) wird also in der Weise variiert, daß die zuletzt gesungene Zeile (Zeile 4 in Strophe i) in der folgenden Strophe der gleichen Art als erste erscheint, während der Strophenkern seine Reihenfolge beibehält. Die zweite Variation kehrt die Konstellation nach dem gleichen Gesetz wieder um und führt auf diese Weise beinahe (aber eben nur beinahe) zur Ausgangsstrophe zurück (i fast $=v$; ii fast $=v i)$. Die beiden Strophengruppen kontrastieren übrigens miteinander nicht nur in ihrem Klangthema, sondern auch durch das Vorwiegen der Ich-Haltung hier, der Du-Haltung dort. $^{204}$

Was die Wiederholungen auf der Wortebene betrifft, so besteht das Gedicht (ohne Titel) aus 116 Wörtern, wovon bloß 37 Wörter nicht eins zu eins wiederholt werden. Zählt man unterschiedliche Flexions- (und im Wortstamm ähnlich bleibende Zeit-)Formen von Verben und Adjektiven sowie die Pronomen ihr/ihren nicht einzeln, so erhöht sich die Iterationsdichte gar auf nur 24 nicht wiederholte Wörter. ${ }^{205}$ Nach Richard Alewyn treten total 24 Reime auf, die aber nur aus 10 Reimwörtern gebildet sind ${ }^{206}$ - die wiederum nur aus vier verschiedenen Reimen mit lediglich zwei unterschiedlichen Reimvokalen und Endkonsonanten bestehen. ${ }^{207}$

Die von der Forschung aufgezeigte, über jenes Similaritätsverhältnis sich konstituierende poetologische Ebene des Textspinnens und -webens ist jedoch vor dem Hintergrund des in dieser Arbeit Behandelten um einen weiteren Abstraktionsschritt zu ergänzen, nämlich durch folgenden Befund:

\footnotetext{
203 Vgl. dazu insbesondere Kirchberger 1975, u. a. S. 418-420.

204 Enzensberger 1961, S. 116.

205 Die einzigen Nomen, die bei dieser Iterationsdichte nicht wiederholt werden, sind wohl nicht zufällig "Jahren“, „Faden“ und "Herz", womit die inhaltlichen Leitthemen Zeit (Text -) Gewebe - Liebe hervorgehoben sind.

206 Vgl. Alewyn 1974, S. 199.

207 Vgl. ebd.; und Schrimpf 1976, S. 386.
} 
Jenes Similaritätsverhältnis gründet auf der Ebene der Form des Gedichtes derart stark auf der Iteration einzelner Wörter, ${ }^{208}$ dass dadurch der Modus der Iteration selbst sich als Gegenstand poetologischer Reflexion aufdrängt, ja als grundlegende Möglichkeitsbedingung eines jeden Textfadens resp. Gewebes ausgestellt wird. Zugleich führt eine derart oft sich vollziehende Iteration einzelner Wörter im Zuge der Lektüre resp. des Singens automatisch zu einer ebenso oft erfolgenden Iteration des Wortklanges. ${ }^{209}$ Dies unterstreicht der doppelte Binnenreim der zweiten (in V. 1 und 2) und der letzten Strophe (in V. 2 und 4) eindrücklich, indem er zum einen die Wörter, spinn (e)'und, sing' über den Reim - durch Iteration von Klang also - miteinander verwebt und zum anderen weil dieses Reimpaar (mit kleiner Abweichung, spinne'/,spinn') wiederum selbst wiederholt wird.

Dieser Befund führt nun direkt zum nächsten wichtigen Element der Variation des Tageliedes durch Brentanos Gedicht:

$\mathrm{Zu}$ b), der Gesang/Klang einer weiteren Sängerinstanz (in diesem Fall der Nachtigall) hat eine erinnernde und keine weckend-warnende Funktion: Durch die Wiederholung von fast drei Vierteln der Wörter - die noch höher, ja fast flächendeckend ist, zählt man andere Klangfiguren wie Alliterationen und Assonanzen hinzu - vollzieht sich im Zuge der Lektürenicht nur eine Iteration des Wortklanges, sondern ebenso eine Iteration des Verstummens ebendieses Wortklanges. Eines Verstummens, das die Gattung der mittelhochdeutschen Tagelieder in ihrem Ende(n) jeweils so inszeniert, dass die primäre semantische Ebene mit der poetologischen Ebene zusammenfällt, um diesen Zusammenfall wiederum ästhetisch produktiv zur Darstellung des Wiedereinschlafens des Paares zu nutzen. Denn das eigene, sich gerade vollziehende Schlafen ist für die Schlafende mittels Sprachzeichen ebenso undarstellbar ${ }^{210}$ wie für den Toten der eigene Tod - Letzteres haben die vorangegangenen Kapitel im Falle der Autobiographie Murrs und von Saras Enden gezeigt. Dadurch, dass nun Der Spinnerin Nachtlied in Strophe I und III (erste Hälfte) den vergangenen „Schall“ der "Nachtigall“ als einen bereits verhallten, zu erinnernden (über die Verben "sang" und "waren") und in Strophe V und III (zweite Hälfte) den aktuellen "Schall“ der „Nachtigall“ als einen erinnernden nennt, vollzieht es gegenüber dem typischen mittelhochdeutschen Tagelied einen Wechsel vom weckenden Gesang hin zum erinnernden Gesang. Die Performativität des Reimpaars

208 Womit, wie Frühwald an der oben zitierten Stelle bereits erwähnt hat, auch die Wiederholung der Handgriffe des Spinnens performativ zur Darstellung kommt.

209 Ob nun laut gesungen/gelesen oder in der stummen Lektüre imaginiert.

210 Dabei ist ein unbewusstes Sprechen im Schlaf ausgeklammert. 
„Nachtigall - Schall“ verstärkt dabei zusätzlich diesen Modus des Erinnerns:211 Der Schall nämlich des Wortes "Nachtigall“ ist bereits ein Vergangener, wenn das Wort "Schall“ gesungen resp. gelesen wird, und muss erinnert werden, um zusammen mit dem Schall des Wortes „Schall“ die Klangfigur eines Reimes zu konstituieren. Der Umstand, dass sich genau in der Mitte der drei Strophen, die von diesem Reim geprägt sind, der Wechsel von einem $z u$ erinnernden Schall hin zu einem Schall, der einen an vergangene Zweisamkeit erinnert, vollzieht, ${ }^{212}$ rückt zudem die Sängerinstanz der Nachtigall, die ohnehin bereits im Mittelalter die Metapher für den Sänger war, ${ }^{213}$ noch näher an das singende Ich und damit auch näher an den realen Sänger resp. Leser. Denn wer ist „die Nachtigall“, die "Nun“, im Jetzt, „mahnet“ und aus der Perspektive des fiktiven singenden Text-Ich "stets singt" (oder vielleicht treffender: stets gesungen haben wird)? Ist es dieses Ich oder der reale Leser, der dem Singen jenes Ich die Stimme leiht?214 All diese Punkte zusammen verstärken wiederum die schon für die Gattung des mittelhochdeutschen Tagelieds zentrale Reflexion des Verstummens des eigenen Klangs und des Verstummens von an Sänger und Leserinnen gebundenen Liedern und Textgeweben im Allgemeinen.

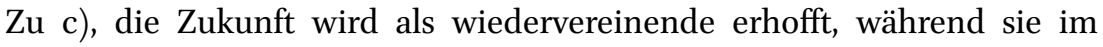
typischen mittelhochdeutschen Tagelied die Trennung herbeiführt: Im mittelhochdeutschen Tagelied ist die gegenwärtige Zweisamkeit dasjenige, das erhalten werden soll. Deshalb nimmt in der Regel die Vergangenheit nahezu keine, die Zukunft jedoch eine bedrohliche, da trennende Rolle ein, was wiederum dazu führt, dass Letztere gefürchtet oder gar geleugnet wird. ${ }^{215} \mathrm{Im}$

211 Zum Reim und zu seiner Relation zu Gedächtnis, der Textur resp. dem Text und dem ihm damit stets inhärenten autoreflexiven Potenzial sowie zum romantischen Verständnis von Musik und Mathematik, gerade auch in der Lyrik Brentanos, vgl. ausführlich Menke 2000, S. 529-539. Diese zitiert dabei auch Wilhelm Schlegel aus einer Notiz für dessen Berliner Vorlesungen, in der er zur "Wirkung des Reimes überhaupt" auch mit Verweis auf das Unendliche schreibt: „Verknüpfung, Paarung, Vergleichung. Erregte Erwartung schon im einzelnen Verse und Befriedigung. Erinnerung und Ahndung, statt dass die alte Rhythmik immer in der Gegenwart festhält, und allen Teilen eine gleiche Dignität gibt. - Daher liegt im Reime das romantische Prinzip, welches das entgegengesetzte des plastischen Isolierens ist. Allgemeines Verschmelzen und hinüber und herüber ziehen. Aussichten ins Unendliche“ (zitiert nach Menke 2000, S. 529).

212 Wobei die beiden Strophenhälften bezeichnenderweise über ebenden Reim "Schall Nachtigall" verbunden sind!

213 Vgl. Sabine Obermaier 1995.

214 Vgl. dazu Alewyns Feststellung: „Es [das Lied, MG] läßt einen Menschen singen, von seinem Singen singen, vom Singen der Nachtigall, und indessen wird es gesungen, ein echter Singsang“ (Alewyn 1974, S. 199).

215 Als eines der eindrücklichsten Beispiele dafür sei hier Wolframs von Eschenbach Sine klawen genannt, dessen zweite Strophe lautet: „Wahtaer, du singest, / daz mir manige 
Nachtlied Brentanos hingegen ist die Vergangenheit als Zeit der Zweisamkeit positiv konnotiert, aber nicht so die einsame Gegenwart, weshalb das Ich eine vereinende Zukunft ersehnt. An dieser Veränderung der typischen Tageliedszene zeigt sich die frühromantische, durch einen Dreischritt (verlorene Vergangenheit; suchende oder sehnende Gegenwart; eine Zukunft, die die beiden Ersteren miteinschließt) ${ }^{216}$ geprägte geschichtliche Perspektive besonders eindrücklich. Und ebenso zeigt sie die romantische Neubesetzung der Nacht mit Attributen des Tages und umgekehrt, wie sie wenig früher Friedrich Schlegel in der Lucinde wohl kaum zufällig ebenfalls in einer Tageliedszene ${ }^{217}$ schon meisterhaft vorgenommen hat. Es zeigt sich aber auch erneut - und viel tief greifender als der von der Forschung bisher herbeigezogene, gewissermaßen auf halber Strecke in die Vergangenheit abbrechende Verweis auf Gryphius' Nachtigallen-Lied ${ }^{218}$ - nicht nur die Verbindung von Der Spinnerin Nachtlied mit dem Barock, sondern vor allem auch mit der mittelalterlichen und spätmittelalterlichen Dichtung. Und zwar nicht nur zum weltlichen Tagelied wie bisher erwähnt, sondern auch zur Gattung des geistlichen Tageliedes. ${ }^{219}$ Diese Verbindung soll im folgenden Abschnitt kurz angetönt werden:

Ein zentraler Unterschied zwischen dem weltlichen und dem geistlichen Tagelied $^{220}$ ist, dass im Falle von letzterem

die ,reale‘ Tageliedsituation jetzt symbolisch überhöht wird. Ihre Konstituenten erscheinen nunmehr als Signifikanten für eigentlich gemeinte spirituelle Sachverhalte. Die Dame mag die Seele, den Leib der Ritter bezeichnen, oder das Paar kann für die Beziehung der Frau Welt und des Christen, jedoch auch etwa für Gott und Maria stehen; der Tagesanbruch meint den Tod und das individuelle Gericht oder auch den allgemeinen Gerichtstag, im 16. Jh. den religiösen Aufbruch im Zeichen der Reformation. ${ }^{221}$

Dabei kommt der Reflexion des Verstummens des Liedes - so die Hypothese entscheidende ästhetische wie poetologische Bedeutung zu: Die dann später

vreude nimt / unde mêret mîn klage. / maer du bringest, / der mich leider niht gezimt, / immer morgens gegen dem tage. / diu solt du mir verswîgen gar. / daz gebiut ich den triuwen dîn. / das lôn ich dir, als ich getar, / sô belîbet hier der geselle mîn." (Tagelieder 2011, S. 92).

216 Vgl. Frühwald 1994, S. 274.

217 F. Schlegel, Lucinde, S. 113-116.

218 Vgl. z. B. Frühwald 1994, S. 278.

219 Zur Gattungsfrage betreffend die geistlichen Tagelieder vgl. Schnyder 2004, S. 624-629; betreffend eine zusammenfassende gattungsgeschichtliche Skizze vgl. ebd., S. 63o-636.

220 Freilich sind die beiden Unterscheidungen in weltliches und geistliches Tagelied „im Wesentlichen Analyseinstrumente der modernen Literaturwissenschaft" (ebd., S. 3).

221 Ebd., S. 11. 
im Barock so stark betonte Vergänglichkeit alles Irdischen und damit letztlich auch der Medien, in denen diese Betonung erfolgt, ${ }^{222}$ ist gerade auch im Falle von Letzterem im geistlichen Tagelied bereits angelegt. Das Lied selbst stellt durch den Zeitpunkt seines Endes seine eigene Vergänglichkeit aus und nimmt dabei im Einzelnen performativ vorweg, was vom Tod resp. Jüngsten Tag für das Irdische im Allgemeinen prophezeit wird. Denn wo im weltlichen Tagelied das Liedende mit dem Tag zusammenfällt (der in der Erzählung des Liedes aber nie endgültig angebrochen sein wird), muss das Liedende des geistlichen Tageliedes (resp. zumindest die des eschatologischen Typus, der dann im 16. Jahrhundert im Zuge der Reformation Hochkonjunktur hat) ${ }^{223}$ mit dem Jüngsten Tag zusammenfallen, der als der Tod alles Irdischen mittels irdischer Zeichen ebenso wenig erzählbar ist wie im Falle der bislang untersuchten Texte Schlaf und Tod durch die Verstorbenen und Schlafenden.

Der Spinnerin Nachtlied kombiniert also nicht nur die Tagelied- mit der Spinnradszene, sondern innerhalb der Tageliedszene die weltliche Liebe des weltlichen mit der ersehnten Zukunft des geistlichen Tageliedes. Brentanos Lied zeigt aber auch, dass bei der Tradierung der Tagelieder deren poetologischer Kern bei aller Variation erhalten bleibt resp. derjenige ist, von dem aus sich die Variationen entfalten. ${ }^{24}$

Dieser Wechsel von einer negativen Besetzung des Tages seitens der Liebenden hin zu einer positiven, der mit dem unter b) beschriebenen Wechsel von Wecken/Warnen hin zum Erinnern einhergeht, ist dabei nahezu wortwörtlich verwoben mit dem letzten Element von Brentanos Variation des mittelhochdeutschen Tageliedes:

$\mathrm{Zu} \mathrm{d}$ ), die explizite Bezeichnung des Liedes als ein Nacht- anstelle eines Tageliedes: Dass ein Begriff für Tagelied im Lied selbst - oder zum Teil gar in einer Titelzeile - vorkommt, war schon bei den mittelhochdeutschen, weltlichen wie geistlichen Tageliedern nicht ungewöhnlich und ist ein weiteres Zeugnis von deren autoreflexivem Gehalt. ${ }^{225}$ Auch in diesem Fall schließt sich die Titelgebung von Brentanos Lied also an mittelhochdeutsche Vorbilder

222 Dazu als Beispiel die bereits in der Einführung zitierte Stelle in Andreas Gryphius' Catharina von Georgien: „Ihr die jhr glaubt daß euer Feder Macht / Den Tod vnd Zeit hab' an ein Joch gebracht? / Glaubt frey die Ewigkeit beruht nicht auff Papir“ (Gryphius, Catharina von Georgien, S. 14 f.).

223 Vgl. Schnyder 2004, S. 630 f. und 632 f. und 634, wo er schreibt: „Beginn und Ende der von uns gezogenen gattungsgeschichtlichen Linie treffen sich im Rekurs auf das Weltgericht als Grund für den geistlichen Weckruf; erstmals ertönt er bei Walther von der Vogelweide am Anfang des 13. Jh.s, vielfach dann bei den einschlägigen, meist apokalyptisch gestimmten protestantischen Kirchenliedern."

224 Vgl. dazu auch Gut 2014, S. 281.

225 Vgl. ebd., S. 261; und für die geistlichen Tagelieder Schnyder 2004, S. 626-628. 
an, freilich bei gleichzeitiger Variation, die jedoch ihrerseits wiederum, es wurde unter c) erwähnt, bereits in den geistlichen Tageliedern angelegt ist: Denn auch das typische geistliche Tagelied ist im Grunde ein Nachtlied, ${ }^{226}$ gesungen in der Nacht des irdischen Lebens in der hoffnungsvoll-mahnenden Ankündigung des Todes oder des Endes aller Tage überhaupt.

Diese im geistlichen Tagelied vorherrschende Verknüpfung des Tages mit dem Tod (und der Wiederauferstehung) ist nun in Brentanos Lied mit der symbolisch und mythologisch hoch aufgeladenen Spinnradszene kombiniert. Oder anders formuliert: Die christliche Konnotation des Tages in den geistlichen Tageliedern wird in Der Spinnerin Nachtlied mit der heidnischen (griechisch-römischen und nordischen), mythologischen Konnotation des Spinnens des Lebens- und Schicksalsfadens verwoben. Endet das Spinnen dieses Fadens oder wird er durchtrennt - so jene Mythologien - endet auch das Leben. (Ebenso wie der Gesang der Nacht-i-gall, althochdeutsch für Nachtsängerin, ${ }^{227}$ enden muss, wenn die Nacht vorüber ist.) Und genau darin begegnen sich die Tagelied- und Spinnradszenen erneut: Beide bieten die Ausgangslage dafür, dass das Verstummen des Lied(text)es insbesondere am jeweiligen Ende des Lied(text)es über das Similaritätsverhältnis zum Ende der Nacht resp. zum Ende des Lebens Undarstellbares darstellen und dies zugleich poetologisch reflektieren kann.

Dabei lassen sich im Lied zwei vermeintlich gegenläufige Bewegungen beobachten, die nur dadurch zustande kommen, dass die typische Tageliedszene hin zur Nachtliedszene gewendet wird: Eine Bewegung ist diejenige von der Nacht hin zu einem in der Zukunft liegenden, ersehnten Tag; die andere Bewegung ist die des in seiner poetologischen Metaphorik das Singen und Leben des singenden Ich garantierenden Spinnens hin zum Ende dieses Lied(text) spinnens, zum „Stillstand des Spinnrades“, zum Reißen des Fadens. ${ }^{228}$ Im Falle der hier zweitgenannten Bewegung kommt hinzu, dass sowohl in der mythologischen als auch der poetologischen Metaphorik nur das Weiterspinnen des Lebens- oder Textfadens die Ewigkeit dieses Fadens garantieren würde.

226 Im Gegensatz zum Begriff Tagelied (mhd. tageliet) gibt es keine wortwörtliche mhd. Entsprechung für ,Nachtlied'. Die Forschung bezeichnet eines von Hadlaubs Tageliedern als ,Nachtlied', was jedoch eine anachronistische Bezeichnung ist (vgl. Dietz-Rüdiger 1970, insbesondere S. 199; und Leppin 1983, insbesondere S. 208 f., die genauer auf verschiedene Fremdbezeichnungen der Forschung eingeht). Bei Hadlaubs ,Nachtlied' stehen die Erlebnisse des Liebespaares in der Nacht und nicht deren bevorstehende Trennung bei Morgengrauen inhaltlich im Zentrum, es hat also wenig mit Brentanos Gedicht zu tun, resp. beide gehen auf Variationen des Tageliedes zurück.

227 Vgl. den Eintrag „Nachtigall“ im Deutschen Wörterbuch, Bd. 13, Sp. 188-191; http:// woerterbuchnetz.de/DWB [Stand:Juni/2018].

228 Vgl. Frühwald 1994, S. 279. 
Wobei der Textfaden resp. Lesensfaden im Gegensatz zum Lebensfaden über den Modus der (Re-)Lektüre den entscheidenden Vorteil besäße, potenziell unendlich oft wiedererweckt werden zu können - nur dass die Möglichkeitsbedingung dieses Vorteils ausgerechnet im potenziell unendlich oft wieder zu erfolgenden Verstummen des gelesenen Textums liegt.

Im Falle des typischen mittelhochdeutschen Tageliedes hat diese Ästhetik des Verstummens zu einem glücklichen Ende für das Liebespaar geführt, das als Textgebilde überhaupt nur im Modus des Morgengrauens, des Aktualisiertund-sogleich-wieder-verhallt-Seins existiert haben wird und immer wieder ,einschläft', bevor es helllichter Tag geworden wäre. Ein solcher Tag wäre nämlich auf der poetologischen Ebene nichts anderes als eine Aktualisation von Zeichen, die dauerhaft aufrechtzuerhalten wäre - dauerhaft aktualisierte Zeichen, die gerade dadurch nicht mehr wiederholbar und damit auch keine Zeichen mehr wären. ${ }^{229}$ Eine derartige Dauerhaftigkeit wurde in der christlich-jüdischen Tradition denn auch allein dem göttlichen Textum zugesprochen. So ist es kein Zufall, dass Brentano - bewusst oder unbewusst und dazu noch ähnlich wie Schiller ${ }^{230}$ - für die Vereinigung des Liebespaares Gott anruft, zumal in einem der beiden einzigen Verspaare, die ohne jegliche Variation wiederholt werden: „Gott wolle uns vereinen“. Die Anrufung Gottes sowie die oben behandelte mythologische Konnotation des Spinnens deuten darauf hin, dass die Trennung der Liebenden wohl nicht auf gesellschaftlichen Konventionen beruht wie in den mittelhochdeutschen Tageliedern, sondern am ehesten auf dem Tod des Geliebten, an den sich das Ich erinnert. ${ }^{231}$ Freilich lässt sich dies nicht zweifelsfrei bestimmen, sicher ist jedoch, dass zumindest die erhoffte Vereinigung durch Gott zusammen mit dem melancholischen Grundton des Gedichts und insbesondere der poetologischen Metaphorik des Lebens- und Textfadens stark darauf hindeuten, dass zumindest eine Wiedervereinigung des Liebespaares nur nach dem Tod erfolgen kann.

Nun ist aber die Ewigkeit Gottes und seines Logos resp. Textums sowie eines Lebens nach dem Tode im Jahre 1802, in dem Brentano das Lied verfasst, längst keine gesicherte mehr. ${ }^{232}$ Und so erstaunt es letztlich nicht, dass Der Spinnerin

\footnotetext{
229 Vgl. Derrida 1999.

230 Die Gegenüberstellung des göttlichen und menschlichen Wortes begegnet uns ebenfalls in Schillers Nänie - und auch dort hält die christliche Vorstellung des Logos Einzug, wo auf den ersten Blick vermeintlich allein heidnische Mythologie hinzugezogen wird; siehe dazu das betreffende Kapitel IV.2.2.

231 Am wenigsten Hinweise aus dem Gedichttext selbst und seinem Bezug auf die Tageliedtradition finden sich für die Deutung einer Trennung aufgrund der „Treulosigkeit des Mannes“, wie sie Marita Metz-Becker vorschlägt (dies. 20o6, S. 48).

232 Vgl. die Einführung sowie die historisch-kontextualisierenden Kapitel.
} 
Nachtlied sich nicht allein auf die Anrufung Gottes verlässt - womit nun die abschließende These der hier Schritt für Schritt über die Punkte a) bis d) entfalteten Argumentation erreicht ist:

Durch die Verknüpfung der Tageliedszene mit derjenigen des Spinnens ist es möglich, analog zum mittelhochdeutschen weltlichen Tagelied das Ende des Liedes derart zu gestalten, dass es auf poetologisch-performativer Ebene die ersehnte Zweisamkeit des Liebespaares doch noch erfüllt. Wo die Tagelieder über den Abbruch der Lieder ,vor' dem hellichten Tag darauf abzielen, jene Zweisamkeit zu bewahren, sucht sie Der Spinnerin Nachtlied wiederherzustellen. Es tut dies über den Abbruch des Lied(text)fadens - und damit auch des Lebens- und Lesensfadens des Ich - am Ende des Liedes. ${ }^{233}$ Wo in den Tageliedern das Liebespaar wieder zusammen einschläft, in die ,Nacht' des unaktualisierten Lied(text) es zurücksinkt, folgt bei Brentano das nächtlich klagende Ich dem Geliebten zumindest auf formal-klanglicher Ebene in den als vereinend erhofften (im geistlichen Tagelied schon angelegten) Tod nach. ${ }^{234}$

\subsubsection{Nachtlied, Tagelied und Lessings Ästhetik des Endens}

Zusammenfassend sowie rück- und ausblickend lässt sich zum Schluss der Auseinandersetzung mit Brentanos Gedicht festhalten: Die bestehende Forschung zu Der Spinnerin Nachtlied hat bereits auf dessen außergewöhnlich hohe Iterationsdichte, die Zirkularität der Verse und das dabei performativ mitdargestellte, endlose Drehen' des Spinnrads durch das (freilich bloß potenziell), endlose Drehen' des Liedes selbst hingewiesen. ${ }^{235}$ Wobei jedoch bereits Joachim Klein und Hans Joachim Schrimpf (vor allem gegen Richard Alewyn) angemerkt haben, dass sich zur zyklisch alternierenden Bewegung des Liedes gleichzeitig in zunehmendem Maße dagegen verlaufend eine lineare, zielgerichtete Bewegung von der Vergangenheit hin zur Gegenwart und zu einer Trost und Hoffnung (auf eine jenseitige Zukunft) bergenden Anrufung Gottes vollziehe. ${ }^{236}$ Das vorliegende Kapitel geht noch weiter und

233 Zum Stillestehen des Spinnrads vgl. Frühwald 1994, S. 279.

234 Wenn man davon ausgeht, dass der/die Geliebte nicht verstorben ist, sondern dass es sich einst um eine Trennung aus anderen Gründen gehandelt hat, müsste man schreiben: Das ,Ich' geht dem/der Geliebten zumindest auf formal-klanglicher Ebene in den als vereinend erhofften (im geistlichen Tagelied schon angelegten) Tod voraus.

235 Vgl. zusammenfassend Schrimpf 1976, S. 387; und Frühwald 1994, S. 272 und 279.

236 Vgl. Klein 1974; und Schrimpf 1976, S. 389-391 (siehe auch die folgende Fußnote). Beide argumentieren zu Recht gegen Alewyns Aussage: „Ja, es fehlt nicht viel, daß man es Zeile für Zeile rückwärts lesen könnte. Es wäre nur die Syntax, nicht der Sinn, was dem im Wege steht. Wenn das Gedicht also geradezu umkehrbar ist, dann ist das ein Zeichen dafür, daß zwischen seinem Anfang und seinem Ende nichts geschehen ist, was irgendeine Folge hätte und damit eine Reihenfolge vorschriebe. Daß das Gedicht umkehrbar ist, verrät, daß die Zeit in diesem Gedicht umkehrbar ist, und das besagt: Die Zeit steht still.“ 
ergänzt die Forschung dahingehend, dass es darauf hinweist, dass Der Spinnerin Nachtlied - im Gegensatz etwa zum Kater Murr ${ }^{237}$ oder Miss Sara Sampson im Grunde weniger eine potenziell endlose Iteration seiner selbst als vielmehr die Kehrseite ebendieses endlosen Drehens resp. Singens betont und für eine eigene Ästhetik des Ende( $n$ )s nutzt: das potenziell unendliche, immer wieder erfolgende Verstummen des Lied(text)es, das immer schon die Möglichkeitsbedingung eines jeden gesungenen oder gelesenen Textgewebes gewesen sein wird.

Der oben für Brentanos Gedicht gewählte Fokus auf die Variationen gegenüber der Gattung des mittelhochdeutschen Tageliedes ermöglicht so schließlich auch den Blick auf eine weitere Variation, die für eine Untersuchung von Operationen zur Ewigkeitsattribuierung von Schriftzeichen und deren historischer Kontextualisierung mindestens ebenso entscheidend ist: eine Variation von Lessings auf dem Mitleiden beruhender Ästhetik des Endens. Eine Variation, die hier zusätzlich mitbedingt ist durch den Umstand, dass es sich bei Der Spinnerin Nachtlied um ein Gedicht resp. ein verschriftlichtes Lied handelt und nicht um ein Trauerspiel resp. einen Trauerspieltext: Das singende "Ich“ des Gedichtes endet mit "weinen“, aber eben nur mit dem Wort „weinen“, nur zeichenhaft auf jene körperliche Gefühlsregung verweisend, die im Trauerspiel, ihrerseits metonymisch, für das Mitleid und das Mitleiden über das Ende des Trauerspiels hinaus steht. Das „Ich“ singt vom Weinen, es weint nicht. Und dies ist auch nicht anders möglich, denn wer weint (sofern nicht nur die Augen tränen), kann ebenso wenig gleichzeitig singen wie jemand, der schläft oder tot ist. Die Vereinigung im Weinen, wie sie Lessings Ästhetik des Mitleide(n)s zugrunde lag und wie sie der Reim "vereinen - weinen“ nahelegt, kann also in Der Spinnerin Nachtlied auf inhaltlicher Ebene allein schon deswegen nicht zustande kommen. ${ }^{238}$

Aber dies ist nur die eine Hälfte von Alewyns Argumentation, denn er fährt im Stile eines Paradoxons weiter: „Und so muss das Gedicht auch durchaus nicht da aufhören, wo es endet. Wie es an jeder anderen Stelle hätte aufhören können, so könnte es auch noch lange weitergehen. Es hat überhaupt kein Ende, so wenig wie es einen Anfang hat, und das besagt: Die Zeit verrinnt. Stillstand der Zeit oder Verrinnen der Zeit - es ist das gleiche“ (Alewyn 1974, S. 200 f.). Wenngleich diesem zweiten Teil und insbesondere der Schlussfolgerung des letzten Satzes in dieser Radikalität ebenso wenig zugestimmt werden kann wie dem ersten Teil, so tendiert gerade jene Schlussfolgerung doch in dieselbe Richtung des hier Vorgelegten, das von zwei Seiten der gleichen Medaille einer potenziell unendlichen Aktualisation handelt.

237 Als vielleicht schlagendstes Argument zieht Schrimpf herbei, dass das letzte Reimwort der a-Strophen, „waren“ (V. 20), nicht wie bei den ei-Strophen mit dem ersten identisch ist (da dieses "Jahren“ lautet und das einzige Reimwort ist, das nur einmal auftritt), wodurch eben gerade kein ,reiner' Doppelzyklus zustande kommt (vgl. Schrimpf 1976, S. 39o), wie es etwa, freilich über andere inhaltliche und formale Mittel, beim Kater Murr der Fall ist.

238 Dies wird denn auch singend beklagt, was jedoch wiederum ein Weinen verhindert usw. Das singende „Ich“ sähe sich so in einem endlosen Klagelied gefangen, wenn die 
Vermeintlich entgegen der von Lessing in seinem Brief an Nicolai postulierten verewigenden Funktion des Mitleide(n)s $s^{239}$ wird hier also auf inhaltlicher Ebene betont, dass die geliebte Person durch das mitleidende Weinen um sie und sich selbst gerade nicht in der irdischen Welt zu halten ist. Was scheinbar bleibt, ist bloß die Hoffnung auf eine Wiedervereinigung im Tode. Aber ausgerechnet die vermeintlich resignierte Antwort auf die Vorstellung eines Mitleid(en)s, das die Beweinten mittels eines Textgewebes für alle Zeiten ${ }^{240}$ bewahren könne, sucht das Verstummen des Textgewebes auf klanglich-formaler Ebene derart zu wenden, dass das Ich nicht bloß auf einen vereinenden Tod hoffen muss, sondern sich diese Hoffnung auf klanglicher Ebene bestätigt sieht. Oder anders formuliert: Nicht das Weinen mag hier die Geliebten dauerhaft zu „vereinen“, sondern ähnlich wie bei den mittelhochdeutschen Tageliedern das, was die beiden Wörter "weinen“ und „vereinen“ als ein Reimpaar vereint: ${ }^{241}$ die potenziell unendlich oft verstummende Aktualisation ihres Gedichtes. ${ }^{242}$

\section{$2.2 \quad$ Ermunterung}

Ermunterung. ${ }^{243}$

Echo des Himmels! heiliges Herz! warum,

Warum verstummst du unter den Lebenden,

Schläfst, freies! von den Götterlosen

[1-4] Ewig hinab in die Nacht verwiesen?

Möglichkeitsbedingung für ein solches potenziell endloses Fortsingen nicht zugleich das ebenso oft erfolgende Verstummen des Gesungenen wäre.

239 Siehe II.1.2.2; resp. vgl. Lessing, Werke, Bd. 3, S. 671.

240 Vgl. ebd.

241 Denn der erste Teil dieses resp. eines jeden Reimpaares muss, gestorben' resp. verstummt sein, damit dessen zweiter Teil überhaupt erklingen resp. gelesen werden kann und umgekehrt.

242 Bemerkenswert ist in diesem Zusammenhang auch die Nähe (gerade in Bezug auf die Textmetaphorik) zu Penelope in der Odyssee, die nachts das tagsüber gewobene Textum wieder auflöst, um sich der zukünftigen Vereinigung mit ihrem Gatten Odysseus zu versichern (vgl. Homer, Odyssee 2, 93-106; S. 20), wo es in der Rede des Freiers Antinoos u. a. heißt: „Einen großen Webstuhl stellte sie auf in den Hallen, / Webte ein feines und überaus großes Gewebe, uns sagend: / Jünglinge, ihr meine Freier, da starb der hehre Odysseus, / Wartet, wie sehr ihr zur Hochzeit drängt, bis daß ich vollende / Dieses Tuch $[\ldots]^{*} /$ Und des Tages webte sie nun an dem großen Gewebe, / Nachts jedoch löste sie's stets wieder auf im Scheine der Fackeln $[\ldots]$..”

243 Als Textgrundlage dient hier die unterschriebene Druckvorlage, wie sie in der Frankfurter Hölderlin-Ausgabe wiedergegeben wird: Hölderlin, Friedrich: Ermunterung, in: D. E. Sattler und Michael Knaupp (Hg.): Friedrich Hölderlin, Sämtliche Werke. Historischkritische Ausgabe, Bd. 5, Oden II. Frankfurt a. M. 1984, S. 768 f. 
Wacht denn, wie vormals, nimmer des Aethers Licht?

Und blüht die alte Mutter, die Erde nicht?

Und übt der Geist nicht da und dort, nicht

[5-8] Lächelnd die Liebe das Recht noch immer?

Nur du nicht mehr! doch mahnen die Himmlischen,

Und stillebildend weht, wie ein kahl Gefild,

Der Othem der Natur dich an, der

[9-12] Alleserheiternde, seelenvolle.

Beim Jova! ${ }^{244}$ bald, bald singen die Haine nicht

Des Lebens Lob allein, denn es ist die Zeit,

Daß aus der Menschen Munde sie, die

[13-16] Schönere Seele sich neuverkündet,

Dann liebender im Bunde mit Sterblichen

Das Element sich bildet, und dann erst reich,

Bei frommer Kinder Dank, der Erde

[17-20] Brust, die unendliche, sich entfaltet

Und unsre Tage wieder, wie Blumen, sind,

Wo sie, des Himmels Sonne sich ausgetheilt

Im stillen Wechsel sieht und wieder

[21-24] Froh in den Frohen das Licht sich findet,

Und er, der sprachlos waltet und unbekannt

Zukünftiges bereitet, der Gott, der Geist

Im Menschenwort, am schönen Tage

[25-28] Kommenden Jahren, wie einst, sich ausspricht.

\subsubsection{Zu Hans-Jost Freys Interpretation der Ode}

Hölderlins etwas weniger bekannte Ode Ermunterung (ca. 180o) ${ }^{245}$ hat im Kapitel „Textrevision bei Hölderlin“ von Hans-Jost Freys Monographie Der unendliche Text ${ }^{246}$ bereits eingehende Behandlung erfahren, die zudem eine ähnliche Fragestellung verfolgt wie das vorliegende Kapitel. Bei Hans-Jost Frey findet sich nach bestem Wissen des Verfassers denn auch die bislang einzige derart ausführliche Auseinandersetzung mit der Ode Ermunterung; kürzere Auseinandersetzungen legten Bernd Oei und, konzentriert auf die letzten vier Strophen und deren Syntax, Charlie Louth vor. ${ }^{247}$ Des Weiteren zeugt Christof Forderers Aufsatz davon, dass das Verhältnis von „Reden und Schweigen“ auch

\footnotetext{
244 Die unterschriebene Druckvorlage der Ode weist hier eine nachträgliche Änderung auf zuerst stand „O Hoffnung!“ anstelle von „Beim Jova!“; vgl. ebd.

245 Zur Entstehung vgl. Hölderlin, Ermunterung, S. 759 f.

246 Vgl. dazu auch das Kapitel zum Forschungsstand in der Einführung.

247 Vgl. Oei 2009, S. 111-113; und Louth 1998, S. 169-176.
} 
in anderen Gedichten Hölderlins eine zentrale Rolle einnimmt, ${ }^{248}$ wenngleich er Ermunterung bedauerlicherweise nur mit einem einzigen Satz erwähnt. ${ }^{249}$

Obschon das vorliegende Kapitel Freys Interpretation in vielem äußerst schätzt, unterstützt und ergänzt, geht es hinsichtlich des Paradigmas des Verstummens und der damit verbundenden Performativität des Gedichtes einen anderen Weg. Weil dies sowohl den Kern der hier vorgelegten Lesart der Ode als auch derjenigen Freys betrifft, sei zur besseren Leserorientierung dieser entscheidende Unterschied gleich zu Beginn transparent gemacht: In beiden Interpretationen sind die Schlussstrophe und das darin formulierte Paradoxon zwischen „sprachlos waltet“ (V. 25) und „sich ausspricht“ (V. 28), auf das die ganze Ode inhaltlich und syntaktisch zusteuert, von zentraler Bedeutung. ${ }^{250}$ Dieses Paradoxon der Schlussstrophe sucht Frey sodann durch den Vergleich mit früheren Textstufen zu verstehen. In der ersten Reinschrift nämlich endet der letzte Vers entgegen dem ersten Entwurf und allen weiteren Abschriften nicht mit „sich ausspricht“, sondern lautet: „Wieder mit Nahmen, wie einst, sich nennet [Hervorhebung MG].“251 Frey legt den inhaltlichen Unterschied zwischen "mit Nahmen [...] sich nennet“ und „sich ausspricht" folgendermaßen dar:

\begin{abstract}
Wenn der sprachlos waltende Geist im Menschenwort mit Namen genannt wird, so ist er dadurch zwar gefasst, aber als im Namen stillgelegter waltet er nicht in der Rede, sondern ist deren Gegenstand. Walten könnte er nur als sich aussprechender. Aber in dem Maße, als dieses Sichaussprechen an das Menschenwort gebunden ist, muß es als ein Sichnennen geschehen und verfällt so immer wieder der Verfestigung im Namen. Wenn der sprachlos waltende Geist sich im Menschenwort aussprechen soll, ohne genannt zu werden, so muß er auf andere Weise als im Sichnennen darin gegenwärtig sein. In der Sprache selbst muß das Sprachlose walten. Sobald es genannt wird, wie in der letzten Strophe von Ermunterung, ist es schon wieder entglitten. ${ }^{252}$
\end{abstract}

Bei aller Scharfsinnigkeit dieser Überlegungen Freys kann hier jedoch einer Gleichsetzung von "sprachlos“ im ersten Vers der letzten Strophe mit ,namenlos', das auch keine der Textstufen rechtfertigen würde (in allen steht „sprachlos"), 253 nicht zugestimmt werden. „[E]r, der sprachlos waltet“ (V. 25) wird in Freys Lesart zu ,Er, der namenlos/ohne zu benennen waltet'. Diese unzulässige

\footnotetext{
248 Forderer 2000.

249 Vgl. ebd., S. 542.

250 Frey 1990, S. $78 \mathrm{f}$.

251 Hölderlin, Ermunterung, S. 766.

252 Frey 1990, S. 8o.

253 Vgl. Hölderlin, Ermunterung, S. 764-767, 769.
} 
Anpassung des Odentextes bildet fortan den Kern von Freys Argumentation und findet sich schon in der soeben zitierten Passage, die die Sprache offensichtlich vom "Menschenwort" trennt und in der impliziert wird, dass das „Menschenwort" letztendlich immer nur nennend sein könne. Aber weshalb soll das „Menschenwort" lediglich (be-)nennen können?254 Was ist das „Menschenwort", wenn nicht Sprache? Und da das „Menschenwort" offensichtlich aus Sprache besteht, weshalb soll dann das "Sprachlose“, das nach Frey „in der Sprache selbst“ walten muss, nicht auch im Menschenwort walten? Bemerkenswerterweise scheint sich Frey hier bereits wieder in dem in der Schlussstrophe formulierten Paradoxon zu verstricken, das er eigentlich aufzulösen gedenkt. Dennoch führt ihn dies zu einer sehr aufschlussreichen Analyse der Echostruktur der ersten Verse von Hölderlins Ode:

Das Wort Echo verstummt in dem Maße, als es genannt wird. Im Wort Echo geschieht kein Echo. Dieses geht im Reden darüber verloren. Aber nur insofern, als dieses Reden ein Nennen ist. Deshalb bleibt es möglich, daß gerade die Verse, die das Verstummen des Echos sagen, im Widerspruch zu ihrer Aussage echohaft reden. Der Stabreim Himmels / heiliges / Herz, die Wiederholung des Wortes warum und die Assonanzreihe Warum / verstummst / du / unter sind Echowirkungen, die geschehen, aber nicht genannt werden. So sind hier von Anfang an der Verlust des Genannten im Genanntwerden und sein namenloses [!] Walten im sprachlichen Vollzug in einem Wortlaut vereinigt. Das Gedicht spricht einerseits so, daß es nennend vom sprachlos Waltenden geschieden und damit in der Situation ist, die es thematisiert, anderseits und zugleich aber so, daß ungesagt in ihm geschieht, wozu es ermuntert. Was es herbeiwünscht, und wovon es sich nennend entfernt, hat es durch seine Redeweise schon erreicht. Es verwirklicht, was es als die bevorstehende Möglichkeit seiner selbst nennt. ${ }^{255}$

Mit anderen Worten: Hölderlins Ermunterung verweist nicht nur auf ein Echo, sondern die Bestandteile der Sequenz, die auf das Wort „Echo“ folgt, sind so ausgewählt, dass deren Klang performativ auch ein Echo herstellt. ${ }^{256}$ Auch ist Frey darin zuzustimmen, dass das Gedicht nicht nur performativ ist resp. genauer: performative Textstellen aufweist, sondern die eigene Performativität zugleich auch autoreflexiv und poetologisch verhandelt (siehe dazu die folgenden Unterkapitel). Allein dort, wo Frey jene Echostruktur auf die

254 Frey erbringt mit seiner Analyse der Echostruktur des Gedichtes ja selbst den Gegenbeweis (siehe das folgende Zitat).

255 Frey 1990, S. 81; das Ausrufezeichen wurde eingefügt durch MG.

256 Zur Verwendung des Begriffes Performativität (resp. perfomativ) in der vorliegenden Arbeit vgl. den einleitenden Teil des Kapitels III, der diese Verse Hölderlins als Beispiel verwendet. 
Schlussstrophe bezieht, ist ihm erneut zu widersprechen, und zwar in zwei Punkten:

1. Wieder liegt Freys Argumentation die unhaltbare Gleichsetzung von „sprachlos" mit dem von ihm konstruierten Adjektiv ,namenlos‘ zugrunde.

2. Auf den ersten Blick scheint sich die später von Hölderlin verworfene Formulierung "mit Nahmen sich nennet" in der letzten Strophe der ersten Reinschrift als Bezeichnung für den bloß verweisenden und nicht performativen Gebrauch von Sprache vielleicht anzubieten. Performativer Sprachgebrauch (nach Austin im engeren Sinne, vgl. Kapitel III) funktioniert aber gerade dadurch, dass im Zuge des Sprechens/Lesens das hergestellt wird, worauf sprechend/lesend verwiesen wird. ${ }^{257}$ Und auch wenn das Wort „Echo“ im Gegensatz zu performativen Verben selbst nicht performativ ist, so sind es die ihm folgenden Klangfiguren nur im Verbund mit der Benennung, die jenes Wort „Echo" vornimmt. Die verweisende resp. konstative Operation von Sprachzeichen ist zwingender Bestandteil von performativem Sprachgebrauch und nicht dessen Verhinderung.

Zudem stellt Frey sehr spät (mehr oder weniger) explizit klar, als was er den ,sprachlos waltenden Geist/Gott' interpretiert:
Was im Aufschub des Nennens ungenannt bleibt, ist die Sprache. Mit der Sprache ist nicht etwas Beliebiges genannt, sondern das, als was das Nennen sich vollzieht. Das Wort Sprache nennt, als was es geschieht. Aber indem die Sprache sich mit Namen nennt, verfestigt sich das Geschehen des Nennens zum Namen Sprache, in welchem das Sprechen erstarrt ist. Deshalb verschiebt das Gedicht die Nennung der Sprache, die es ist, und nennt schließlich das Sichnennen des sprachlos - weil ungenannt namenlos Waltenden, als das es sich versteht, als etwas Zukünftiges, ihm immer Bevorstehendes. Sprache als sich nennende steht sich immer bevor. Zwar geschieht das Nennen der Sprache als Sprache, aber im Nennen ist sie noch nicht genannt, und im Namen hat sie schon aufgehört zu geschehen. ${ }^{258}$

Hat Frey in seinen oben zitierten Überlegungen zur Echostruktur mit ,sprachlos waltenden Geist/Gott' noch die Performativität des Gedichtes gemeint, so tendiert er hier zu einer Interpretation des sprachlos Waltenden' als des Prozesses, in dem Sprache (z. B. als Text, der freilich immer an eine Lektüre gebunden wäre) dabei ist, implizit über sich selbst zu sprechen. Oder anders formuliert: Zuerst deutet Frey das sprachlos Waltende' als Performativität, später als Poetologie, ohne diesen Wechsel in seiner Argumentation

257 Betreffend ein lautes oder leises Lesen vgl. das Ende des vorliegenden Unterkapitels.

258 Frey 199o, S. 86 f. 
transparent zu machen. ${ }^{259}$ Dass sich dieser Wechsel in Freys Argumentation vollzieht, erstaunt aber letztlich nicht, denn in der Tat sind Performativität und Poetologie in der Ermunterung eng miteinander verknüpft, und zwar auch das hat Frey gestreift, ohne es aber in diese Relation zu setzen - über das Verstummen der Ode.

All diese, Hans-Jost Frey zum Teil widersprechenden, ihn aber hauptsächlich ergänzenden Beobachtungen lassen sich in einer Leitthese zusammenführen, die der im Folgenden dargelegten Auseinandersetzung mit der Ode vorangestellt sei:

Die Performativität von Hölderlins Ermunterung konstituiert sich über das Verstummen der Ode im Zuge ihrer Lektüre bei gleichzeitigem explizitem Verweis auf ein echohaftes Verstummen („verstummst“, V. 2). Dieser Verweis wiederum ist Ausgangslage dafür, dass die Ode ihr eigenes Verstummen poetologisch thematisiert. Dies, tut' sie als ein an die Lektüre gebundenes Zeichengebilde unter besonderer Berücksichtigung der Iteration resp. Iterabilität ${ }^{260}$ sowohl einzelner ihrer Bestandteile (wie etwa im Falle der Geminatio „warum, / Warum") als auch des gesamten Odentextes.

Diese Leitthese mag von Beginn an betonen, dass die Ode Ermunterung wie auch jedes Sprachzeichen - nur "sich ausspricht“, wenn ein Leser ihr seine Stimme leiht. Als Grundlage des folgenden Unterkapitels dienen denn auch, anders als bei Frey, nicht die unterschiedlichen Textstufen, sondern der Text der unterschriebenen Druckvorlage im Zuge seiner Lektüre. (Im Folgenden steht dabei explizit nicht der Unterschied zwischen mündlicher Rede resp. lautem Lesen oder Singen und einem leisen Lesen zur Diskussion. Bei der stillen Lektüre der ersten Verse von Hölderlins Ermunterung etwa vollzöge sich streng genommen kein Echo, da ja stumm gelesen wird, sondern nur ein Echoeffekt. Dieser Unterschied ist für unten stehende Ausführungen aber insofern irrelevant, als dass etwa im Falle von Klangfiguren auch bei stiller Lektüre von einem imaginierten Klang ausgegangen werden kann, während in Bezug auf das „Echo“ hier zusätzlich der Fokus stark auf der raumzeitlichen Deixis liegt.)

\footnotetext{
259 Außerdem konzentriert sich Frey die letzte Strophe betreffend allein auf die Unterschiede zwischen den Textstufen, während er ihre Gemeinsamkeiten wohl zu stark außer Acht lässt: Der Einschub „wie einst" ist allen Textstufen gemeinsam und wird ausgerechnet in der von Frey so stark einbezogenen ersten Reinschrift zusätzlich durch das erste Wort des letzten Verses, „Wieder“, ergänzt. Sowohl „wie einst“ als auch das „Wieder“ betonen an zentraler Stelle das Paradigma der Wiederholung, das, wie zu zeigen ist, nicht nur die erste Strophe mit ihrer Echostruktur, sondern die ganze Ode durchzieht. Vgl. dazu auch Oei 2009, S. 112.

26o Vgl. zum Begriff Iterabilität Kapitel 1.1 des Schlussteils.
} 
Mit Blick auf die Gliederung der vorliegenden Arbeit zeigt die soeben formulierte Leitthese zudem, dass Hölderlins Ode sich auch als Beispieltext zu den Grundoperationen Autonome Performative Produktion oder Reflexivität behandeln ließe. Da aber sowohl ihre Performativität als auch ihre poetologisch-autoreflexive Ebene sich in ihrem potenziell unendlich oft wiedererfolgenden Verstummen gründen, ${ }^{261}$ ist das vorliegende Kapitel der angemessenste Ort, die Ode zu behandeln. Oder mit anderen Worten: In Hölderlins Ermunterung findet sich besonders exemplarisch die Unteroperation Unendliches Verstummen, die in dieser Ode gegenüber anderen, ebenfalls prominent auftretenden Operationen zur Ewigkeitsattribuierung von Schriftzeichen eine dominante Rolle einnimmt. Die Ode wird hier aber auch bewusst als letztes Textbeispiel zur Grundoperation Unendliche Aktualisation angeführt, da sie durchaus bereits vorauszuweisen vermag auf die Kapitel zu den beiden anderen Grundoperationen.

2.2 .2

Strophen eins bis drei: verstummendes „Echo“ und antithetische Zeitstruktur

Die sieben Strophen umfassende Ode Ermunterung lässt sich grob in zwei Teile gliedern: in einen ersten Teil, der die Strophen eins bis drei umfasst, und in einen zweiten, gebildet aus den Strophen fünf bis sieben. In der Mittelstrophe vier (und ein wenig schon in Strophe drei) vollzieht sich dabei der Übergang vom ersten zum zweiten Teil. Jedem dieser beiden Teile sei hier ein Unterkapitel gewidmet, dem jeweils zur besseren Orientierung eine These vorangestellt sei, die den jeweiligen Teil ein erstes Mal umreißt. Für den ersten Teil ist dies die folgende:

Die Strophen eins bis drei sind geprägt durch das Einbringen des Echos (auf semantischer und klanglicher Ebene) und den Aufbau zweier antithetischer Strukturen ,jetzt'vs. ,einst' und ,himmlisch-göttlich'vs. ,irdisch-menschlich/ sterblich'vor dem Hintergrund einer auf inhaltlicher Ebene als "ewig“ (V. 4) bezeichneten Bewegung.

Echo des Himmels! heiliges Herz! warum,

Warum verstummst du unter den Lebenden,

Schläfst, freies! von den Götterlosen

Ewig hinab in die Nacht verwiesen? [V. 1-4]

261 Bereits Bernd Oei hat festgehalten: „Das ,verstummst der ersten Strophe ist das Leitmotiv, beginnend mit dem ersten Wort ,Echo' (das die Dichter auf Göttliches geben sollen), denn um die Sprachlosigkeit des Göttlichen geht es primär“" (ders. 2009, S. 111). Wenngleich ihm hier im Falle des „Leitmotivs“ grundsätzlich recht zu geben ist, werden die im Folgenden daraus entwickelten Thesen zu anderen, differenzierteren Schlussfolgerungen führen, als sie Oei hier knapp formuliert. 
Wacht denn, wie vormals, nimmer des Aethers Licht?

Und blüht die alte Mutter, die Erde nicht?

Und übt der Geist nicht da und dort, nicht

Lächelnd die Liebe das Recht noch immer? [V. 5-8]

Nur du nicht mehr! doch mahnen die Himmlischen,

Und stillebildend weht, wie ein kahl Gefild,

Der Othem der Natur dich an, der

Alleserheiternde, seelenvolle. [V. 9-12]

Wie bereits von Frey festgestellt und oben zitiert, verweisen die ersten beiden Verse der ersten Strophe nicht nur auf semantischer Ebene stellvertretend auf ein Echo, sondern stellen auf klanglicher Ebene im Zuge einer jeden Lektüre über zahlreiche Wiederholungsfiguren ${ }^{262}$ auch performativ ein Echo resp. einen Echoeffekt her. ${ }^{263}$ Zusätzlich unterstreicht die in der ersten Strophe enthaltene dreifache Anrede („Echo des Himmels!“; „heiliges Herz!“; „freies!“) diese performative Echostruktur auf grammatikalisch-syntaktischer Ebene. Und wie ebenfalls oben genannt, bietet die Performativität der ersten Verse die Ausgangslage dafür, das "Echo“ auch als eine poetologisch-autoreflexive Metapher für das Verstummen der Ode selbst und von aktualisierten Sprachzeichen im Allgemeinem zu lesen. Denn das „Echo“, von dem die Rede ist, ist aufgrund der in den ersten Versen entfalteten Performativität auch das Echo der im Zuge ihrer Lektüre wieder verstummenden Ode selbst. ${ }^{264}$ Eine solche poetologische Metaphorik wird in der ersten und zweiten Strophe auf inhaltlicher und formaler Ebene weiter unterstützt durch folgende Elemente:

- „Herz“ stellt ebenfalls ein Similaritätsverhältnis zum Text im Zuge seiner Lektüre her, und zwar durch folgende Lesarten:

- der Rhythmus des Herzschlages als Metapher für den Rhythmus des/ eines Gedichtes

262 Darauf, dass die Ode zudem als Ganze einige ihrer Ausdrücke wiederholt, hat Oei aufzählend hingewiesen; vgl. ders. 2009, S. 112; sorgfältiger jedoch Frey 199o, S. 82. Charlie Louth betont zudem, dass durch die gestreckte, wohl über das (grammatikalisch) Mögliche hinausreichende Syntax der letzten Strophen höchste Konzentration vom Leser gefordert werde (ders. 1998, S. 172) - anders formuliert könnte man auch sagen: Die in die Länge gezogene Syntax und die damit notwendige Erinnerungsanforderung an soeben Gelesenes machen dem Leser die Flüchtigkeit der eigenen Lektüre und der immer sogleich wieder verstummenden Ode bewusst.

263 Dies geht so weit, als dass die Echoeffekte der ersten Verse auch dann noch ein Echo der einstigen Bedeutung des ersten Wortes Echo wären, wenn sich diese Bedeutung dereinst gewandelt haben wird (vgl. dazu auch den Beginn von Kapitel III).

264 Zur kulturgeschichtlichen Aufladung des Wortes Echo vgl. u. a. Menke 2003; sowie insbesondere Menke 200o; weiterhin Börnchen 2006, S. 285-316; Gehring 2006 (zum "Problem der Wiederholungsstimme“, vor allem auch in Bezug auf den Mythos bei Ovid); und Weigel 2006, S. 28-32. 
- die aufeinanderfolgenden Herzschläge als lebenspendendes Echo

- Die Deixis des Pronomens „du“ lässt sich auch als eine direkte Anrede an das Gedicht selbst lesen ...

- ... dabei wird über das Verb „verstummst“ explizit nach den Gründen für dessen Verstummen „unter den Lebenden“ gefragt.

- „Lebenden“ wiederum bildet - in Verknüpfung mit dem Leben spendenden Organ „Herz" - ein Minimalpaar mit „Lesenden“, was die Frage, welche die hier verfolgte poetologische Lesart aufwirft, wie folgt auf den Punkt bringt: „Echo des Himmels! heiliges Herz! warum, / Warum verstummst du unter den Le[s]enden [?]“

- Verse vier und fünf entfalten mit der dritten Anrufung "schläfst!" und „Nacht" das Wortfeld von Nacht/Schlaf/Einschlafen ...

- ... das im ersten Vers der zweiten Strophe durch "Wacht“ und „Licht“ implizit mit Tag, wachen, aufwecken und aufwachen ergänzt wird - einem Wortfeld also, das in seiner poetologischen Metaphorik schon in Brentanos Der Spinnerin Nachtlied zu beobachten war resp. von der Gattung der Tagelieder her bekannt ist und das nun auch hier kaum zufällig wieder begegnet.

- Das Verb „verwiesen“ wird ergänzt mit dem direktionalen Lokaladverb „hinab“ (a) und dem Temporaladverb „ewig“ (b).

- a) entspricht zugleich der Richtung des lesenden Augen-„Licht“-es, das den Versen der Ode „hinab“-folgt.

- b) signalisiert, dass es sich bei jenem Verweisen entweder um einen Prozess handelt, der nun für alle Zeiten abgeschlossen ist, oder aber um einen Prozess, der sich während seines Vollzugs einem ewig gültigen Gesetz folgend unendlich weiter "hinab“ bewegt resp. bewegt haben wird (es wird unten darauf zurückgekommen). ${ }^{265}$ Letzteres lässt sich u. a. zusammen mit der poetologischen Metaphorik von „Nacht“ zum einen als semiologischer Kommentar zur Flüchtigkeit der Aktualisation von (Sprach-)Zeichen lesen, zum anderen passt diese Lesart auch besser zum ermunternden Ton der Ode und zur damit verbundenen antithetischen Struktur ,jetzt - einst', die auf eine Operation des Erneuerns resp. Wiederholens abzielt und dadurch einem für alle Zeiten „ewig“ abgeschlossenen Prozess widerspricht.

Als Zwischenfazit lässt sich somit festhalten: Vor allem die erste Strophe der Ermunterung wirft eine der grundsätzlichsten Fragen zu Sprachzeichen im

265 Liest man es nicht als Temporaladverb, so wäre es zudem gewissermaßen ein Attribut zu „Echo“, das ,als ein Ewiges" „hinab in die Nacht verwiesen“ würde. 
Allgemeinen auf: Weshalb verstummt jedes Sprachzeichen, sobald es ausgesprochen resp. gelesen wurde? Und implizit damit verknüpft: Gibt es eine Möglichkeit, so zu sprechen, zu lesen, zu schreiben, dass die Sprachzeichen nicht verstummen, nicht wie ein Echo verhallen, nicht wieder ,einschlafen', sondern anstatt „Ewig hinab in die Nacht verwiesen“, ewig wach resp. klingend dem Tag angehören würden?

Im Anschluss an dieses Zwischenfazit ist jedoch noch einmal zum letzten oben aufgeführten Punkt zurückzukehren: Dass die Phrase „Ewig hinab in die Nacht verwiesen" einen ewig-endgültigen Zustand beschreibt, der das Resultat eines vergangenen Verweisens ist, dagegen spricht vor allem auch die zweite Strophe. Diese betont zwar in drei resp. vier Fragen einen einstigen, vergangenen Zustand (,wie vormals, nimmer [...] nicht; alte; noch immer [...] nicht"), das zweimal nachgestellte "nicht“ sowie "noch immer" deuten aber darauf hin, dass es sich allesamt um rhetorische Fragen handelt. Einer Lesart der ersten Strophe, sie handle von einer für alle Zeiten abgeschlossenen Bewegung „hinab“, wird in der zweiten Strophe also ein seit unbestimmter Zeit an- und in der Gegenwart fortdauernder Prozess entgegengehalten. Das „Nur du nicht mehr!" des ersten Verses der dritten Strophe bestätigt die Fragen in Strophe zwei als rhetorische, scheint aber zugleich nochmals zu betonen, dass sich das angesprochene „Echo“ „nicht mehr“ so verhalte wie früher. Letzteres nimmt aber der zweite Teil des ersten Verses der dritten Strophe mit dem adversativen „Doch“ sogleich wieder zurück und schlägt einen ermunterndprophetischen Ton an, der zumindest eine Wieder-in-Gang-Setzung jenes Verhaltens ankündigt. Eines Verhaltens (oder umfassender: eines über die Ode hinausreichenden Zustandes), das gemäß der hier vertretenen Lesart nichts Geringeres wäre als eine nicht verstummende, „ewig“ anhaltende Aktualisation der Ode und von (Schrift-)Zeichen im Allgemeinen.

$\mathrm{Zu}$ einer solchen antithetischen Gegenüberstellung von verstummendem "Echo" einerseits und einer „ewig" andauernden Aktualisation von Zeichen, die nie verstummt, andererseits passt auch die zweite große Antithese der Ode: In den ersten drei Strophen bilden das Attribut "des Himmels“ und das Adjektiv "heiliges“, die „Echo“ und „Herz“ ergänzen, mit „ewig“, „Aethers“, („Mutter“), „Geist“, „Himmlischen“, („Natur“) und „seelenvolle“ ein Paradigma des Himmlisch/Göttlich-Unsterblichen. Dieses wiederum ist dem Paradigma des Irdischen/Menschlich-Sterblichen gegenübergestellt, das Wörter wie "Lebenden“ und "Götterlosen“ versammelt. Diese Gegenüberstellung von Göttlich-Unsterblichem und Menschlich-Sterblichem durchzieht das gesamte Gedicht und ist im zweiten Teil der Ode gar noch stärker betont (siehe das folgende Unterkapitel). Frey schreibt denn auch: „Ermunterung handelt von 
einem Reden, worin die Entsprechung des Himmlischen und des Menschlichen sich herstellen würde. ${ }^{\text {“266 }}$ Diese These sei hier wie folgt geschärft:

Ermunterung handelt u. a. von derverstummenden Aktualisation von Sprachresp. Schriftzeichen, die einer, göttlich-himmlischen; nicht verstummenden und damit "ewig“ andauernden Aktualisation gegenübergestellt wird. Dabei wird impliziert, dass erstere letzterer einst entsprochen habe, und prophezeit, dass dies zukünftig wieder der Fall sein werde. Gleichzeitig wird dabei versucht, auf klanglich-performativer und poetologisch-autoreflexiver Ebene jene Entsprechung von sterblicher und göttlicher Aktualisation bereits im Zuge der Lektüre der Ode selbst wieder zu verwirklichen.

Es ist somit kein Zufall, dass gerade auch der zweite Teil des ersten Verses der dritten Strophe, der mit seinem „doch“ die Kontinuität betont und die in Strophe vier beginnende, auf die Zukunft gerichtete Bewegung des Gedichtes anbahnt, in dem metonymischen Verweis auf Göttliches („Himmlischen“) jene Entsprechung in der Gegenwart der Lektüre zu erreichen sucht: Dadurch, dass „Himmlischen“ als Figura etymologica auf "Himmels“ im ersten Vers der Ode anklingt, bildet es auf klanglicher Ebene wortwörtlich ein „Echo des [Wortes] Himmels“. Die „Himmlischen“ werden dadurch auch zu Metaphern für die verstummenden Klangfiguren des Gedichtes, die gerade durch dieses Verstummen ihre Performativität entfalten und damit von bloß verweisenden Zeichengebilden in die Nähe von himmlisch-ewigen Zeichen gerückt werden - und gerade dadurch "mahnen“ (V. 9) sie. Oder anders formuliert: Die Performativität des Wortes ,Himmlischen' soll offenbar die Glaubwürdigkeit und Berechtigung der „Himmlischen“, zu "mahnen“, dass ewig-göttliche Rede in menschlicher Lektüre (dereinst) wieder möglich sei, untermauern resp. vielleicht sogar überhaupt erst herstellen. Dass aber auch hier das Paradoxon einer an sterbliche Leser gebundenen Unendlichen Aktualisation zugleich mitreflektiert wird, zeigen die restlichen drei Verse der dritten Strophe, wo der "Othem der Natur" in seiner Similarität und Metonymie zum aktualisierenden Atem des Lesers als alleserheiternd ${ }^{267}$ und seelenvoll, aber zugleich eben auch als "stillebildend“ bezeichnet ist. ${ }^{268}$

266 Frey 1990, S. 78.

267 Womit auch auf das Paradigma des (Augen-)Lichts angespielt wird.

268 ,Stille` und ,Göttersprache werden damit hier anders interpretiert, als es Christof Forderer in seinem Aufsatz „Das Singen der ,Sprachen des Himmels'. Überlegungen zu Reden und Schweigen in Hölderlins Gedichten“ tut (vgl. ders. 2000, S. 539 und 541), nämlich hinsichtlich ihrer poetologischen Metaphorik. Einzig Forderers Schlusssatz weist in die Richtung des vorliegenden Kapitels, wenn er (der die Ode Ermunterung selbst nur in einem einzigen Satz erwähnt; ebd., S. 542) schreibt, Reden sei u. a. nur dann möglich, wenn es „dem 
2.2.3 Strophen vier bis sieben: Versuch einer selbsterfüllenden Prophezeiung

In der vierten Strophe, also in der Mitte der sieben Strophen umfassenden Ode, vollzieht sich der Übergang vom ersten Teil derselben zum zweiten. Der erste Teil der Ode wurde zu Beginn von Kapitel 2.2.2 wie folgt umrissen:

Die Strophen eins bis drei sind geprägt durch das Einbringen des Echos (auf semantischer und klanglicher Ebene) und den Aufbau zweier antithetischer Strukturen ,jetzt'vs. ,einst' und ,himmlisch-göttlich'vs. ,irdisch-menschlich/ sterblich“ vor dem Hintergrund einer auf inhaltlicher Ebene als „ewig“ (V. 4) bezeichneten Bewegung.

Dasselbe lässt sich für den zweiten Teil wie folgt tun:

Die Strophen fünf bis sieben sind strukturiert durch einen einzigen Konditionalsatz, dessen erste Hälfte implizit in der vierten Strophe beginnt und dessen zweite Hälfte mit dem „Dann“ der fünften Strophe einsetzt. Damit spricht der zweite Teil der Ode im Gegensatz zum ersten von zukünftigen Geschehnissen und Zuständen, die offenbar mit einem „Bunde“ von „Sterblichen“ mit den ,Göttlich/ Himmlisch-Unsterblichen' einhergehen.

Diese beiden Umrisse müssen jedoch ausgehend von der These am Ende des vorangegangenen Unterkapitels 2.2.2 um folgenden Zusatz ergänzt werden:

Beide Teile der Ode sprechen von einem vergangenen resp. zukünftigen Zustande in einem Modus, der implizit diesen Zustand in der Gegenwart der Lektüre der Ode zu verwirklichen sucht.

Vor diesem Hintergrund sei nun zunächst die vierte Strophe in den Blick genommen:

Beim Jova! bald, bald singen die Haine nicht

Des Lebens Lob allein, denn es ist die Zeit,

Daß aus der Menschen Munde sie, die

Schönere Seele sich neuverkündet, [V. 13-16]

Sie ist diejenige Strophe, die neben der ersten und sechsten aufgrund vor allem der „bald, bald“-Geminatio und der l-, m- und s-Alliterationen die stärkste und offensichtlichste Echostruktur aufweist und damit jenen Echoeffekt ebenfalls im Zuge der Lektüre herstellt. Mehr noch: Der erste Vers der vierten Strophe bildet in seiner Analogie (über die Anrufung und Geminatio) zum Beginn der ersten Strophe auch ein strukturelles Echo der ersten Strophe als solche. In der vierten Strophe findet sich innerhalb der Ode mit „neuverkündet“ hingegen auch das erste Wort, das explizit dem Wortfeld des Neuen resp.

Himmel gegenüber rechtzeitig abbricht und mit Wendungen wie ,Vieles wäre / Zu sagen davon' das Schweigen in seinen Gestus aufnimmt“ (ebd., S. 546). 
Wiederhergestellten entstammt, wobei es zugleich antithetisch auf „alte“ (V. 6), das Adjektiv zu „Mutter", verweist. Des Weiteren ist, wenngleich auf den ersten Blick weniger offensichtlich, „Haine“ ebenfalls antithetisch „kahl Gefild" (V. 10) gegenübergestellt. Es ließe sich sogar sagen, aus „kahl Gefild“ sei auf einer abstrakten, wortwörtlichen Ebene der Ode selbst bereits (wieder) ein ,Hain' geworden. ${ }^{269}$ Ähnliches gilt in grammatikalisch-syntaktischer Hinsicht mit Bezug auf die Konjunktion „denn“ (V. 14), die - es wurde bereits angedeutet - zugleich ein ,wenn“ ist, das den Konditionalsatz mit „Dann“(V. 17) bildet. Zudem muss das „ist“ (V. 14) nicht zwingend als futurisches Präsens gelesen, sondern kann auch schlicht als Präsens aufgefasst werden, womit auch das „denn“ auf die Gegenwart und nicht auf die Zukunft zu beziehen wäre. Dies alles führt zu einer weiteren, Obenstehendes ergänzenden Beobachtung:

Der Versuch, die in den Strophen fünf bis sieben angekündigte Zukunft bereits in der Gegenwart der Lektüre der Ode herzustellen, erstreckt sich nicht nur auf die klangliche, sondern auch auf die semantische und grammatikalisch-syntaktische Ebene der Ode.

Damit geht einher, dass es in einem abstrakten Sinne tatsächlich bereits "die Zeit" (V. 14) ist, in der nicht nur „die Schönere Seele“ (V. 16), sondern eben auch die Ode selbst (potenziell unendlich oft) „sich neuverkündet“, und zwar wortwörtlich, in dem Moment, in dem sie gelesen wird, „aus der Menschen Munde"(V. 15).

Über all dies wird der Eindruck vermittelt, als ob die in den Strophen eins bis drei erfolgte „Ermunterung“ an das „Echo des Himmels“ erste, kleine Erfolge zeige, was das Verschwinden der direkten Du-Anrede und der Wechsel hin zu einem mehr erzählenden, auf die dritte Person Singular gerichteten Stil unterstreichen. Dieser findet sich auch im Ausruf „Beim Jova!", der die vierte Strophe eröffnet und sich wohl an den jüdisch-christlichen Gott Jehova richtet, ${ }^{270}$ in dem aber auch der römische Gott Iovis/Jupiter (echohaft) anklingt.

269 Und zwar durch den „Othem der Natur“ (V. 11) resp. durch „der Menschen Munde“, was der Verfasser beides als poetologische Metaphern resp. Metonymien für das Lesen von Schriftzeichen interpretiert. Das „kahl Gefild“ stünde demnach auch als Metapher für den unaktualisierten, leblosen Text, während die Haine auf die durch das Lesen zum Leben erweckten Texte verweisen.

270 Im Zusammenhang mit Hölderlins Überlegungen zu Hesperiern und alten Griechen ist es durchaus denkbar, dass sogar eine Verschmelzung der beiden Namen hier mit hineinspielt. Klopstock verwendet den Namen Jova (wohl aus metrischen Gründen neben „Jehovah“) auch für den jüdisch-christlichen Gott: „Die Hand kam hervor einst, und Schrift stand: Dich wog Jova! / Und es fand dich, der den Weltkreis, wie er will, herrscht, zu leicht, König! / Daß des Gerichts Tag es vernähme, wie leicht Der sey, / Welcher an ihm sündigte!, gebot es von des Throns Höh’ Gott“ (Klopstock, Messias, S. 294 resp. Gesang 


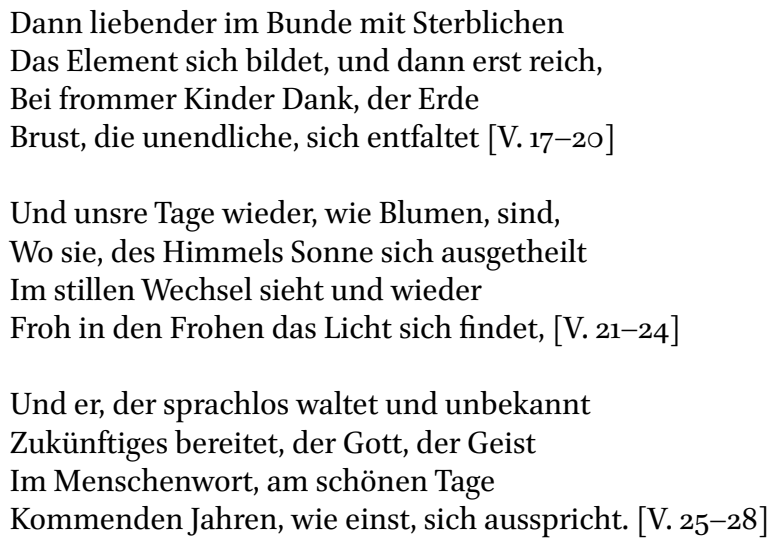

In den Strophen fünf bis sieben lässt sich vieles, wenngleich zum Teil akzentuierter, beobachten, was bereits zu den Strophen eins bis drei festgestellt wurde, und erneut sind zahlreiche Bezüge zu den vorangegangenen Strophen auszumachen: „im Bunde mit Sterblichen“ (V. 17) bezieht sich sowohl inhaltlich als auch über das Minimalpaar "Munde - Bunde“ auf "aus der Menschen Munde“ (V. 5). Dies ist eine weitere Bestätigung dafür, einerseits die reflexiven Verben der Strophen vier bis sieben, „sich neuverkündet“, „sich bildet“, „sich entfaltet“, „sich ausgetheilt“, „das Licht sich findet“, „sich ausspricht“, und andererseits die Subjekte derselben, „das Element“, „der Erde Brust“, „des Himmels Sonne“, „das Licht“, „der Gott, der Geist“, auch poetologisch zu lesen:271 Letztere als unterschiedliche Metaphern für die Ode (und Text im Allgemeinen) im Zustand ihres Gelesenwerdens, Erstere als Metaphern für die Aktion des Lesens/Gelesenwerdens, wobei Wortfelder des Akustischen und Visiblen vorherrschend sind. Damit ist hier auch, wie bereits erwähnt, dieselbe poetologische Metaphorik von Nacht und Tag wie bei Brentanos Der Spinnerin Nachtlied zu beobachten. ${ }^{272}$ Und wie schon bei den mittelhochdeutschen Tageliedern scheint auch hier die poetologische Metaphorik von ,Tag' nicht bloß für den aktualisierten Zustand von Sprachzeichen zu stehen, sondern für einen (freilich semiotisch unmöglichen) dauerhaft aktualisierten Zustand derselben, der im Falle der Ode Ermunterung prophezeit wird. ${ }^{273}$ Die Ode Ermunterung ist denn vielleicht nicht zufällig im Umfeld der Nacht-Gesänge

20, V. 984-987; vgl. dazu auch den nicht ganz präzisen Verweis in: Hölderlin, Werke, Bd. 5 , S. 760 ).

271 Vgl. dazu auch Louth 1998, S. 171.

272 Vgl. dazu auch Oei 2009, S. 111.

273 Auf die Bewegung der Ode von "Nacht“ in der ersten Strophe hin zu „Tage“ in der letzten hat zudem bereits Oei hingewiesen, wobei er "Sonne“ und „Licht“ jedoch als Metaphern 
entstanden, eine Bezeichnung, die wie schon Brentanos Nacht-lied u. a. auch eine Beziehung zur Tage-Lied-Szene herstellt.

Die soeben genannte poetologische Metaphorik verbindet sich in Hölderlins Ode mit der auf inhaltlicher und syntaktischer Ebene in Strophe vier begonnenen Prophezeiung eines Aktualisierens von Text im Allgemeinen und der Ode selbst, das sich nicht bloß aus dem Munde von sterblichen Menschen vollzogen haben wird, sondern in Vereinigung mit dem/den GöttlichHimmlischen eine Lektüre sein wird, die sich „ewig“ resp. „unendlich“ am Vollziehen ist und die nicht „verstummt“. Dass es sich bei dieser zukünftigen Aktualisation gegenüber derjenigen, die im ersten Teil der Ode noch als verstummende beschrieben wird, um eine gesteigerte handelt, wird weiter unterstrichen durch die Verwendung des Komparativs („liebender“, V. 17, der wiederum auf Liebe, V. 8, verweist) und die Formulierung "dann erst reich“ (V. 18). Und noch immer wird mit denselben Mitteln - starke Echostruktur auf klanglicher Ebene, inhaltliche Vor- und Rückverweise und auf syntaktischer Ebene die wiederholte Verwendung von Analogien - versucht, jene Prophezeiung performativ zu einer selbsterfüllenden ${ }^{274} \mathrm{zu}$ machen.

In Strophe sechs ist daran zusätzlich die Metametapher „Blumen“ (V. 21) beteiligt: „Blumen“ verweist als gängige Metapher für Redeschmuck gerade darauf, dass „unsre Tage“ tatsächlich „wie Blumen sind“, denn als Metapher resp. Metonymie für ,unsere Zeiten', die ,Gegenwart', ist die Formulierung „unsre Tage“ tatsächlich ,blumige Rede', ebenso wie die Similitudo „wie Blumen“ selbst. Und wie die biologischen Blumen "des [physikalischen] Himmels Sonne“ (V. 22) zum Blühen (vgl. Str. 2) brauchen, so benötigen die rhetorischen „Blumen“ der Ode „Licht“ und "Sonne“ in deren poetologischer Metaphorik des lesenden Augenlichts. Und auch hier geht die Performativität der Strophe einher mit dem Verweis sowohl auf das Göttlich-Himmlische als auch auf das Echo, indem „des Himmels“ als Attribut zu „Sonne“ diese dem gleichen Bereich zuschreibt, wie es dasselbe Attribut in Vers eins mit dem „Echo" getan hat. Ein Echo zudem, das auf klanglicher Ebene in Strophe sechs wieder besonders dicht ist und mit der doppelten Nennung von "wieder" die Iteration und deren Verhallen als Möglichkeitsbedingung eines jeden Echos, jeder echohaften Klangfigur und überhaupt jeder Verwendung von (sprachlichen) Zeichen ausstellt.

für die Seele interpretiert, wogegen - verfolgt man keine poetologische Lesart - nichts einzuwenden ist (vgl. Oei 2009, S. 111 f.).

Die zahlreichen reflexiven Verben im zweiten Teil der Ode deuten ebenfalls darauf hin. 
All das bisher Dargelegte führt schließlich auch zu einer Lektüre der letzten Strophe, die die Exemplarität von Hölderlins Ode für die Auseinandersetzung mit der Ewigkeit oder Unendlichkeit von Text nicht wie Frey primär im potenziell endlosen Aufschub- resp. Änderungsprozess sieht, dem die Ode und ihre Textstufen und Lesarten unterworfen sind, und die vor allem ohne Freys Konstruktion "namenlos anstelle von „sprachlos" (V. 25) auskommt. Vielmehr vermag die hier dargelegte Lektüre darauf hinzuweisen, dass die Ode die zwei historischen Bedeutungen des Wortes ,sprachlos' miteinander kombiniert: einerseits die eines im älteren Neuhochdeutschen ${ }^{275}$ verwendeten Synonyms für ,stumm' (im Sinne von des Sprechens dauerhaft nicht fähig sein); und andererseits die der zeitgenössischen und noch heute gebräuchlichen Bedeutung und Verwendung von ,sprachlos - nämlich der eines vorübergehenden Zustandes des Nichtsprechens, der auch bloßes Verstummen ausdrücken kann -,276 was wiederum von der Verwendung des Verbes „verstummst“ in Vers 2 unterstützt wird. Denn die letzte Strophe thematisiert wie schon die gesamte Ode einerseits die zeitgenössische Stummheit des Göttlichen und andererseits den potenziell unendlichen Prozess eines immer wieder erfolgenden Verstummens des menschlichen Wortes. Letzteres deutet zudem darauf hin, dass Hölderlin genau die umgekehrte Perspektive auf das „abstrakte Problem der Wiederholungs-Stimme“277 einnimmt als Ovid in den Metamorphosen. Zu Ovids Narziss und Echo hat Petra Gehring nämlich beobachtet, dieser Mythos vermittle den unheimlichen Befund, dass „ein Ende jeglicher Möglichkeit des Kommunizierens [...] nicht am wirksamsten

275 „imältern nhd. bezeichnet sprachlos gewöhnlich einen, der nicht sprechen kann, dem das vermögen der sprache fehlt: die tauben macht er hörend, und die sprachlosen redend. Marc.“ (Deutsches Wörterbuch von Jacob Grimm und Wilhelm Grimm: sprachlos bis sprachmäszig; Bd. 16, Sp. 2768-2771; http://woerterbuchnetz.de/DWB/ [Stand: 6/2018]).

276 „sprachlos bezeichnet nicht immer einen dauernden, sondern auch und häufiger einen [z. B. durch Krankheit, MG] vorübergehenden zustand [...] doch meistens in milderem sinne, wenn infolge von schreck oder heftiger erregung die sprache momentan versagt (zuweilen auch blosz das verstummen ausdrückend, dann also in die bedeutung 1 übergehend). so schon mhd. [...] sprachlos in diesem sinne wird in der klassischen zeit des 18. jahrh. üblich und seitdem ist dies die gewöhnlichste gebrauchsweise; es wird dabei in der regel prädicativ (oder als apposition) verwendet und jetzt leicht als adverb empfunden: Franz ... das war dumm! (wirft sich sprachlos in einen sessel). SCHILler 2, 291 (räuber 4, 8 trauersp.)“ (ebd.). Diese Bedeutung ist auch am nächsten an der ursprünglichen Bedeutung des Wortes im Mhd. und Frühnhd.: „1) wer nicht spricht, schweigend [...]“ (ebd.).

277 Gehring 2006, S. 85 . 
durch Schweigen, sondern noch wirksamer im Medium der Stimme besiegelt [wird]“.278

Hölderlins Ode sucht gerade nicht wie jene Gestaltung des Mythos von Narziss und Echo bei Ovid ein echohaftes unendliches, aber eben auch jegliche Kommunikation zerstörendes Sprechen positiv zu konstituieren, sondern unendlich-göttliches Sprechen über ein radikales Betonen des Verstummens negativ einzuholen. Die Schlussphrase „sich ausspricht“ "spricht' dabei auf einer poetologischen Ebene und als Höhepunkt der Ode explizit ,aus', dass Ermunterung den prophezeiten Zustand einer Synthese von menschlichem und göttlichem Wort wortwörtlich gerade „ausspricht“, indem sie ihn performativ herzustellen beansprucht. Gleichzeitig aber endet die Ode auch ausgerechnet mit diesem ungeheuerlichen Anspruch, womit sie in ihrem eigenen Verstummen diesen Anspruch sogleich wieder zunichtemachen muss - einem Verstummen aber, das sie zugleich dahingehend zu nutzen sucht, jenes göttliche, ewige Aktualisiert-Sein von Sprachzeichen performativ wieder- resp. neu „im Menschenwort" herzustellen. Oder mit anderen Worten:

Hölderlins Ode ist von Anfang an das Paradoxon eingeschrieben, dass ein jedes Echo als „Menschenwort“ gemäß der Semantik von Echo kein Echo mehr ist, sollte es nicht mehrverstummen. Das Einzige, was der menschlichen Sprache in diesem Falle bleibt, um sich als göttlich-ewige zu inszenieren, ist, die potenziell unendliche Iteration ihres eigenen Verstummens selbst performativ zu nutzen, ${ }^{279}$ um sich gerade dadurch das Attribut der Ewigkeit zuzuschreiben. ${ }^{280}$

Diese Performativität ist ihrerseits wiederum an das Verstummen menschlicher Sprachzeichen gebunden, doch selbst noch dieses Verstummen performativer Textstellen - und das macht Hölderlins Ermunterung derart exemplarisch für die hier behandelte Unteroperation Unendliches Verstummen - versucht die Ode zur Stärkung resp. Dauer ebendieser Performativität zu nutzen, um Ewigkeitsattribuierung zu erreichen.

Die Ode Ermunterung ${ }^{281}$ mag aber auch - vorausblickend auf das sogleich folgende Kapitel - für die historische Kontextualisierung der bisher behandelten

278 Ebd., S. 110.

279 Bereits Claudia Benthien hat in ihren, vor allem anhand von Beispielen aus der Frühen Neuzeit und dem Beginn des 20. Jahrhunderts angestellten Überlegungen zur „vanitas der Stimme" gefolgert, dass "[g]enauso wie für das Sprechen eine performative und eine referenzielle Funktion zu unterscheiden sind, so hat das Schweigen ebendiese beiden Dimensionen inne“ (dies. 2006, S. 265).

280 Zum Verhältnis von Ewigkeit und Unendlichkeit vgl. das folgende Kapitel; sowie die Kapitel 1.1 und 2.1 des Schlussteils.

281 Und vielleicht auch andere Gedichte Hölderlins von ähnlicher Struktur wie etwa Der gefesselte Strom/Ganymed, Dichtermuth/Blödigkeit oder Chiron/Der blinde Sänger; vgl. dazu auch Forderer 2000. 
Operationen zur Ewigkeitsattribuierung von besonderer Exemplarität sein. Und zwar im Kontext eines im Zuge der zunehmenden Säkularisierung erfolgenden Verlustes der Heiligen Schrift sowie der Kompensation desselben durch eine Heiligung der Schrift als solcher. Die Ode ist vor diesem Hintergrund insofern exemplarisch, als dass in ihr einerseits vom auf die „Götterlosen“ (V.3) zurückzuführenden Verstummen des einst dauerhaft präsenten göttlichen Wortes die Rede ist, aber andererseits an ihr ebenfalls deutlich wird, dass offenbar gerade die „Götterlosen“ es sind, die über die Ewigkeitsattribuierung von Schriftzeichen eine neue Göttlichkeit in der eigenen Gegenwart zu erschreiben suchen.

\section{Historische Kontextualisierung der Grundoperation Unendliche Aktualisation}

Dass die einzelnen innersprachlichen Grundoperationen für die Ewigkeitsattribuierung von Schriftzeichen untereinander Überschneidungen aufweisen, darauf wurde in der Einführung bereits hingewiesen. Jede Gliederung, die eine Typologie vornimmt, ist letztlich heuristischer Natur. Dasselbe gilt folglich auch für die historische Kontextualisierung der einzelnen in dieser Arbeit besprochenen Operationen. So sind denn auch die Befunde und Thesen aus dem Kapitel IV.3, das ebenfalls der historischen Kontextualisierung gewidmet ist, im Folgenden ebenfalls mitzudenken - und umgekehrt. Eine der zentralen Thesen aus Kapitel IV.3.3 zur Genieästhetik bildet denn auch hier den Ausgangspunkt für die kommenden Unterkapitel:

Und genau aus diesem Versuch, sich selbst dauerhaft als, Genie' zu versichern, resultiert der implizite Zwang nach entweder endlosem Erschaffen - das freilich spätestens mit dem Tod des Genies enden wird - oder, als einzige (scheinbar) übrig bleibende Rettung, nach dem Erschaffen von Ewigem, dem Erschaffen eines ewigen Werkes.

Oder anders formuliert:

Ein Genie muss, um ein solches wortwörtlich zu bleiben, entweder Ewiges erschaffen oder aber ewig erschaffen.

Kapitel IV fokussiert denn auch, vereinfacht ausgedrückt, auf die historische Kontextualisierung vor allem von Verfahren des Erschaffens eines ewigen Werkes und der dabei zu beobachtenden Operationen des Bezuges eines Textes auf sich selber. Das vorliegende Kapitel hingegen konzentriert sich vor allem auf Verfahren eines ewigen Erschaffens. Damit ist in erster Linie nicht die unter III behandelte Grundoperation Autonome Performative Produktion gemeint, sondern eine historische Kontextualisierung derjenigen 
Unteroperationen, die besonders auf ein potenziell endloses Weiter- oder Wiederlesen (oder auch Weiterschreiben) eines Textes abzielen und deshalb unter der Grundoperation Unendliche Aktualisation zu fassen sind: Unendliche Lektüre und Unendliches Verstummen.

Unendliche Lektüre und unendliches Schreiben - mit einem Exkurs zuJean Paul

Zu Beginn der nun in Angriff zu nehmenden historischen Kontextualisierung ist zunächst ein Schritt hinter das in den Kapiteln II.1 und II.2 Erarbeitete zurückzugehen und von dem soeben beschriebenen Ausgangspunkt aus erst einmal vermeintlich trivial festzustellen: Grundvoraussetzung für ein unendlich voranschreitendes Lesen wäre ein unendlich fortfahrendes Schreiben. ${ }^{282}$ Mit Blick auf die das Genie konstituierenden und von diesem deshalb stets unter Beweis zu stellenden göttlichen Attribute des Schöpferischen und Ewigen bringt dies folgenden Problemkomplex mit sich: Während es auf der Seite der Lektüre theoretisch möglich wäre, dass nach dem Tod des stetig lesenden Lesers $\mathrm{x}$, Leser y nahtlos mit der Lektüre fortfahren würde usw., kann kein noch so großes Genie - und niemand, der schreibt - sein Schreiben über den eigenen physischen Tod hinaus fortsetzen. Was es geschrieben hat, kann zitiert, kommentiert, adaptiert, variiert usw. werden (und da kommt auch entscheidend die Funktion Herausgeber ins Spiel, siehe dazu weiter unten das Kapitel 3.3), aber selbst wenn das Genie das ganze Leben lang pausenlos geschrieben hätte, endet mit diesem Leben zwangsläufig auch sein Schreiben. ${ }^{283}$

Somit bleibt dem schreibenden Genie, das nicht direkt über die Ewigkeit des Erschaffenen, sondern über das ewige Erschaffen sich der Unsterblichkeit zu versichern sucht, nur noch ein paradoxaler Ausweg übrig: Es muss sich Operationen bedienen, die einerseits jene unendliche Lektüre zeitgenössischer und zukünftiger Leser ermöglichen - ja um sicherzugehen, gar möglichst erzwingen -, die aber andererseits nicht auf ein eigenes ewiges (Weiter-)Schreiben angewiesen sind. Bevor in den nächsten Unterkapiteln auf die Operationen Unendliche Lektüre und Unendliches Verstummen weiter eingegangen wird, sei deshalb vorab noch ein kleiner Exkurs zu demjenigen Autor erlaubt, der wohl wie kein anderer deutschsprachiger Autor des 18. und

282 Dies gilt - in Anlehnung an Derrida - auch umgekehrt.

283 Zur Unmöglichkeit eines absoluten Buches und zu deren Eigendynamik in Bezug auf die Romantik vgl., wenn auch kritisch, Schreiber 1983, insbesondere S. 183, der jedoch erstaunlicherweise kaum auf die in Kapitel IV.1.1 behandelte Höhlenszene im Heinrich von Ofterdingen eingeht. 
frühen 19. Jahrhunderts entgegen der Unausweichlichkeit des Todes auf dem Versuch eines ewigen Schreibens insistiert zu haben scheint: Jean Paul.

Die 2013 erschienene, äußerst erhellende Jean-Paul-Biographie Helmut Pfotenhauers, die für diesen Exkurs die Basis bildet, bietet die zurzeit umfassendste und profundeste Überblicksdarstellung zu Jean Paul und seinem Schreiben resp. "seine[m] Schreib-Leben[]“. ${ }^{284}$ Sie zeigt anhand von Jean Pauls Wirken und Werken in nuce vieles auf, was auch für die vorliegende Arbeit relevant ist, wobei umgekehrt die vorliegende Arbeit vieles zu bestätigen, zu ergänzen und weiterzuführen vermag, was Pfotenhauer anspricht. Während Pfotenhauer überwiegend auf das ,Wie‘ von Jean Pauls Schreiben fokussiert, konzentriert sich Dirk Göttsche in seiner groß angelegten Studie zur literarischen Zeitreflexion vor allem auf das ,Was', so auch im Falle seines Kapitels zu Jean Paul, ${ }^{285}$ in dem er festhält: „Den Ausgangspunkt und die ,Grundmelodie' der Zeitreflexion bildet bei Jean Paul die Vergänglichkeit menschlichen Lebens, die ,seit dem Barock [...] niemand so intensiv wie er zum Gegenstand literarischer Reflexion gemacht hat.“286 Wenngleich Göttsche hierbei zuzustimmen ist, interessiert im Rahmen der vorliegenden Arbeit vor allem das, $\mathrm{Wie}^{287}$ von Jean Pauls Schreiben, weshalb Pfotenhauers ,Werkbiographie‘ auch über den behandelten Autor hinaus als eines der Referenzwerke für die im gesamten Kapitel II.3 angestellten Überlegungen gelten mag.

284 Pfotenhauer 2013, S. 20.

285 Göttsche 2001, S. 115-141.

286 Göttsche 2001, S. 120. Den Begriff „Reflexion“ verwendet hier Göttsche im Sinne von „nachdenken über“/,thematisieren“ (und nicht im Sinne der unter Kapitel IV behandelten Grundoperation Reflexivität). Zur Selbstkritik, die dieser Reflexion Jean Pauls auf sich und sein eigenes Schreiben inhärent war, vgl. etwa Wölfel 1989, S. 270 f.

287 Aber auch Göttsche hält - dieses Mal u. a. im Sinne der in Kapitel IV behandelten Grundoperation Reflexivität - fest: „Spiegeln die Variationen und Schwerpunktverschiebungen der Zeitmotivik und der mit ihr verbundenen Zeitmetaphorik die Entwicklung von Jean Pauls Werk in seinen sukzessiven Phasen, so erfasst die Verzeitlichung aller Selbst- und Wirklichkeitsverhältnisse darüber hinaus auch die Erzählverfahren als solche. Das autoreflexive Spiel mit dem Verhältnis von erzählter Zeit und Erzählzeit, die Verzeitlichung des Raumes und die Verräumlichung der Zeit im Zuge der Darstellung einer von Erinnerung und Erwartung geprägten subjektiven Wirklichkeitswahrnehmung und die Entfaltung der dargestellten (Lebens-)Geschichten anhand hervorgehobener Augenblicke, in denen der epische Vorgang gleichsam aufgehoben scheint, schreiben die Zeitreflexion den grundlegenden Strukturen des Erzählens ein. Jean Pauls Werk zählt damit zu den herausragenden Belegen für die Kulmination der Verzeitlichungsprozesse im letzten Jahrzehnt des 18. Jahrhunderts" (Göttsche 2001, S. 118 f.; vgl. des Weiteren auch S. 136 f.). Zur Auseinandersetzung mit den von Göttsche, aber auch vom DFG-Schwerpunktprogramm „Ästhetische Eigenzeiten“ aufgegriffenen „Verzeitlichungsprozesse[n]“ vgl. Kapitel 2.1 des Schlussteils der vorliegenden Arbeit. 
Soeben wurde behauptet, Jean Paul hätte auf dem Versuch eines ewigen Schreibens insistiert. Dies ist denn auch einer der Hauptbefunde Pfotenhauers und manifestiert sich bereits im Untertitel seiner Biographie: „Das Leben als Schreiben/Biographie“, womit zugleich auch der performative Akt Pfotenhauers ausgestellt wird - denn auch dieser schreibt mit der Biographie ein Leben, nämlich dasjenige von Jean Paul. Es lohnt sich, einen Moment bei diesem Schreiben Pfotenhauers zu verweilen, der die Biographie wie folgt mit einem kommentierten Zitat von Ludwig Börnes ${ }^{288}$ Rede anlässlich des Todes von Jean Paul (1825) schließt:

[...] Nicht allen hat er [Jean Paul, MG] gelebt! Aber eine Zeit wird kommen, da wird er allen geboren, und alle werden ihn beweinen. Er aber steht geduldig an der Pforte des zwanzigsten Jahrhunderts und wartet lächelnd, bis sein schleichend Volk ihm nachkomme.

Heute, fast zweihundert Jahre später, will man die Hoffnung immer noch nicht aufgeben, daß Jean Paul geduldig an der Pforte neuer Jahrzehnte und des neuen Jahrhunderts stehen möge und lächelnd auf das schleichend Volk seiner Leser warte. ${ }^{289}$

Börne und Pfotenhauer setzen dabei ganz offenbar die Ewigkeitsattribuierung von Jean Pauls Schreiben und Geschriebenem fort. Bezeichnenderweise sind, einen Zitatrahmen um die Biographie bildend, dem Vorwort derselben - in an den Kater Murr erinnernder, Anfang und Ende entortender Manier - bereits drei Zitate aus Jean Pauls Werken vorangestellt. Das letzte stammt aus der Unsichtbaren Loge und beinhaltet kaum zufällig eine explizite Ewigkeitsbehauptung gegenüber Schriftzeichen:

Und eben dieses, daß die Hand des Menschen über so wenige Jahre hinausreicht und daß die [sic] so wenige gute Hände fassen kann, das muß ihn entschuldigen, wenn er ein Buch macht: seine Stimme reicht weiter als seine Hand, sein enger Kreis der Liebe zerfließet in weitere Zirkel, und wenn er selbst nicht mehr ist, so wehen seine nachtönenden Gedanken in dem papiernen Laube ${ }^{290}$ noch fort. ${ }^{291}$

Pfotenhauers Jean-Paul-Biographie ist, wie jede andere Biographie, auch ein Versuch, ein Leben zu schreiben und damit dauerhaft festzuhalten. ${ }^{292}$ Das Besondere in ihrem Fall ist jedoch, dass es in Jean Pauls Leben und Werk

\footnotetext{
2881825 noch Juda Löb Baruch geheißen.

289 Pfotenhauer 2013, S. 408.

290 Zur langen Tradition dieser Lebens-Blätter-Metaphorik vgl. Kapitel IV.3.3.2 zu Herders Shakespeare- Aufsatz und Homers Ilias.

291 Zitiert nach Pfotenhauer 2013, S. 13.

292 Vgl. dazu auch Angehrn 2017, insbesondere S. 117-130.
} 
gewissermaßen angelegt ist, dass eine künftige Biographie über ihn nicht nur über ein Leben schreibt, sondern zugleich auch ein von Jean Paul erschriebenes Leben weiterschreibt. ${ }^{293}$ Schließlich ist nun in einem dritten Schritt auch die vorliegende Arbeit selbst bis zu einem gewissen Grad an einer solchen Ewigkeitsattribuierung beteiligt, der sie einzig durch den expliziten Hinweis darauf entgegenzuwirken vermag. ${ }^{294}$ Inwiefern dieses Weiterschreiben von Jean Pauls „Schreibleben“ bereits in Verfahren angelegt ist, die in dessen Werken zu beobachten sind, sei im Folgenden knapp umrissen.

Zum fehlenden Schluss der Unsichtbaren Loge (1793) hält Pfotenhauer fest: „Auch das ist höchst charakteristisch für Richter. Nicht so sehr der Abschluss interessiert ihn, die Fertigstellung, die Rundung, sondern das Weiterschreiben, das Besserschreiben. ${ }^{2}{ }^{295}$ Dies alles manifestiere sich nicht nur im Immerweiter-Schreiben, sondern auch schon innerhalb der einzelnen Texte, deren Sprache „in unerhörte Wendungen und eine bis zum Zerreißen gespannte, schier endlose Syntax“ zerdehnt werde. ${ }^{296}$ Dabei gehe es Jean Paul letztlich vor allem

um die ständige Gewährleistung des Schreibflusses. Denn Schreiben ist das Leben. Diese Lebensbeschreibungen, diese Biographien, wie es fast alle Texte Jean Pauls sind, beschreiben anderes, fiktives Leben. Dieses Leben der Figuren wird in eine höhere, poetische, von der Erdenschwere des gemeinen Lebens befreite Sphäre transportiert. Aber dabei geht es immer auch um das Leben des Lebensbeschreibers, der sozusagen um sein Leben schreibt: Im Schreiben ist das wahre Leben, das, welches das bloß gelebte Leben mit all seinen Bedrängnissen, seiner Nähe zum Elend, zum Tod, zu den persönlichen Kränkungen vergessen läßt, das es aufhebt, ihm eine schriftliche Dauer und Situationsenthobenheit gewährt. Deshalb muß unablässig fortgeschrieben werden. ${ }^{297}$

Jean Paul sei bei seinem Versuch, sich durch die Verfahren eines endlosen Weiterschreibens der Ewigkeit zu versichern, also derart konsequent, dass sein Leben immer mehr zum Schreiben werde. Inwiefern ein solches ewiges Schreiben noch als Leben bezeichnet werden könnte, wäre genauer zu verfolgen und deckt sich mit einem der Hauptbefunde aus Albrecht Koschorkes Untersuchung Körperströme und Schriftverkehr, nämlich dass im Zuge des 18. Jahrhunderts die körperliche Distanz zwischen (lebenden) Körpern größer

\footnotetext{
293 Vgl. Pfotenhauer 2013, S. $17 \mathrm{f}$.

294 Vgl. dazu auch das letzte Kapitel des Schlussteils.

295 Ebd., S. 101. In eine ähnliche Richtung geht Sascha Michel in Bezug auf den Siebenkäs, unter besonderer Berücksichtigung von dessen Fußnoten; vgl. ders. 2006, insbesondere S. 169-173.

296 Pfotenhauer 2013, S. 74.

297 Ebd., S. 119.
} 
wird, die der zunehmende Verkehr mittels (toter) Schrift auf paradoxaltragische Weise zugleich überbrückt und verstärkt. ${ }^{298}$ Für Koschorkes These gäbe Jean Paul - wie ihn Pfotenhauer zeichnet -, dessen Freundschaften und (Liebes-)Beziehungen vor allem Schriftbeziehungen, Schriftlieben sind, geradezu das Paradebeispiel ab. 299

Die unermessliche schöpferische Macht, die sich Jean Paul, das bestehende Geniekonzept mit aller Konsequenz aufnehmend, mit der Umwandlung seines sterblichen Lebens in ein ewiges Weiterschreiben wortwörtlich zuschreibt, manifestiert sich auch in seinem eigenen Namen: „Jean Paul benennt sich nach seiner eigenen Romanfigur. Das Leben lebt die Fiktion nach. Mit diesem Gedanken, der den größten Triumph des Autors bedeutet, wird Jean Paul von nun an immer wieder spielen. ${ }^{300}$ Das Schreiben wird damit zu einem Akt selbsterfüllender Prophezeiung, denn Pfotenhauers Argumentation hieße konsequenterweise, dass das Leben nicht nur die Fiktion nachlebe, sondern auch Umgekehrtes der Fall wäre - was der Figur eines Hysteron-Proterons im engen Sinne entspräche. Oder anders formuliert: Ein Schreiben, das zugleich das Leben wäre (und umgekehrt), wäre ein Schreiben im Modus absoluter Performativität. ${ }^{301}$ Alles Geschriebene würde nicht auf etwas Abwesendes verweisen, sondern Präsenz überhaupt erst herstellen. ${ }^{302}$

Der Versuch, dieses Schreiben ewig fortzusetzen, ist jedoch, selbst an der eigenen Binnenlogik gemessen, paradoxal: Wenn jemand ewig schreiben

298 Vgl. Koschorke 1999.

299 Vor allem was solche Beziehungen zu Frauen anbelangt, sollen sie gewissermaßen in der Rolle als Musen bloß den Fluss der Schrift befördern; bei allem, was darüber hinausgeht und darunter fällt das Befördern etwaiger Körperflüsse -, tut sich Jean Paul jedoch lange schwer. Auch direktem weiblichem Einfluss auf sein Schreiben steht er ablehnend gegenüber. So antwortet er am 8. November 1796 in einem Brief an Charlotte Kalb, die Kritik an der Mondfinsternis in Geschichte meiner Vorrede zur zweiten Auflage des Quintus Fixlein geübt hatte, mit den bezeichnenden Worten: „Ich kan [sic] viel opfern, aber nicht meine Begeisterung für die Unsterblichkeit und deren Hoffnung. Kein Verhältnis darf auf das des Dichters einen Einflus [sic] gewinnen“ (zitiert nach Pfotenhauer 2013, S. 181).

300 Ebd., S. 102.

301 Vgl. dazu die Kapitel III und IV.2.2.

302 Ein Anspruch, der allein schon in den Versuchen, ihn zu verwirklichen, zu unheimlichen Parallelen führen muss oder - aus hermeneutischer, etwas kritischer Perspektive gesagt das Suchen und Finden solcher Parallelen befördert. So schreibt Jean Paul am Todestag (ohne dies zu wissen) von Moritz am 38. Kapitel des Hesperus, dem 38. Hundposttag, in dem die Figur Emanuel stirbt, die wiederum Karl Philipp Moritz gewidmet ist (vgl. Pfotenhauer 2013, S. 116; der jedoch, sich wohl schlicht verschreibend, den 26. April 1793 als den Todestag Moritz' angibt, nach dem besten Wissen des Verfassers war es aber der 26. Juni). „Das ist nicht nur Schmerz, sondern auch Triumph. Der Tod hat in seiner literarischen Vorsehung den Schrecken des wirklichen [sic] verklärend aufgehoben“ (vgl. ebd., S. 121). 
könnte, würde dies implizieren, dass er ewig leben muss, ansonsten könnte er ja nicht ewig schreiben. Damit würde aber der Schreibende als Möglichkeitsbedingung für sein ewiges Schreiben bereits mitbringen, was er mit diesem Schreiben eigentlich zu erlangen sucht: ein ewiges Leben. Daraus lässt sich wiederum die These ableiten,

dass dem Versuch Jean Pauls, ewig weiterzuschreiben, noch ein weiteres Verfahren zugrunde liegt, das jenem Paradoxon zu entfliehen vermag und letztlich anstatt auf die Ewigkeit des Schreibens doch auf die Ewigkeit des Geschriebenen abzielt: Denn wenn das Leben nur noch aus dem Schreiben von Werken besteht, entspricht das, Gesamtwerk' dem Leben.

Diese anhand von Jean Pauls Schreiben und Pfotenhauers Untersuchung desselben ${ }^{303}$ aufgestellte These wird in Kapitel 3.4 noch einmal aufgegriffen, da sie den Ausgangspunkt für Überlegungen bietet, die den Blick auf die Grundoperationen zur Ewigkeitsattribuierung von Schriftzeichen Unendliche Aktualisation sowie Reflexivität weiter schärfen und u. a. auch als Fortführung und Ergänzung von Pfotenhauers Argumentation zu verstehen sind.

Sie sei aber nun vorerst beiseitegelegt, um die hier geführte Auseinandersetzung mit Jean Paul noch in Rücksicht auf seine Stellung zwischen der sogenannten Klassik Goethes und Schillers einerseits und der Romantik andererseits zu beschließen. Zu Jean Pauls erstem Besuch in Weimar (1796) schreibt Pfotenhauer:

Zwei Welten treffen hier ja aufeinander: hier die intellektuelle Elite Deutschlands am Schauplatz seiner kulturellen Blüte, dort der bis vor kurzem noch gänzlich unbekannte junge Schriftsteller aus der oberfränkischen Provinz. Hier, mit Goethe und Schiller, die formstrengen Klassizisten, dort der neue Vorreiter einer Auflösung der Formen, die in den romantischen Antiklassizismus führen wird, mit welchem der Protagonist aber seinerseits wiederum nichts zu tun haben will. $^{304}$

Dass freilich gerade unterschiedliche Vorstellungen zur Begehung desselben Weges zu Missverständnissen, Spannungen und Abgrenzungsreflexen führen, ist nicht nur aus der Literaturgeschichte bekannt. Was jene gegenseitige „Irritation“305 zwischen Goethe, Schiller und Jean Paul betrifft, so lässt sich

303 In dieselbe Richtung wie Pfotenhauer gehen u. a. Michel 2006, der sich zudem auch mit Figurationen der Unterbrechung bei Brentano und Wieland befasst; Wieland 2013; und der Sammelband zur Ausstellung "Jean Paul, Dintenuniversum“ im Max Liebermann Haus, Berlin, Bernauer/Steinsiek/Weber 2013. Vgl. dazu auch kritisch das Kapitel zu Jean Paul in Jochen Schmidts Geschichte des Genie-Gedankens (ders. 2004, Bd. 1, S. 430-450).

304 Pfotenhauer 2013, S. 139.

305 Ebd., S. 138. 
denn auch aus dem oben Dargelegten hypothetisch und etwas plakativ Folgendes ableiten:

Die Spannung zwischen dem überwiegend auf die Geschlossenheit und Autonomie (vgl. Kapitel IV.3.2) des Werkes abzielenden Kunstverständnis der Weimarer Klassik Goethes und Schillers einerseits und Jean Pauls (und aller, die sich auf die Linie [Cervantes -] Sterne berufen) Kunstverständnis der Digression andererseits, ${ }^{306}$ das auf ein potenziell unendlich weiter sich ausdehnendes Werk abzielt, liegt auch darin begründet, dass beide Parteien in ihrem Kunstverständnis je eine andere Gruppe ${ }^{307}$ von Operationen zur Ewigkeitsattribuierung besonders prominent einsetzen, um ihre Werke (und damit letztlich auch sich selbst) als unsterblich zu erweisen. Im Falle Ersterer sind dies Operationen, die auf eine Autonomie des Geschriebenen abzielen, im Falle von Letzterem Operationen, die eine unendliche Aktualisation des Geschriebenen zu erreichen suchen. Das heißt natürlich nicht, dass die jeweils anderen Operationen in den betreffenden Werken nicht zu beobachten wären oder dass man sich solcher Überschneidungen untereinander gänzlich unbewusst wäre. ${ }^{308}$ Dass zu jener Spannung nicht nur Ablehnung, sondern eben auch Anziehung gehört und sich die beiden Parteien in manchem ähneln, ${ }^{309}$ liegt auch an der Komplementarität dieser einzelnen Operationen.

,Die Romantiker' wiederum, so scheint es, betreiben aus dieser Perspektive weniger einen "Antiklassizismus", 310 sondern suchen vielmehr - wie unten noch zu zeigen ist - die große Synthese, indem sie in ihrer Kunstauffassung beide Gruppen von Operationen zur Ewigkeitsattribuierung, sowohl den potenziell endlosen Verweis des Textes auf sich selbst und/oder seine Möglichkeitsbedingungen

306 Vgl. dazu u. a. Michel 2006; und Wieland 2013.

307 Vgl. dazu die zusammenfassende Darstellung in Kapitel 1.1 des Schlussteils.

308 Pfotenhauer selbst schreibt dazu u. a. „Und er [Goethe, MG] selbst hat ja in den gleichzeitigen Erzählungen der Unterhaltungen deutscher Ausgewanderten, die in Schillers Horen erscheinen, Novellistisches als Augenblickhaftes und Diskontinuierliches der romanesken Verpflichtung auf Entwicklung[, die er im zeitgleich zum Hesperus erschienenen Wilhelm Meister verfolgt, MG] entgegengestellt" (Pfotenhauer 2013, S. 148). Umgekehrt wird in Jean Pauls Werken z. B. sehr oft über das Schreiben und die Möglichkeitsbedingungen desselben reflektiert, was unter die (u. a.) auf Autonomie von Zeit und Kontext abzielende Grundoperation Reflexivität fällt. Zu Goethes Einstellung zur Unsterblichkeit des Menschen in Verbindung mit auf Tätigkeit abzielenden Bewältigungsstrategien gegenüber Todesfällen resp. dem Tod, aber auch hinsichtlich des „in sich vollendeten Kunstwerks" vgl. Steinby/Schmidt 2017, S. 24 f.; und insbesondere Hilgers 2002, S. 117-139, 203-218, die sich auch vertiefter und über Goethe hinaus zum Verhältnis von Unsterblichkeitsvorstellungen im 18. Jahrhundert und zum Paradigma der Perfektibilität äußert (ebd., S. 178-196).

309 Vgl. Pfotenhauer 2013, S. 138-163, vor allem S. $148 \mathrm{f}$.

310 Vgl. das oben angeführte, eingerückte Zitat Helmut Pfotenhauers. 
als auch die potenziell unbeendbare Lektüre samt ihrer Kehrseite, ${ }^{311}$ gleichwertig zu gewichten suchen.

Hinsichtlich der Ewigkeitsattribuierung von Schriftzeichen ließe sich Jean Pauls in der Forschung vielfach vertretene Sonderstellung zwischen Klassik und Romantik somit einerseits bestätigen, andererseits auch widerlegen, hat er doch Teil an demselben - ,Klassiker' wie, Romantiker prägenden - Versuch, sich über innersprachliche Operationen der Ewigkeit zu versichern.

\section{2 Ästhetik des Endens: die Linie Lessing-Jean Paul - Romantik}

Im Kapitel zu Lessings Miss Sara Sampson (1755) wurde u. a. folgende, auf die Forschung Müller Nielabas gestützte ${ }^{312}$ These vertreten:

Der von Lessing durch seine Neuinterpretation von Aristoteles' Begriff phóbos angestrebte Paradigmenwechsel innerhalb der zeitgenössischen Gattung des Trauerspiels von einer Betonung des Schauderns/Schreckens hin zum Mitleid(en) ging nicht nur einher mit einer Priorisierung der Dauer des Mitleidens gegenüber dem schrecklichen Augenblick, sondern führte zugleich zur Auflösung einer anderen zentralen Begrifflichkeit in Aristoteles' Poetik, nämlich der für die Tragödie geforderten Dreieinigkeit von Anfang, Mitte und Ende, insofern als bei Lessing das Ende in ein Enden überführt und damit zur Mitte wird.

Im Folgenden soll dieser These weiter nachgegangen werden, und zwar hinsichtlich der literaturgeschichtlichen Auswirkungen dieses von Lessing vorgenommenen Aufbrechens der aristotelischen Einheit der Tragödie und, davon abgeleitet, eines literarischen Werkes im Allgemeinen. Berücksichtigt werden dafür Jean Paul, die Frühromantik und E. T. A. Hoffmann. Die dabei beobachtete literaturgeschichtliche Linie vermag allein schon wegen des beschränkten Rahmens, der ihr hier gewidmet werden kann, keinen Anspruch auf absolute Gültigkeit zu erheben, aber eine Tendenz aufzuzeigen, der vielleicht künftige Untersuchungen vertieft nachgehen mögen.

\subsection{1 $\quad$ Lessing und Jean Paul}

Wie bereits im Kapitel zur Miss Sara Sampson behandelt und von Lessing in der Hamburgischen Dramaturgie selbst auf den Punkt gebracht, ${ }^{313}$ ist zur Konstitution des Mitleid(en)s eine gewisse Dauer notwendig, während der Schrecken auf den (flüchtigen) Moment angewiesen ist (und damit auch eine

311 Ästhetisch prominent nutzbar gemacht vor allem im Fragmentarischen; vgl. unten Kapitel II.3.4

312 Vgl. Müller Nielaba 1999.

313 Vgl. Lessing, Werke, Bd. 6, S. 553 (Hamburgische Dramaturgie, 74. Stück), S. 556 f. (75. Stück), S. 566 (77. Stück); und Kapitel II.1.2. 
jede Ewigkeitsattribuierung unterlaufen muss). Bei Lessing ist es nun gerade das Mitleid und dessen Dauer, das den Schrecken des Todes der tragischen Figuren überführt in ein Enden, welches das Ende des Kunstwerkes - das jeweils metonymisch den Namen jener Sterbenden trägt ${ }^{314}$ - gegen den Schrecken des Todes zur Mitte werden lässt. In Lessings Trauerspiel(text)en steht, das Kapitel zur Miss Sara Sampson hat es gezeigt, also nicht nur die Dauer des Lebens der tragischen Figuren auf dem Spiel, sondern auch die Dauer des Lesens ebendieser Leben. Im vorangegangenen Exkurs zu Jean Paul wiederum wurde bereits ausführlich dargelegt, wie dieser um ein Immer-weiter-Schreiben bemüht ist, was sich nicht nur in seiner exzessiven Schreibtätigkeit, sondern und vor allem auch anhand seiner Romane zeigt. Was Lessing mit dem Trauerspiel begonnen hat, scheint Jean Paul nämlich wenige Jahrzehnte später für die neue Gattung des Romans bis ins Extrem umzusetzen.

Als Paradebeispiel dafür mag der Hesperus (1795) gelten, „[d]enn Emanuel stirbt ja über fast 700 Seiten - oder meint zu sterben, bis er dann, wirklich tot ist". ${ }^{315}$ Der Tod ereilt Emanuel im "38. Hundposttag“, in dem Emanuel zuerst zu sterben glaubt, ${ }^{316}$ dann träumt, gestorben zu sein, ${ }^{317}$ um schließlich doch zu sterben. ${ }^{318}$ Emanuel stirbt jedoch in einem Unterkapitel (oder danach?) des „38. Hundposttages“, das mit „Traum Emanuels, daß alle Seelen Eine Wonne vernichte "319 überschrieben ist und somit wiederum die Grenze zwischen Traum und Wirklichkeit verwischt. Diese Verwischung erfolgt nicht nur auf der inhaltlichen Ebene, sondern auch auf der formalen, indem das Ende des betreffenden Unterkapitels nicht durch die Überschrift eines weiteren Unterkapitels und noch nicht durch die Überschrift "39. Hundposttag" signalisiert wird, sondern bloß durch eine Leerzeile, in deren Mitte (!) ausgerechnet drei Sternchen prangen:

Endlich sagte leise der Engel des Endes: sie sind am süßesten vergangen an ihren Geliebten.-

Und er zerdrückte weinend das Wölkgen der Zeit. -

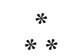

In Emanuels Augen glänzten die Fieberbilder des Todes, mit denen sich jeder Schlaf, sogar der letzte [sic] anfängt. Sein Geist hing wiegend in seinen schlaffen

314 So tragen die Trauerspiele Lessings die Titel Miss Sara Sampson, Philotas und Emilia Galotti.

315 Pfotenhauer 2013, S. 133.

316 Vgl. Jean Paul, Hesperus, S. 294-301.

317 Ebd., S. 306-308.

318 Ebd., S. 322.

319 Ebd., S. 316. 
Nerven, von sanften Lüften angeweht: denn er war schon in jener zersetzenden Nerven-Entzückung der Ohnmächtigen, der Gebährenden, der Verbluteten, der Sterbenden. ${ }^{320}$

Diese Sternchen stehen inhaltlich gesprochen am Ende von Emanuels Traum und aus textlinguistischer Sicht als Gliederungshinweise ${ }^{321}$ am Ende des Unterkapitels; damit aber auch zwischen diesen Enden und dem Rest des „38. Hundposttages“, worin dann erst Viktor den Tod Emanuels aus der Außenperspektive bestätigt. Damit spricht Viktor aus, was - wie in II.1 und II.2 bereits mehrfach behandelt - die Figur, die tot ist, nicht aussprechen kann, nämlich deren Tod: „Spiele das Lied der Entzückung fort, er ist gestorben.“322 Und noch etwas begegnet uns hier bei Jean Paul erneut: der Gedankenstrich. ${ }^{323}$ Gerade weil die Figur Emanuel wie Sara Sampson, wie Emilia Galotti, wie Philotas, wie Murr den eigenen Tod nicht aussprechen kann, ist das letzte Schriftzeichen vor dem Sternchen wie schon bei Lessing und wie später bei Hoffmann ein Gedankenstrich. Besonders bemerkenswert ist bezüglich einer von Lessing ausgehenden Ästhetik des Endens dabei auch, dass der Gedankenstrich im deutschen Sprachraum zunächst ausschließlich im Drama verwendet wurde, um dann im Zuge des 18. Jahrhunderts rasch vermehrten Eingang in die

320 Ebd., S. 320.

321 Vgl. Hausendorf/Kesselheim 2008.

322 Jean Paul, Hesperus, S. 322.

323 Magnus Wieland hat den Gedankenstrichen bei Jean Paul ein eigenes Kapitel gewidmet; vgl. ders. 2013, S. 299-306. Darin kommt er auch explizit auf das Verhältnis von Gedankenstrich und Tod zu sprechen. Die betreffende, sehr prägnant formulierte und genau in die Richtung des hier Interessierenden gehende Stelle sei deshalb ausführlich wiedergegeben: „Neben diesem typographischen Einsatz verleiht Jean Paul dem Gedankenstrich in einem frühen Aphorismus auch eine transzendente Bedeutung: ,Der Tod ist kein Punkt, sondern nur ein Abtheilungszeichen im menschlichen Dasein, ist ein Gedankenstrich, der zwo Welten verbindet' $[\ldots]$. Für einen digressiven Autor verwundert es nicht, wenn selbst der Tod kein endgültiges Ende bedeutet, kein Punkt, der dem ausufernden Schreibfluss Einhalt gebietet, sondern ein Gedankenstrich, der darauf verweist, dass nach dem ,Abbruch einer Periode' stets noch eine neue folgt. Hier eröffnet sich eine existentielle Komponente der Digression im Hinblick darauf, was Michel Foucault die ,langage à l'infini' nennt [zu Foucault und dem betreffenden Aufsatz „Das unendliche Sprechen“ vgl. die kritische Auseinandersetzung mit der hermeneutischen Tradition im Kapitel zum Forschungsstand in der Einführung, MG]. Die Digression bedeutet auch ein Anschreiben gegen den Tod. Im Schreiben und insbesondere im digressiven Schreiben liegt ein phantasmatischer und bis zu einem gewissen Grade auch melancholischer Wunsch verborgen, wie Scheherazade den Tod doch noch um eine Nacht aufschieben zu können, das Erzählen, das Schreiben nicht abbrechen und zu keinem Ende kommen zu lassen, um vor dem tatsächlichen Ende bewahrt zu sein“ (ebd., S. 303 f.). 
anderen Gattungen zu finden. ${ }^{324}$ (Auf die prominent eingesetzten Gedankenstriche bei Kleist kann hier nicht näher eingegangen werden, man halte sich hierfür zusammenfassend an das ausführliche Kapitel in Thomas Nehrlichs Monographie, wobei insbesondere dessen Ausführungen zur Marquise von $O$... und die Ergebnisse der vorliegenden Arbeit einander bestätigen mögen. ${ }^{325}$

Dass den typographischen Mitteln gerade bei Jean Paul eine wichtige Rolle zukommt, ist demnach nicht weiter verwunderlich und wurde bereits von Helmut Pfotenhauer anhand der Unsichtbaren Loge mit Blick auf Sterne angemerkt, jedoch ohne auf Lessing zurück- oder auf Hoffmann vorzuverweisen:

Typographische Mittel werden sprechend gemacht - ganz wie bei Sterne. Jean Paul' rät seinem fiktiven Verleger denn auch, sich für den Druck seiner Biographie einen großen Vorrat an Gedankenstrichen (man denke an das Motto), Frage- und Ausrufezeichen zuzulegen. Der Biograph des Romans weiß, wie sehr er ständig gegen die Zeit, den Zufall und das drohende Ende zu kämpfen hat. ${ }^{326}$

Und zum dem Roman Die Unsichtbare Loge vorangestellten Motto, das „Der Mensch ist der große Gedankenstrich im Buche der Natur“327 lautet und als (grobes) Selbstzitat aus den Teufelspapieren ${ }^{328}$ den Anfang des Romans hin auf einen anderen Text verwischt, kommentiert Pfotenhauer: „Der Mensch

324 Vgl. Nehrlich 2012, S. 118. Zum statistisch nachweisbaren, sprunghaften Anstieg von Gedankenstrich und Ausrufezeichen in der zweiten Hälfte des 18. Jahrhunderts vgl. auch Polaschegg 2012, insbesondere S. 16o-162; sie erwähnt dabei auch die hohe Gedankenstrichdichte in Lessings Trauerspielen. Äußerst bemerkenswert ist hierbei auch ihre am Ende von Kapitel II.1.2 aufgegriffene These, dass die in der zweiten Hälfte des 18. Jahrhunderts gewissermaßen zu ,Affektzeichen' werdenden Satzzeichen einhergehen mit der Konstitution des modernen Individuums und der modernen Autorschaft (vgl. ebd., S. 181 f.).

325 Vgl. Nehrlich 2012, S. 115-162. Zum Ende(n) der Marquise von $O$... schreibt Nehrlich u. a.: „Wie kein zweites typographisches Merkmal des Kleistschen Erzählwerks wirkt sich der Gedankenstrich in der Marquise auf die Materialität der Lektüre aus. Wie bereits erwähnt, veranlasst er die Änderung der Leserichtung: Während im ersten Lesegang die Neugier des Lesers ganz auf die Lösung des Rätsels zielt und die Lektüre im steten, auf den Ausgang gerichteten Vorwärtsgang weder Verzug noch Aufenthalt duldet, so bewirkt die nur halbe Aufklärung des Schlusses, dass der Leser nun, auf der Suche nach dem entscheidenden Augenblick, der seiner Aufmerksamkeit entgangen sein mag, den Text von hinten nach vorn durchkämmt: Vom Ende, das die Begier des Lesers nicht vollständig befriedigt, jäh in die Erzählung zurückgeworfen, verläuft die Lektüre nun rückwärts“ (ebd., S. 160).

326 Pfotenhauer 2013, S. 108.

327 Jean Paul, Unsichtbare Loge, S. 4.

328 Die Stelle in den Teufelspapieren weicht jedoch vom Motto der Unsichtbaren Loge ab und setzt den „lange[n] Gedankenstrich“ auch gleich performativ ein: „Der sonderbare Mensch ist im Buche der Natur der lange Gedankenstrich“ (ebenfalls nach der 
also als Schriftzeichen, als Zeichen für eine Leerstelle, die durch Gedanken auszufüllen wären, welche in ein Buch zu schreiben sind. In der Tat kann man Jean Pauls Schriftabsolutismus kaum besser zum Ausdruck bringen. Papierene Anthropologie könnte man das auch nennen. ${ }^{329}$ Diese Beobachtungen Helmut Pfotenhauers sind zu ergänzen mit den Beobachtungen zum Gedankenstrich im Kapitel zu Lessings Miss Sara Sampson und mit der dabei festgestellten Analogie dieses Satzzeichens, das als einziges allgemeingebräuchliches Schriftzeichen der deutschen Sprache zwischen zwei Leerschlägen zu stehen kommt, mit dem menschlichen Leben und Sterben. ${ }^{330}$

Die Sternchen am Ende von Emanuels Traum stehen nicht nur zwischen dessen anzunehmendem Tod, der mit dem Ende des Traums zusammenfällt, einerseits und dem von Viktor eine Seite später bestätigten Tod andererseits, sondern können zugleich auch als ikonische Zeichen gelesen werden, nämlich als Zeichen für einen Stern resp. für Sterne. Dabei eröffnen sich wiederum mindestens drei Lesarten des Verweises auf einen Stern: a) ein Stern als Verweis auf den Sterne, Laurence Sterne, den Verfasser von The Life and Opinions of Tristram Shandy, Gentleman, auf das große Vorbild Jean Pauls, wie auch auf E. T. A. Hoffmanns Kater Murr in Sachen Digression und sprechender Typographie; b) ein Verweis auf die traditionelle Symbolik des Sterns als Zeichen für die Ewigkeit im Allgemeinen, aber auch in der Tradition von Ovids Nachwort zu den Metamorphosen als Zeichen für die Unsterblichkeit des Autors im Speziellen; ${ }^{331}$ c) ein Stern als Zeichen für den Hesperus, den Abend- und Morgenstern, der zugleich sowohl Anfang und Ende des Tages als auch der Nacht figuriert; den Hesperus, der als astronomische Anadiplose als Metapher für die Figuration von Anfang und Ende des Lebens resp. poetologisch für die Figuration von Anfang und Ende des Lesens des Romans Hesperus stehen kann. ${ }^{332}$ Was oben insbesondere im Falle von Hoffmanns Kater Murr festgestellt wurde, lässt sich somit bereits in ähnlicher Weise für den 25 Jahre früher erschienenen Hesperus Jean Pauls beobachten: Auf der Mikroebene der Typographie wird an entscheidender Stelle die auf der Makroebene angestrebte Überführung des Endes hin zu einem Enden und damit zu einer Mitte ausgestellt und unterstützt.

Erstausgabe abgedruckt im Apparat von: Jean Paul, Unsichtbare Loge, S. 4; resp. vgl. Jean Paul, Teufelspapiere, S. 241).

329 Pfotenhauer 2013, S. 107.

33 O Vgl. Kapitel II.1.2.2.

331 Vgl. zu Ovid Kapitel 4.2 der Einführung.

332 Zur poetologischen Metaphorik von Tag und Nacht vgl. das Kapitel II.2.1 zu Der Spinnerin Nachtlied. 
Von hier aus sei nun wieder zur Makroebene des Hesperus zurückgekehrt, die bezeichnenderweise auch Pfotenhauer beschreibt - und dies, ohne es zu be- oder vermerken, ganz vor der Folie von Lessings Transformation der abschreckenden Tragödie hin zu einem Trauerspiel, das ganz auf das Mitleiden abzielt:

Emanuels Vernichtvision ist nun, wie der Titel [„Traum Emanuels, daß alle Seelen Eine Wonne vernichte“, MG] schon besagt, ein wonnevoller Blick in die andere Welt, kein grausiges Erschrecken über die Hinfälligkeit des Lebens. Die Literatur versucht hier ihre Macht angesichts dieser Schwellensituation zu demonstrieren. Und das merkwürdige Ineinander von Sterben und schreibendem Aufheben seiner Schrecken scheint sie eindrucksvoll zu bestätigen. Deshalb sind Emanuels sich durch das ganze Buch ziehende Vorstellungen vom eigenen Sterben, sein Beschreiben seines Sterbens, auch wiederum Sprachereignisse. ${ }^{333}$

Das „Ineinander von Sterben“- eben Dauer beanspruchendes Sterben und nicht plötzlicher Tod - „und schreibendem Aufheben seiner Schrecken“ ist denn, so die hier vertretene These, auch alles andere als "merkwürdig“, sondern Jean Pauls Übertragung von Lessings Transformation der Tragödie auf den Roman.

\subsubsection{Lessing und die frühromantische Fragmentästhetik}

Während der entscheidende Einfluss Lessings auf das Auflösen der aristotelischen Einheit des Werkes, das im Zuge der zweiten Hälfte des 18. und des frühen 19.Jahrhunderts immer stärker erfolgt und als ein wesentliches Merkmal der Moderne gilt, ${ }^{334}$ in der Forschung bislang nicht mit Blick auf dessen in den Trauerspielen entfaltete Ästhetik des Endens untersucht wurde, erfolgte dies umso mehr in anderer Hinsicht. Dabei scheinen - abgesehen von Dieter Burdorfs Aufsatz, der den vor allem durch die Übersetzungstätigkeit Wilhelm Schlegels vermittelten Einfluss der fragmentarischen Überlieferung antiker Texte stark macht ${ }^{335}$ - vor allem zwei Ausgangspunkte dominant: ${ }^{336}$ einerseits ein sehr weiter, auf die Ebene von Stil und Inhalt fokussierender Fragmentbegriff, der Friedrich Schlegels Urteil "Alles was Lessing geschrieben ein $\operatorname{Fr}[$ agment $]$ “ folgt, ${ }^{337}$ so etwa in Lothar Pikuliks Aufsatz Lessing als Vorläufer des

\footnotetext{
333 Pfotenhauer 2013, S. 132, Hervorhebungen MG.

334 Vgl. u. a. Ostermann 1991.

335 Vgl. Burdorf 2011.

336 Vgl. zum Forschungsstand u. a. zusammenfassend Braun 2002, S. 34-45; und Weiß 2015, S. 13-20.

337 Die im Zusammenhang der frühromantischen Fragmentästhetik immer wieder zitierte Stelle stammt aus den „Philosophischen Lehrjahren, [V] Philosophische Fragmente,
} 
frühromantischen Fragmentismus ${ }^{338}$ oder in der Monographie von Johannes Weiß; und andererseits, nun unter dem Gesichtspunkt der Form, Lessings Herausgabe der sogenannten Reimarus-Fragmente (1774). Der erstgenannte Ausgangspunkt ist derjenige in der Forschung stärker verfolgte und in seiner Wirkmächtigkeit höher eingeschätzte, einer Forschung die dabei ganz von Friedrich Schlegels explizitem Nachdenken über Lessing eingenommen ist. ${ }^{339}$ Dies gilt auch für die 2015 erschienene Monographie Das frühromantische Fragment. Eine Entstehungs- und Wirkungsgeschichte von Johannes Weiß, dem es ein „zentrales Anliegen“ ist, zu klären, „ob die neue, fragmentarische Weltsicht der Frühromantik tatsächlich ihre Entsprechung im Gebrauch einer neuen, fragmentarischen Darstellungsform findet" oder ob es sich dabei bloß um eine "Variante des konventionellen Aphorismus“340 handle, und der als die wesentlichen Einflüsse Chamfort, Lessing sowie Goethes und Schillers Xenien ausmacht. ${ }^{341} \mathrm{Zu}$ all dem, aber eben gerade auch hinsichtlich des hier verfolgten Einflusses von Lessings Ästhetik des Endens, kommt hinzu, dass Rüdiger Campe in den Versuchen (insbesondere Friedrich Schlegels) um 180o, den Roman theoretisch zu fassen, einen Wechsel vom statischen Formbegriff hin zu einer potenziell endlosen Operation der formation (auf Englisch auch in bezeichnender Nähe zu formation im Sinne von deutsch „Bildung“) feststellt:

Thus nearly every passage in which Schlegel speaks of the art of life is marked by the biological concept of developmental formation (Bildung). A form thus comes about that consists or rather manifests itself in its constant selfdifferentiation from non-form. In Schlegel's art of life, the form of life turns out to be the result of its being differentiated from what it is not. Thus, however, a paradox ensues: every instance of differentiating formed from formless life brings about new life that again falls outside of the limits of form. ${ }^{342}$

Der Roman, der das Leben seiner Hauptfigur zu fassen sucht, wäre demnach für Friedrich Schlegel per definitionem eine Gattung, die - drückt man den Forschungskonsens in Anlehnung an aristotelische Begrifflichkeit aus - im

Zweyte Epoche II“ [Fragment 118]: „Wolfs Proleg[omena] eine Idee von $x p$ [kritischem] Experiment. Alles was Lessing geschrieben ein Fr[agment]“ (KFSA 18, S. 333).

338 Vgl. Pikulik 1993.

339 Vgl. u. a. Braun 2002, S. 34 und 36, der sich wiederum auf Pikulik 1993 stützt.

340 Weiß 2015, S. 10.

341 Vgl. ebd., S. 21-91. Vgl. dazu auch Strack 2004; zum beschränkten Einfluss von Chamfort etwa S. 349; zu Unterschieden zwischen Friedrich Schlegels und Novalis' Fragmentkonzeption S. 355-359.

342 Campe 2011, S. 6 o f. 
Wesentlichen durch die Transformation des Endes (und des Anfangs) zur Mitte konstituiert wird.

An dieser Stelle sei noch eine Stufe weiter ,herausgezoomt' und die Fragmentästhetik vor dem Hintergrund der geistesgeschichtlichen Veränderungen des 18. Jahrhunderts in den Blick genommen. Die Begriffs- und Gattungsgeschichte, die von Michael Braun - zu großen Teilen Ernst Behler paraphrasierend $^{343}$ - zusammenfassend aufgearbeitet worden ist, lehrt, dass die Erweiterung des lateinischen Begriffs fragmentum sich erst im Mittelalter auch auf geistige Erzeugnisse beziehen konnte, während er sich ursprünglich nur auf physische Überbleibsel oder Spuren bezog und eine ästhetische Nutzbarmachung des Fragmentarischen, ganz in der Tradition des Aristoteles, noch undenkbar war. Diese Begriffserweiterung geht wohl vom Speisungswunder Jesu im Johannesevangelium aus, wo es heißt: „Als sie aber satt waren, sagte er zu seinen Jüngern: Sammelt die übrig gebliebenen Brocken, damit nichts verloren geht. Sie sammelten sie und füllten zwölf Körbe mit den Brocken, die von den fünf Gerstenbroten übrig blieben, nachdem sie gegessen hatten“ (Johannes 6:12-13). ${ }^{344}$

Jesu Auftrag, die übriggebliebenen Brocken aufzulesen, damit nichts verlorengehe, wurde im eucharistischen Sinne als Vorwegnahme des Versprechens vom Brot des Lebens gedeutet, spätestens seit Luther - der "fragmentum“ mit „Stückwerk" übersetzte - aber auch in allegorischer Auslegungsmanier so verstanden, daß Christus zum Aufsammeln der verstreuten Brocken seiner Lehre auffordere. Damit bekamen die "fragmenta" einen heilsgeschichtlichen Nebensinn: Als Überreste einer göttlichen Speise sind die Fragmente Zeugnisse des Wunders und Mittel religiöser Erkenntnis. So konnte der Begriff auf den StückwerkCharakter der menschlichen Erkenntnis übertragen werden [...]. Diese Bedeutungserweiterung des Fragments steht anthropologiegeschichtlich an der Schnittstelle zwischen Philosophie, Theologie und Medizin, die im späten 18. Jahrhundert eine einflußreiche Liaison eingingen. ${ }^{345}$

\section{Und Elizabeth Wanning Harries stellt ergänzend dazu fest:}

As long as the Bible was understood to be the word of God, unmediated by human efforts, this kind of critical inquiry was not possible. It had to be seen as essentially a seamless narrative, with only occasional and almost inexplicable lapses and inconsistencies. When the biblical text was understood, however, as having a history parallel to that of classical texts - as a palimpsest of various

343 Vgl. Behler 1985, vor allem S. 126-137.

344 Zitiert nach der Zürcher Bibel 2007. Michael Braun weist darauf hin, dass „fragmentum“, hier mit „Brocken“ übersetzt, in diesem Zusammenhang neunmal bei den Evangelisten auftaucht, wobei er auch die Stellen angibt (vgl. Braun 2002, S. 30).

Braun 2002, S. $30 \mathrm{f}$. 
versions, written over time by actual people, human if inspired - it became possible to examine the textual layers that had accreted through time, to carry out what might be called textual archaeology. ${ }^{346}$

Ein hervorragendes, bereits von Behler und dann von Braun genanntes Beispiel $^{347}$ für die im 18. Jahrhundert erfolgende Verknüpfung der heilsgeschichtlichen Konnotation des Fragmentbegriffs mit der menschlichen Erkenntnis ist der Schluss des Achten Fragments aus Lavaters Physiognomischen Fragmenten (1775), der an den ersten Korintherbrief ${ }^{348}$ angelehnt ist:

Das letzte, was ich diesem Fragmente noch beysetze - sey, wiewohl es in anderer Absicht gesagt worden seyn mag, einem großen Manne [gemeint ist Paulus, MG] nachgestammelt [...] [:] "Jetzt erkennen wir noch Stückweise - und unser Auslegen und Commentiren ist Stückwerk! weg mit diesen Fragmenten, wenn die Vollkommenheit kömmt! Noch ist's Stammlen eines Kindes, was ich schreibe! Kindische Einfälle und Bemühungen werden sie mir einst scheinen, wenn ich Mann seyn werde! Denn jetzt sehn wir die Herrlichkeit des Menschen nur durch ein düster Glas - bald von Angesicht zu Angesicht - Itzt fragmentsweise; dann werd ich's durch und durch erkennen - wie ich - von dem erkennt bin, aus dem und durch den und in dem alle Dinge sind! Ehr' sey ihm in Ewigkeit! Amen!"349

Was jedoch weder Behler noch Braun erwähnen (und auch nicht zitieren), ist, dass abgesehen von jener Verknüpfung Gott am Ende des Achten Fragments dieses Fragment selbst wortwörtlich mit seiner „Ewigkeit“ rahmt und dass mit dem lateinisch-liturgischen Wort für Ende, „Amen“, das Ende des Fragments performativ im Namen Gottes gesetzt wird.

Der Fragmentbegriff hatte also seit dem Mittelalter eine enge Anbindung an das Heilsgeschehen, an das Sammeln und schriftlich dauerhafte Festhalten desselben. Dabei war in dem Begriff schon damals eine autoreflexive Ebene angelegt, die auf die Bibel selbst, welche die ewig gültige und zur Ewigkeit

346 Wanning Harries 1994, S. 38 f.

347 Vgl. Behler 1985, S. 129; Braun 2002, S. 31.

348 „8 Die Liebe kommt niemals zu Fall: Prophetische Gaben - sie werden zunichte werden; Zungenreden - sie werden aufhören; Erkenntnis - sie wird zunichte werden. 9 Denn Stückwerk ist unser Erkennen und Stückwerk unser prophetisches Reden. 1o Wenn aber das Vollkommene kommt, dann wird zunichte werden, was Stückwerk ist. 11 Als ich ein Kind war, redete ich wie ein Kind, dachte wie ein Kind, überlegte wie ein Kind. Als ich aber erwachsen war, hatte ich das Wesen des Kindes abgelegt. 12 Denn jetzt sehen wir alles in einem Spiegel, in rätselhafter Gestalt, dann aber von Angesicht zu Angesicht. Jetzt ist mein Erkennen Stückwerk, dann aber werde ich ganz erkennen, wie ich auch ganz erkannt worden bin. 13 Nun aber bleiben Glaube, Hoffnung, Liebe, diese drei. Die größte unter ihnen aber ist die Liebe." (1. Korinther 13, 8-13; Zürcher Bibel 2007). 
hinführende Botschaft mittels Schriftzeichen bis zum Jüngsten Tag bewahren soll, Bezug nimmt. (Es verwundert also wenig, dass dann das Autoreflexive und das Attribut der Ewigkeit bei den Frühromantikern derart eng mit dem Fragment verknüpft sein werden.) In einem weiteren Schritt lässt sich nun das bislang zu Lessing und zum Fragmentarischen Dargelegte in folgende These überführen:

Im Zuge des 18. Jahrhunderts, in dem die ewige Gültigkeit der Heiligen Schrift und das ewige Leben nach dem Tode infrage gestellt ist, wird der Fragmentbegriff in dem Maße, in dem er nicht mehr in einem heilsgeschichtlichen Sinne auf die Ewigkeit Gottes verweist, für die Ewigkeitsattribuierung der Schrift resp. des schriftlichen (Kunst-)Werkes fruchtbar gemacht. Dabei spielt die Grundoperation Unendliche Aktualisation mit ihren beiden komplementären Unteroperationen Unendliche Lektüre und Unendliches Verstummen eine zentrale Rolle.

Die in der Einführung genannte Beobachtung, im Zuge des 18. Jahrhunderts führe der Verlust der Heiligen Schrift zu einer Heiligung der Schrift als solcher, findet sich hier somit eindrücklich bestätigt. Etwas plakativ ließe sich denn auch sagen: Während etwa bei Lavater 1775 noch Gott „in Ewigkeit“ (gar wortwörtlich) die Fragmente zu einem Ganzen vereint, sollen 25 Jahre später Fragmente die verlorene Ewigkeit wieder einholen. ${ }^{350}$ Oder mit anderen Worten:

Während der ewige, einheitliche Text der Bibel zu einer fragmentarischen Sammlung von Fragmenten wird, sollen die künstlich erschaffenen Fragmente zum ewigen Text werden.

Bestes Beispiel dafür ist die von Eberhard Ostermann festgestellte, vehemente frühromantische Besetzung des Fragments als eines futurischen: ${ }^{351}$

Das Fragmentarische der [frühromantischen, MG] Poesie ist mithin nicht ihr defizitärer Status, sondern die negative Erscheinungsform ihres Ermöglichungsgrundes, der sich als abwesender und dennoch realer manifestiert. Als Fragmente aus der Zukunft sind die Werke der Poesie Emanationen einer schon

$35^{\circ}$ Bereits bei den resp. dem Enden von Lessings Trauerspielen lässt sich beobachten, wie (der christliche) Gott als Garant der Hoffnung auf ein Leben nach dem Tode immer mehr in den Hintergrund tritt: Bezieht sich die sterbende Sara in ihren letzten beiden Äußerungen noch direkt auf Gott (vgl. Lessing, Werke, Bd. 3, S. 524) und Philotas zumindest noch auf "Götter" und die "Göttin des Friedens" (Lessing, Werke, Bd. 4, S. 35), so ist es beim Ende(n) von Emilia Galotti nur noch Odoardo, der sich indirekt an den „Richter von uns allen“ (Lessing, Werke, Bd. 7, S. 371) wendet. Die letzten Worte beider weiblichen Hauptfiguren, „- mein Vater -“ (Lessing, Werke, Bd. 7, S. 370; ebd., Bd. 3, S. 525; vgl. auch II.1.2), lassen sich jedoch in beiden Fällen nicht nur auf den leiblichen Vater, sondern auch auf Gott-Vater beziehen.

$35^{1}$ „Dieses futurische Element des Fragments ist das eigentlich Neue und Revolutionäre [mit Blick auf die heilsgeschichtliche Konnotation der fragmenta in der Bibel vielleicht eher: Evolutionäre, MG] an Schlegels ästhetischer Konzeption“ (Braun 2002, S. 43). 
vorhandenen, aber jenseits der Geschichte liegenden dynamischen Totalität, die mit Namen wie „unendliche Fülle“, „werdende Gottheit“, „das Höchste“ bezeichnet wird, und deren wirkliche Erscheinung sich als Bruchstück indirekt ankündigt. ${ }^{352}$

Und Michael Braun, der vieles des soeben Besprochenen komprimiert und dabei zugleich vorauszuweisen vermag auf die in Kapitel IV zu behandelnde Grundoperation Reflexivität, hält fest:

Die frühromantische Theorie des Fragments meint „weder das Werk als monolithischen Torso noch als Vanitas-Symbol; sie zielt vielmehr auf jenen Kristallisationspunkt der poetischen Reflexion, an dem sich das Unendliche im Endlichen zusammenzieht“. [ein Zitat Eberhard Ostermanns, MG] Auf diese Weise entwickelt Schlegel das Fragment zur Erkenntnisform der Dialektik von Endlichkeit und Unendlichkeit, von Diesseits und Jenseits, ohne übrigens den Bezug zum biblischen Begriffsursprung preiszugeben: „Die poetischen Fragmente ganz biblisch - Sprüche “. ${ }^{353}$ Die biblische Gattung der Sprüche wird in den Dienst der Fragmentkunst gestellt. ${ }^{354}$

Nach diesen Betrachtungen zur Geschichte des Fragments sei nun vorerst übergeleitet zur Funktion des Herausgebers, um dann noch einmal auf das Fragmentarische zurückzukommen.

\subsection{Der Herausgeber als Ewigkeitsgarant}

Verknüpft man nun die soeben in Kapitel 3.2 behandelte Ästhetik des Endens mit den grundsätzlichen Überlegungen zum Genie und zum Schöpferischen in Kapitel 3.1 (und IV.3.3), so ist festzuhalten, dass jeder Versuch eines ewigen Schreibens mit dem Tod desjenigen, der schreibt, zwangsläufig in einem Fragment enden muss. Das Unternehmen, ewig zu erschaffen, scheitert an der Sterblichkeit des Menschen, schlimmer noch: würde es in aller Konsequenz verfolgt, so kann es zugleich auch die Hoffnung zunichtemachen, Ewiges zu erschaffen. Dann nämlich, wenn aufgrund des Todes desjenigen, der ewig schreiben wollte (und sich deshalb um nichts anderes kümmern konnte), das Geschriebene weder gedruckt noch sonst wie einer Leserschaft zugänglich gemacht, von den Hinterbliebenen übersehen oder vernichtet wird usw. Und genau hier tritt eine Instanz resp. nach Uwe Wirth eine „Funktion“355 auf den Plan, die nicht zufällig im Verlauf des 18. Jahrhunderts Hochkonjunktur

352 Ostermann 1991, S. 194.

353 Braun zitiert hier Friedrich Schlegel, Philosophische Lehrjahre, S. 72.

354 Braun 2002, S. 44.

355 Vgl. Wirth 2008, vor allem S. 19-43. 
hat: die Funktion Herausgeber. Sie allein besitzt die Macht, dafür zu sorgen, dass ein Werk postum erscheint. ${ }^{356}$ Selbst die Autobiographie des "göttliche[n] Murr[s]“357 (und damit auch er selbst) wäre der Vergessenheit anheimgefallen, wäre da nicht ein Herausgeber gewesen, der sie gedruckt und veröffentlicht hätte. Im Folgenden sei deshalb vor dem Hintergrund von Uwe Wirths Monographie Die Geburt des Autors aus dem Geiste der Herausgeberfiktion dem Beitrag der Funktion Herausgeber resp. der Herausgeberfiktion zur Ewigkeitsattribuierung von Schriftzeichen nachgegangen.

Die Auseinandersetzung mit den Lebens-Ansichten des Katers Murr hat es bereits angedeutet: Nicht nur der reale Herausgeber ist es, der im 18. und frühen 19. Jahrhundert verstärkt auf den Plan tritt, sondern insbesondere auch die Herausgeberfiktion, „die in der Literatur des 18. Jahrhunderts aufgrund der Briefromanpoetik der Regelfall ist“. ${ }^{358}$ Neben der „Rahmungsfunktion“, 359 welche die Herausgeberfiktion innehat, ist sie auch in zunehmendem Maße und mit immer komplexeren Spielarten einer „aufklärerischen Tendenz“ verpflichtet, die den Leser dazu anregen soll, „das Verhältnis von Wahrheit und Fiktion“, 360 aber auch von Rahmen und Gerahmtem kritisch zu reflektieren, insbesondere dann, wenn sich der fiktive Herausgeber als unzuverlässig erweist. ${ }^{361}$ Damit sind mindestens vier Tendenzen des 18. Jahrhunderts eng mit der Herausgeberfiktion verknüpft: die Aufwertung des Fiktiven bei gleichzeitiger, impliziter Aufforderung zur kritischen Hinterfragung (und Rahmung) desselben; das Aufbrechen der aristotelischen Werkeinheit, bestehend aus Anfang, Mitte und Ende, sowie die Rahmung, die das Zur-Mitte-Werden von Anfang und Ende erfordert (vgl. die folgenden Abschnitte); eine sich über die Herausgeberfiktion konstituierende, selbstbewusste Autorschaft, die eng mit dem Geniediskurs verknüpft ist; und - so die hier vertretene und Wirth

356 „Wie der Autor ist der Herausgeber eine Instanz, die das ,Prinzip einer gewissen Einheit des Schreibens' sichert, und zwar auch dann noch, wenn der Autor abwesend gestorben - ist" (Wirth 2008, S. 13).

357 Hoffmann, Werke, Bd. 5, S. 38.

$35^{8}$ Und weiter: „Erst, um 1800` wird die Herausgeberfiktion allmählich von der Fiktion eines auktorialen Erzählers abgelöst - etwa in Goethes Wilhelm Meister, auf dessen Titelblatt die Interferenz von Autorschafts- und Herausgeberschaftskonzepten anschaulich zum Ausdruck kommt, denn es heißt im Untertitel: ,Ein Roman. Herausgegeben von Goethe ${ }^{\text {u“ }}$ (Wirth 2008, S. 13); vgl. auch ebd., S. 143-16o.

359 Ebd., insbesondere S. 16o-164.

36o Ebd., S. 231.

361 Ebd., S. 179. Ein Paradebeispiel für solche Strategien wäre z. B. Wielands Agathon, der darauf abzielt, „den Leser durch eine Modulation seines Deutungsrahmens in einen philosophischen Leser zu verwandeln“ (ebd., S. 23o.); oder eben auch Hoffmanns LebensAnsichten des Katers Murr (vgl. dazu auch Wirth 2008, S. 377-421). 
ergänzende These - die akzentuierte Ewigkeitsattribuierung von Schriftzeichen resp. insbesondere von literarischen Texten. Denn während der reale Herausgeber die Veröffentlichung eines Werkes über den physischen Tod des Autors hinaus sicherzustellen vermag, kann der Autor über die Herausgeberfiktion versuchen, den eigenen Tod zu antizipieren und so für das Überdauern seines Werkes ,vorzusorgen ‘ ${ }^{362}$ Für Letzteres wiederum werden alle hier behandelten Grundoperationen zur Ewigkeitsattribuierung von Schriftzeichen bemüht:

Erstens hat, wie von Uwe Wirth aufgezeigt, die Herausgeberfiktion immer eine grundlegend performative Konstituente (vgl. die Grundoperation Autonome Performative Produktion): Sie setzt mittels einer paradoxalen Operation den Rahmen des Werkes, das sie ,herausgibt' und von dem sie - meist in einem Vorwort, aber zuweilen auch schon auf dem Titelblatt (vgl. die LebensAnsichten des Katers Murr), in Einschüben, in einem Nachwort - spricht: „Mit anderen Worten, die editoriale Tätigkeit ist zum einen die rahmensetzende Entgegensetzung jeder absoluten auktorialen Setzung, zum anderen ist sie der performative und parergonale Rahmen jeder auktorialen Tätigkeit.“363 Die fiktive Herausgeberschaft muss dabei - wenn nicht bloß im Titelblatt genannt - ebenfalls auf irgendeine Weise erzählt und dadurch konstituiert werden. Dies geschieht über einen Paratext, typischerweise ein Vorwort, das aber auch durch Texteinschübe und/oder ein Nachwort ergänzt resp. ersetzt werden kann. Hier kommen die beiden anderen Grundoperationen ins Spiel:

Zweitens bildet bereits die Nennung einer Herausgeberfiktion auf dem Titelblatt ${ }^{364}$ und erst recht die explizite Entfaltung derselben in den weiteren Paratexten, etwa in einem Vorwort, die Grundlage dafür, den Text auf sich selbst und seine Möglichkeitsbedingungen verweisen zu lassen (vgl. die Grundoperation Reflexivität). Dies wiederum kommt insbesondere der romantischen Poetik einer Poesie der Poesie (vgl. Kapitel IV.3.1) zugute resp. steht mit ihr in

362 Dafür spricht auch Wirths These, dass sich Autorschaft wesentlich durch Selbstherausgeberschaft konstituiert (vgl. Wirth 2008, u. a. S. 283). Als Paradebeispiel für ein solches Vorausschreiben bei gleichzeitiger Reflexion desselben mag Jean Pauls KonjekturalBiographie (1799) gelten, deren erste Sätze lauten: „Lieber Otto! Jetzt treibt mich eine Idee durch die Alleen und Gärten, die schon alle Wände meines Kopfes mit Grün und Hesperiden-Fruchtschnüren überzogen hat; - sie soll aber vollends herauswachsen ins Freie mit ihren vollen Zweigen dem Publikum in die Hand. Sieh'! ich will meine Lebensgeschichte, die mir noch bevorsteht, treu in poetischen Episteln aufsetzen. Sollt' ich sie wider Verhoffen nicht erleben: so hab’ ich doch die Komödienprobe, die gestikulierende Lufterscheinung, das Panorama davon gehabt und halb Europa die Beschreibung“ (Jean Paul, Konjekturalbiographie, S. 453; vgl. dazu auch Pfotenhauer 2013, S. 127).

363 Wirth 2008, S. 329.

364 In den Lebens-Ansichten des Katers Murr beispielsweise die Phrase: „Herausgegeben von E. T. A. Hoffmann". 
einer Wechselwirkung, was auch eines der zentralen Ergebnisse von Wirths Untersuchung ist: „In der Romantik weicht die fingierte Herausgeberschaft einer Spielform der Herausgeberfiktion, die der ironischen,Selbstbespiegelung narrativer Rahmungsverfahren dient. “365 Verbindet man nun die Herausgeberfiktion mit der frühromantischen Auseinandersetzung mit Kant und Fichte, so hieße dies weiter,

daß Novalis und Schlegel die ,poesis‘ als Akt begreifen, der zwischen dem Ideal einer ursprünglich-setzenden, auktorialen Tätigkeit und der Realität einer nachträglich-umbildenden, editorialen Tätigkeit oszilliert. Diese editoriale Autorschaft verbindet die Geste absorbierenden Zitierens mit der autoreflexiven Geste des Sich-selbst-Zitierens. ${ }^{366}$

Die Möglichkeit des „Sich-selbst-Zitierens“, die für die Herausgeberfiktion und die daraus entstehende moderne Autorschaft konstitutiv ist, führt den hier verfolgten Gedankengang sodann zu:

Drittens - und mit besonderem Fokus auf die im vorliegenden Kapitel II zur Diskussion stehende Grundoperation Unendliche Aktualisation - gilt für all jene Formen des Paratextes, ja für Paratexte im Allgemeinen, was Wirth mit Verweis auf Derrida und Swift für das Vorwort festgestellt hat: „Der Vorwortakt erweist sich als Collage von immer neuen ersten Seiten [...] Durch die prinzipiell unbegrenzte Möglichkeit der Wiederholbarkeit dieser Geste bringt das Vorwort als aufpfropfende Vor-Schrift einen unentwegten Rahmungsprozess in Gang - und eben hierdurch ist die préface incessante ausgezeichnet."367 Oder anders und wiederum in Anlehnung an Aristoteles' Terminologie ausgedrückt: Das Vorwort, insbesondere wenn es einer Herausgeberfiktion dient, soll verhindern, dass der Anfang zur Mitte wird, führt aber gleichzeitig gerade zu einer Entgrenzung des Anfangs, die mit einem weiteren Vorwort zum Vorwort eingegrenzt werden müsste usw. ad infinitum. Als Paradebeispiel dafür sei an die drei Vorworte (und an die Nachschrift des Herausgebers zum letzten derselben) des ersten Bandes der Lebens-Ansichten des Katers Murr erinnert.

Aus all dem leitet sich wiederum folgende Ergänzung von Wirths Überlegungen (sowie deren Kombination mit der These Andrea Polascheggs, vgl. das Ende von Kapitel II.2.1) ab: Dieser fragt sich zu Beginn seiner Untersuchung, „welche Rolle der fiktive Herausgeber bei der Genese moderner Autorschaft spielt, ja ob der emphatische Autorbegriff der Genieästhetik womöglich nur eine spezifische Transformation der Funktion Herausgeber

365 Wirth 2008, S. 423 f.

366 Ebd., S. 288.

367 Ebd., S. 97 . 
ist “, 368 und beantwortet im weiteren Verlauf seiner Monographie dieses „ob“ mit einem Ja. ${ }^{369}$

Nun zeigt die vorliegende Arbeit, dass einerseits eine zentrale Konstituente des Genies und seiner Werke das Attribut der Ewigkeit ist (vgl. Kapitel IV.3.3) und andererseits die Funktion Herausgeber und insbesondere die Herausgeberfiktion als Garanten ebenjener Ewigkeit auftreten. Die Ewigkeitsattribuierung von Schriftzeichen ist somit eine wesentliche, wenn nicht gar die entscheidende Konstituente sowohl des "fiktive[n] Herausgeber[s]" als auch der "Genese moderner Autorschaft", die umgekehrt wiederum - also in einer selbst potenziell endlosen Operation der Wechselwirkung - zur Ewigkeitsattribuierung von Schriftzeichen beitragen. ${ }^{370}$

Dieser Befund geht zudem einher mit der folgenden Feststellung Uwe Wirths: „Dabei ist die Funktion Herausgeber als Rahmen von Autorschaft in spezifischer Weise auf die allgemeine Iterabilität der Schrift bezogen: ${ }^{371}$ Autorschaft als Recht an den Kopien des eigenen Werks impliziert das Recht, sich selbst zu zitieren“372 - und, so ist nun anzufügen, sich selbst zu verewigen.

\subsection{Zusammenführung der Ergebnisse}

Zum Schluss dieses historisch-kontextualisierenden Kapitels zur Grundoperation Unendliche Aktualisation sei nun das bisher Dargelegte zusammengeführt und dabei in sechs aufeinander aufbauenden Schritten folgende literaturgeschichtliche Beobachtung angestellt:

1. Die bisherige Fragmentforschung ergänzend lässt sich eine Tendenz beobachten, die von Lessings tragischer Ästhetik des Endens ausgeht, welche anstelle eines Moments des Schreckens eine das aristotelische Ende zur Mitte transformierende Dauer des Mitleidens schafft. Jean Paul mag dabei als Extrembeispiel dafür gelten, wie Lessings Ästhetik des Endens - von der Orientierung an der Linie Cervantes - Sterne unterstützt und deren Prinzip der Digression ${ }^{373}$ zugleich implizit legitimierend - auf den Roman übertragen

368 Ebd., S. 13 .

369 Vgl. ebd., u. a. S. 283.

370 In diesem Zusammenhang wäre es äußerst spannend, sich umfassender auch mit älteren Formen der Herausgeber- und Autorfiktion auseinanderzusetzen; z. B. auch unter Einbezug von Texten aus dem alten Ägypten, wo etwa im Papyrus Chester Beatty (13. Jahrhundert v. Chr.) fiktive Assertoren inklusive Rahmenerzählung vorkommen, und zwar in Texten, in denen es explizit um Verewigung geht (vgl. J. Assmann 1991, S. 176, Anm. 6).

371 Zur Iterabilität im Zusammenhang mit den Operationen zur Ewigkeitsattribuierung von Schriftzeichen vgl. Kapitel 1.1 des Schlussteils.

372 Wirth 2008, S. 114.

373 So schreibt Helmut Pfotenhauer zur Digression bei Jean Paul: „Denn dieser Autor hasst oder verachtet nachgerade das unaufhörlich Voranschreitende der Lebenszeit, weil dies 
wurde. Und wie schon in Lessings Trauerspielen ist auch bei Jean Paul das Enden ein Anschreiben gegen das Ende und den Schrecken des Todes.

(Auch der eingangs des Kapitels zur Miss Sara Sampson angemerkte Befund Cornelia Mönchs breit angelegter Studie zum bürgerlichen Trauerspiel des 18. Jahrhunderts, „[d]as Lessing'sche Modell des bürgerlichen Trauerspiels spielt [innerhalb der Gattung der Trauerspiele, MG] eine untergeordnete, zeitlich begrenzte Rolle“, ${ }^{374}$ ließe sich von hier aus kritisch weiterverfolgen. Es wäre dabei zu fragen, ob die Stücke, die nach der sich in der Gattung des Trauerspiels durchsetzenden Maxime der "poetischen Gerechtigkeit“ gebildet sind und die „Auflösung des Mitleids mit der verfolgten Tugend in einen gerechten Befriedigungsaffekt ${ }^{4375}$ vornehmen, Lessings Ästhetik des Endens übernehmen oder nicht. Und ob, falls Letzteres zuträfe, das „eklatante ,Versagen der ,Miss Sara Sampson' als Modellvorgabe “376 für die Gattung des Trauerspiels nicht einhergeht mit einer - so die hier vertretene These - Übertragung ebendieser Modellvorgabe von der Dramatik auf die Epik resp. den Roman. Einer Modellvorgabe, die in dieser Hinsicht sowohl in ihrer Ästhetik des Endens als auch in ihren Auswirkungen auf die Ästhetik des Fragmentarischen von literaturgeschichtlich herausragender Bedeutung wäre.)

2. Parallel zu dem unter 1 . Genannten ist eine zweite Tendenz zu beobachten, nämlich ein immer stärkeres Aufkommen der,Form` des Fragments. Sie scheint im deutschsprachigen Raum, gemäß der bisherigen Forschung, in der zweiten Hälfte der 175oer-Jahre von den künstlichen Fragmenten von Johann Georg Hamann ${ }^{377}$ und Herder und dann später vor allem von Lessings Reimarus-Fragmenten ${ }^{378}$ ausgegangen zu sein und wurde in den folgenden Jahrzehnten von zahlreichen Autoren aufgegriffen - darunter dann auch

das Leben ja letzten Endes in das Zeichen des physischen Verfalls, des Todes, stellt. Aufgabe der Dichtung ist es für Jean Paul, dagegen anzuschreiben, das heißt, das Kontinuum erzählerisch zu unterbrechen, wo immer es nur geht“ (Pfotenhauer 2013, S. 103).

374 Mönch 1993, S. 35 o.

375 Ebd., S. 341.

376 Ebd.

377 Hamanns erstes publiziertes Werk, Beylage zu Dangueil, enthält bereits eine „protoSternean nonchalance" und das Einfügen eines fragmentarischen Blattes (vgl. Wanning Harries 1994, S. 36). Besonders bemerkenswert ist für die hier vertretene Wirkmächtigkeit von Lessings Ästhetik des Endens aber, dass es 1756 und damit ein Jahr nach Lessings Miss Sara Sampson erschien.

378 Vgl. Braun 2002, S. 35 f.; und vor allem Wanning Harries 1994, S. 34-38. 
Goethe, ${ }^{379}$ Jean Paul und die Frühromantiker. ${ }^{380}$ Letztere sind zudem weiter beeinflusst durch den aphoristisch-fragmentarischen Stil Chamforts und von Goethes und Schillers Xenien.

3. Die Frühromantiker, allen voran Friedrich Schlegel, erheben das Fragmentarische sodann zu einem zentralen Prinzip ihrer Poetik resp. der romantischen Ironie. Friedrich Schlegel nimmt in seinen theoretischen Überlegungen ausgerechnet explizit Bezug auf den vermeintlich aphoristischfragmentarischen Stil Lessings, ${ }^{381}$ der aber letztlich eine bloße Zuschreibung seitens Friedrich Schlegels war. ${ }^{382}$ Und dennoch - so die hier vertretene These ist Friedrich Schlegels Verweis auf Lessings Einfluss auf die frühromantische Fragmentästhetik richtig, bloß ist dieser Einfluss weniger in Lessings Stil begründet als vielmehr in seiner Transformation der Tragödie und der damit verbundenen Ästhetik des Endens, die entscheidend daran beteiligt ist, die aristotelische Einheit eines Werkes aufzulösen. Denn Lessing - dessen Miss Sara Sampson noch vor Hamanns erstem publiziertem Werk erscheint ${ }^{383}$ - trägt damit wesentlich zum "fragmentarischen Bewusstsein des achtzehnten Jahrhunderts" bei, aus dem dann bei „Friedrich Schlegel und Novalis die Form oder Gattung des Fragments erzeugt wurde". 384

Der Einfluss von Lessings Ästhetik des Endens ${ }^{385}$ vermag dabei auch zu erklären helfen, weshalb sich eine Fragmentästhetik in der zweiten Hälfte des 18. Jahrhunderts gerade „in Deutschland quer zur europäischen Tradition des Fragments herauszubilden beginnt ${ }^{\prime,}, 386$ und dabei aufzuzeigen, dass wohl auch

379 Vgl. die nicht mehr geschlossene Rahmenhandlung am Ende der Unterhaltungen deutscher Ausgewanderten - dazu auch Pfotenhauer 2013, S. 148 f.

380 Vgl. Behler 1985, S. 129 f.; Wanning Harries 1994, S. 34-37; Braun 2002, S. 35 f. und 38 f.; Weiß 2015, u. a. S. 15-16; vgl. ergänzend dazu auch Gesine Lenore Schiewers Arbeit zu den historischen Bezügen zwischen Lamberts Semiotik, Herder, Jean Paul und Novalis; Schiewer 1996.

381 Vgl. u. a. Weiß 2015, S. 21-128, insbesondere S. 76-83.

382 Vgl. dazu Weiß: „Da Schlegel in den Fragmenten keine ,Kunstwerke der Darstellung, sondern bloß Mittel der Anregung' sieht, kommt es ihm vorrangig auf die Wirksamkeit dieser Anregung und nicht auf die Erfüllung bestimmter formaler und inhaltlicher Kriterien an. So kann er selbst Lessing zum vorbildlichen Fragmentisten erklären, obwohl dieser weder in Aphorismen noch über die für die Frühromantiker einschlägigen Themen geschrieben hat" (ebd., S. 79 f.). Und Behler: „Was den fragmentarischen Charakter Lessings für Schlegel ausmachte, lag wiederum nicht so sehr in der Form seiner Schriften, als in der Art seines Denkens" (Behler 1985, S. 130).

383 Vgl. Punkt 2 und die dazugehörigen Fußnoten; resp. Wanning Harries 1994, S. 36.

384 Behler 1985, S. 141.

385 Dazu, dass Lessings Miss Sara Sampson noch ein Jahr vor Hamanns erstem publiziertem Werk erschienen ist, vgl. Punkt 2 und die dazugehörigen Fußnoten.

386 Behler 1985, S. 131. 
im Falle des Fragments - indirekt über Lessings Trauerspiel - die Auseinandersetzung mit ${ }^{387}$ und die Abgrenzungsbestrebungen von der zeitgenössischen französischen Literatur eine zentrale Rolle gespielt haben.

4. Nun ließe sich aber einwenden, weshalb ausgerechnet Lessings Ästhetik des Endens, die sich der Operation Unendliche Lektüre bediene, wesentlich an einer Ästhetik beteiligt sein soll, der im Fragment die radikalst mögliche Ausprägung der Operation Unendliches Verstummen zugrunde liege. Die Antwort darauf ist: Aufgrund der Komplementarität der beiden Operationen führt die radikalste Ausprägung der Operation Unendliche Lektüre zwangsläufig in das Fragmentarische. (Dasselbe gilt umgekehrt: Die bei Brentanos Der Spinnerin Nachtlied, den mittelhochdeutschen Tageliedern und deren Adaptionen ${ }^{388}$ sowie in Hölderlins Ermunterung beobachtete ästhetische ,Nutzbarmachung‘ der semiotischen und klanglichen Flüchtigkeit von Schriftzeichen würde in ihrer radikalsten Form etwa einem fragmentarischen Gedicht entsprechen, das mitten in der Strophe abbricht.) Oder in anderen Worten: die radikalste Umsetzung einer Ästhetik, die das Ende immer weiter auszudehnen sucht, ist der Verzicht auf ein Ende - und letztlich auch auf einen Anfang. Ein Höhepunkt dieser Entwicklung findet sich in E. T. A. Hoffmanns Lebens-Ansichten des Katers Murr: Nicht nur das Ende wird in diesem Doppelroman zur Mitte, sondern auch der Anfang, und beide gehen sowohl auf der Mikro- als auch auf der Makroebene ineinander über, womit Aristoteles' Einheitsbegriff bestehend aus Anfang, Mitte und Ende endgültig abgelöst wird.

5. Eine Ästhetik des Fragments sucht, gerade in dessen potenziell unendlich oft erfolgendem Abbrechen, so weit wie möglich einen Prozess des unendlichen Weiterlesens (und Weiterschreibens) auszulösen und damit eine Immanenz der Transzendenz und eine Transzendenz der Immanenz zu erreichen. Das Fragmentarische, so ließe sich sagen, ist somit die radikale Ausprägung zweier Operationen zur Ewigkeitsattribuierung von Schriftzeichen (der Operation Unendliche Lektüre und der Operation Unendliches Verstummen), die gerade aufgrund ihrer Radikalität zugleich eine die fragmentarischen Texte weiterführende, potenziell unendliche Bewegung lostritt. Oder anders ausgedrückt:

Das ausgehende 18. Jahrhundert findet im Fragmentarischen gewissermaßen die bestmögliche Kombination der Unteroperationen Unendliches Verstummen und Unendliche Lektüre, was zum wirksamst möglichen Auftreten der Grundoperation Unendliche Aktualisation führt.

387 Vgl. u. a. Weiß 2015, S. 21-62.

388 Vgl. dazu auch Wolf 2011. 
6. Die ebenfalls in der zweiten Hälfte des 18. Jahrhunderts sich verstärkt vollziehende Genese der modernen Autorschaft steht dabei in enger Verbindung mit der aufkommenden Ästhetik des Fragmentarischen und der Ewigkeitsattribuierung von Schriftzeichen, sucht sie doch Fragmentarisches zu rahmen und dadurch dessen Überlieferung zu sichern - und ist dabei zugleich selbst Teil einer potenziell endlosen Wechselwirkung. 